Final Report

Grant No. DE-FG04-91AL75029

\title{
An In-Cylinder Study of Soot and NO in a DI Diesel Engine
}

\author{
prepared by \\ Thomas A. Litzinger \\ Professor of Mechanical Engineering \\ The Pennsylvania State University
}




\section{DISCLAIMER}

This report was prepared as an account of work sponsored by an agency of the United States Government. Neither the United States Government nor any agency thereof, nor any of their employees, make any warranty, express or implied, or assumes any legal liability or responsibility for the accuracy, completeness, or usefulness of any information, apparatus, product, or process disclosed, or represents that its use would not infringe privately owned rights. Reference herein to any specific commercial product, process, or service by trade name, trademark, manufacturer, or otherwise does not necessarily constitute or imply its endorsement, recommendation, or favoring by the United States Government or any agency thereof. The views and opinions of authors expressed herein do not necessarily state or reflect those of the United States Government or any agency thereof. 


\section{DISCLAIMER}

Portions of this document may be illegible in electronic image products. Images are produced from the best available original document. 


\section{Table of Contents}

pg.

Summary

ii

1.0 Introduction 1

2.0 Basic Experimental Approach 1

3.0 Development of Planar NO and Soot Diagnostics

3.1 NO Imaging with Oxygen Enrichment 4

3.2 NO Imaging without Oxygen Enrichment 9

3.3 Simultaneous LII and Light Scattering for Quantitative Soot Imaging 13

4.0 Parametric Studies

4.1 Intake Charge Dilution at Constant Start of Combustion 23

4.2 Effects of CO2 Dilution on Soot Evolution at Constant Start of Combustion 29

4.3 Effects of $\mathrm{CO} 2$ Dilution on Soot Evolution with Control of Heat Release Rate 35

4.4 Effects of Intake Charge Temperature on Soot Evolution and Emissions 44

4.5 Effect of Fuel Composition of Soot Evolution 55

5.0 References $\quad 56$ 


\section{Summary}

Clearly the reduction of NOx and particulate emissions remains a major challenge to Diesel engine manufacturers due to increasingly stringent emission standards in the US and other countries. The well documented NOx/particulate trade-off observed in Diesel engines makes the simultaneous reduction of both emissions particularly difficult for manufacturers to achieve. In an effort to provide an improved understanding of the fundamental processes which result in this trade-off, a program was carried out at Penn State to develop the appropriate engine facilities and laser diagnostics to permit in-cylinder studies of Diesel combustion and emissions production with the support of the Department of Energy Advanced Industrial Technology Division . This work has also been supported by the Cummins Engine Company, Lubrizol Corporation and the National Science Foundation.

An optically accessible, direct injection, Diesel engine was constructed for these studies. The major objective of the design of the engine was to maximize optical access under conditions representative of Diesel engine combustion in small bore, commercial engines. Intake air is preheated and boosted in pressure to make the in-cylinder conditions of heat release and pressure as realistic as possible. Another important objective of the design was flexibility in combustion chamber geometry to permit a variety of head and bowl geometries to be studied. In all the results reported in this report a square bowl was used to simplify the introduction of laser light sheets into the engine.

Over the life of the project a number of relatively standard diagnostics have been used including laser Doppler velocimetry, shadowgraph and direct photography. In addition exciplex fluorescence has been applied to study injection and fuel/air mixing. Optical techniques to study NO and soot during the combustion process were first implemented in flame studies and then transferred to the en

gine. These diagnostics included light scattering and laser induced incandescence for soot and laser induced fluorescence for NO. In all cases the diagnostics were applied in a planar manner to obtain information on the spatial distribution of the soot and NO. Temporal information was obtained by triggering the laser to fire at different engine crank angles. In addition heat release analysis proved to be a very important tool for this work.

This report discusses the accomplishments on the program for the second contract period. It discusses the demonstration of NO imaging under realistic engine conditions as well as the use of a combination of LII and light scattering to yield quantitative, planar soot images so that soot volume fraction and particle size can be determined. Then results from three parametric studies are presented - effects of EGR, effects of intake air temperature and effects of fuel composition on emissions from the engine. Major accomplishements and conclusions of this work were:

1) First demonstration of planar, laser-induced fluorescence imaging in a DI Diesel engine

2) First quantitative application of simultaneous laser-induced incandescence and Mie scattering in a DI Diesel engine to obtain soot volume fraction and size during combustion.

2) A study of the effects of intake charge dilution with $\mathrm{CO} 2$ at fixed start of combustion showed both NOx and soot to be reduced substantially.

2) The reduction of soot by intake charge dilution with $\mathrm{CO} 2$ appears to be primarily driven by changes in heat release; however, some results indicate that a chemical effect may be present.

3) The effect of increasing air temperature at fixed start of injection is to increase soot production throughout the combustion event and to increase NOx.

4) The presence of a high concentration aromatic species in a fuel increases the soot production throughout the combustion process compared to a purely paraffinic fuel.

Throughout its history this project has supported eleven graduate students, four Ph.D. and seven Masters. Of these students ten have graduate; seven now work in the automotive industry or for oil companies, two work at government related laboratories, and one has a faculty position in Turkey. It has resulted in more than 20 technical papers and presentations at technical meetings. 


\subsection{Introduction}

- This report summarizes the major accomplishments over the program over the contract period. It first presents a description of the experimental engine constructed and the general experimental methods used for this program. It then describes the results obtained during the development and demonstration of the NO imaging and simultaneous Mie scattering and laser induced incandescence measurements. Finally the experimental conditions and results from three parametric studies are presented in summary form; the studies are the effects of intake charge dilution, intake charge temperature, and fuel composition. In all cases references to detailed information available in the open literature are given to allow the reader to obtain more details if desired.

\subsection{Basic Experimental Approach}

The Penn State optically accessible engine, shown schematically in Fig. 2-1, is a single cylinder, direct injection, two stroke diesel engine which features optical access from the top and sides of the combustion chamber. Relevant engine dimensions and specifications are shown in Table 2-1. The engine consists of an extended piston and cylinder mounted on a Waukesha CFR crankcase. The combustion chamber is located in the cylinder head and is formed by quartz bricks on two sides and a quartz cylinder on top to allow optical access to the chamber. In order to remove the fuel injector from the optical path required for laser measurements, the fuel injector is located in the piston. The location of the injector in the piston and the combustion chamber in the cylinder head effectively inverts the traditional diesel engine arrangement and maximizes optical access. In order to prevent window fouling that adversely affects optical measurements, the upper end of the piston is dry lubricated using Vespel rings which are impregnated with graphite. If in-cylinder air motion was desired, it was created using insert in the intake ports. Typically quiescent and low-swirl conditions were used.

The fuel used is a mix of $41 \%$ cetane and $59 \%$ heptamethylnonane by volume yielding a cetane number of 50 , except for the study of fuel composition effects where composition was varied. It is delivered to a four hole Stanadyne injector by an American Bosch APE$1 \mathrm{~B}$ injection pump. Fuel injection is triggered and synchronized with the firing of the lasers, cameras and data acquisition equipment using a PC based control system which permits single shot fuel injection. A minimum of five motored cycles occurred between every fired cycle to ensure that the cylinder would be completely scavenged before each fired cycle.

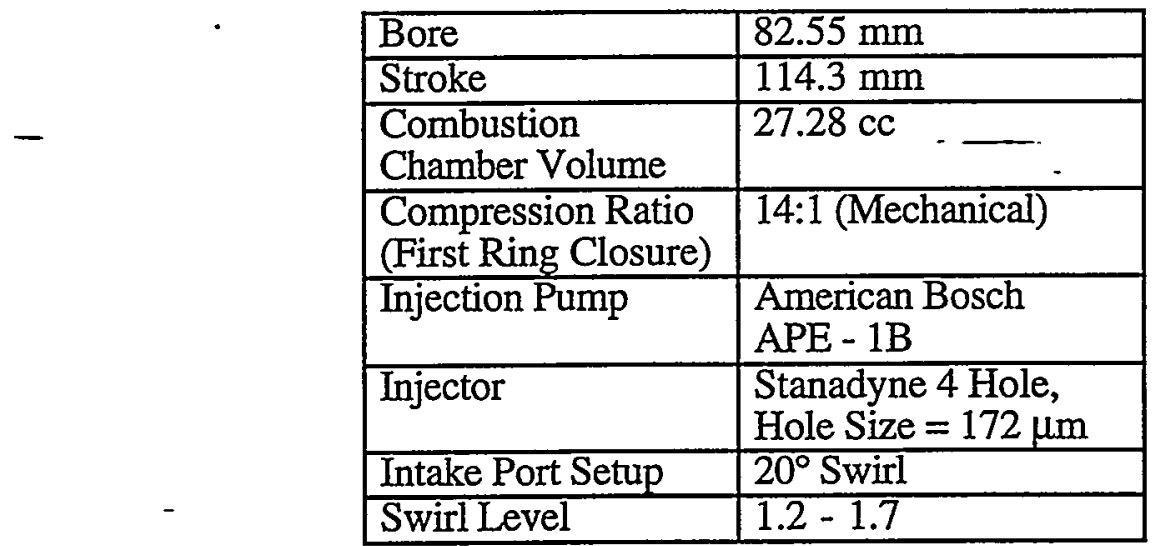

Table 2-1. Engine specifications. 
- For intake charge dilution and oxygen enriched studies, a gas feed system was used to meter bottled the desired gas, nitrogen, carbon dioxide or oxygen, into the intake manifold through variable area flow meters where it mixed with a compressed air supply. The compressed air supply provided air with constant humidity and also allowed boosting of the intake air pressure to simulate turbocharging. The gases were metered into this stream to obtain the desired oxygen mole fraction. Typical experimental conditions, listed in Table 22 , were chosen so that the heat release of the baseline air case was similar to that for current, direct injection diesel engines at similar load and speed conditions.

Table 2-2: Experimental Conditions

$\begin{array}{ll}\text { Engine Speed } & 900 \mathrm{R} . \mathrm{P} . \mathrm{M} . \\ \text { Exhaust Pressure } & 152 \mathrm{kPa} \\ \text { Head Temp. } & 394 \mathrm{~K} \\ \text { Injector Cracking Pressure } & 20.7 \mathrm{MPa} \\ \text { Intake Air Temp. } & 394 \mathrm{~K}\end{array}$

In a typical experiment, injection timing was adjusted to hold start of combustion constant. Injection timing was changed using a concentric helix timing box with a micrometer adjustment knob which allowed accurate and repeatable timing settings for each case. Start of combustion was determined by taking the first derivative of the cylinder pressure curve for fired traces. Pressure data for analyzing start of combustion and for heat release analysis was taken at a rate of four points per crank angle degree. To compensate for cycle by cycle variation, at least 25 traces were averaged for each condition for both pressure derivative and heat release analysis.

After the timing settings were established, the apparent heat release rate was determined. The heat release code used for the analysis was based on the model by Krieger and Borman. The start of combustion was defined as the point at which the heat release curve first becomes positive. To determine the premixed burn fraction, the area from the start of combustion to the peak burning rate was doubled. The resultant area was then divided by the total heat release area.

Emissions data for both cases was taken using a chemiluiminescence analyzer for $N O_{X}$ measurement, a paramagnetic analyzer for oxygen content, and a non-dispersive infrared analyzer for measuring $\mathrm{CO}_{2}$. Exhaust gas was sampled after a mixing plenum, drawn through a glass fiber filter to remove particulate matter and then dried before it was drawn through the analyzers. Because the $\mathrm{NO}_{\mathrm{X}}$ emissions were measured from a stream mixed with the air from the five motored cycles, the $\mathrm{NO}_{\mathrm{X}}$ data had to be corrected to eliminate the dilution effect. The necessary correction was simply multiplication by a factor of six.

In some experiments, exhaust soot emissions were deterrmined in-cylinder from the extinction of a beam of light at $488 \mathrm{~nm}$ from an argon ion laser at top dead center (TDC) of the motored cycle immediately following the fired cycle. Based upon the measured scavenging efficency of the optically accessible engine of 0.6 , more than one-half of the soot remains in the cylinder for the motored cycle. Measurement of the soot on the motored cycle overcame several obstacles that made extinction measurements of soot on the fired cycle very difficult. First, by TDC of the motored cycle, the soot particles have become evenly distributed throughout the cylinder due to vigorous mixing during the preceding expansion and compression stroke; the even distribution of the soot was verfied by planar Mie scattering on the motored cycle. This uniformity reduces the error which would otherwise occur with a line of sight measurement when the soot distribution is not uniform throughout the cylinder. Second, the absence of fuel droplets in the motored cycle eliminates interference which they would otherwise create on the fired cycle. 


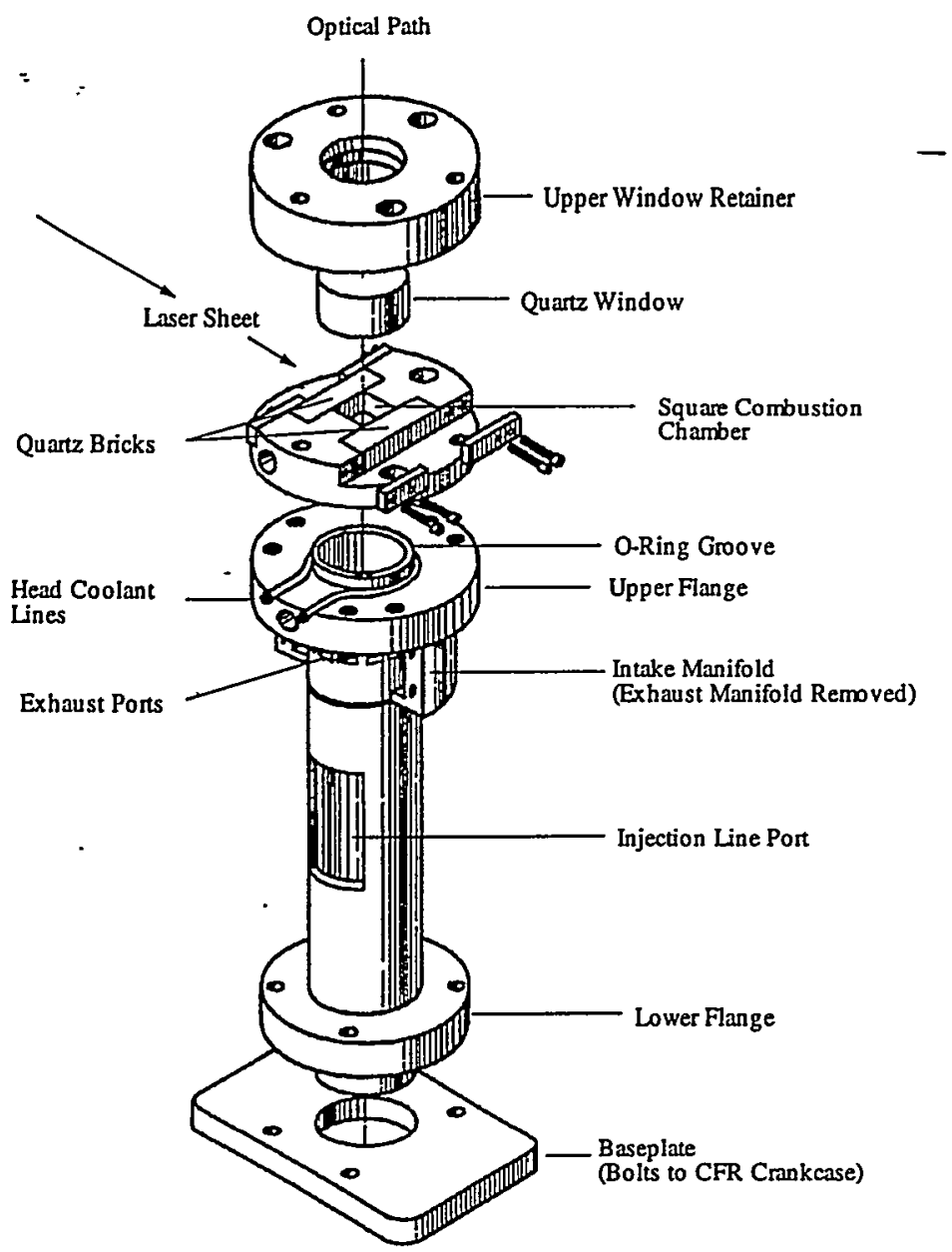

Figure 2-1 Optically accessible engine cylinder and head configuration 


\subsection{Development of Planar NO and Soot Diagnostics}

\subsection{NO Imaging with Oxygen Enrichment [1]}

In this series of experiments oxygen enrichment was used to increase NO and decrease soot and polynuclear aromatics that were interfering with the NO measurements. The experimental conditions used in this study and a later one in which oxygen enrichment was not required are given in Table 3-1.

Table 3-1: Experimental Conditions

\begin{tabular}{|l|c|c|c|}
\hline Parameter & $\begin{array}{c}\text { NO } \\
\text { Measurements - } \\
\text { Oxygen Enriched }\end{array}$ & $\begin{array}{c}\text { NO } \\
\text { Measurements - } \\
\text { Air }\end{array}$ & $\begin{array}{c}\text { Typical Baseline } \\
\text { Conditions }\end{array}$ \\
\hline Oxygen Conc. & $40 \%$ & $21 \%$ & $21 \%$ \\
\hline Equivalence ratio & 0.3 & 0.4 & 0.4 \\
\hline Tailpipe NO & $>1100 \mathrm{ppm}$ & $650 \mathrm{ppm}$ & $370 \mathrm{ppm}$ \\
\hline Head Temp. & $100^{\circ} \mathrm{F}$ & $210^{\circ} \mathrm{F}$ & $250^{\circ} \mathrm{F}$ \\
\hline Intake Air Temp. & $100^{\circ} \mathrm{F}$ & $210^{\circ} \mathrm{F}$ & $250^{\circ} \mathrm{F}$ \\
\hline Intake Pressure & $0.3 \mathrm{psi}$ & $5.3 \mathrm{psi}$ & 5.3 \\
\hline
\end{tabular}

The imaging system consisted of a Pulnix CCD camera with $768 \times 480$ pixels, a Stanford plug-in type intensifier with a maximum gain of $10^{4}$ and a personal computer with an Epix image acquisition system. The laser system consisted of a Quanta-Ray DCR-3 Nd:YAG laser which provided a $10 \mathrm{~ns}, 360 \mathrm{~mJ}$ pulse at $532 \mathrm{~nm}$ while operating at $10 \mathrm{~Hz}$, as well as a PDL-3 tunable dye laser and a WEX-2 wave extension system, both manufactured by Quanta-Ray, to obtain the UV beam needed for PLIF imaging of NO. The output from this system was $2.7-2.8 \mathrm{~mJ} / \mathrm{pulse}$ at $226 \mathrm{~nm}$. The LII and Mie scattering images were acquired using the $532 \mathrm{~nm}$ output of the Nd:YAG laser. The laser energy was set at $200 \mathrm{~mJ} / \mathrm{pulse}$ for the $\mathrm{LI}$ and $50 \mathrm{~mJ} / \mathrm{pulse}$ for the Mie scattering experiments. The laser beam was converted into a sheet $1 \mathrm{~cm}$ wide for NO imaging and $2 \mathrm{~cm}$ wide for soot imaging. The sheet thickness was about $0.2 \mathrm{~mm}$ in both cases.

The NO images were acquired with a photographic quality, UV transmitting reflective lens. The intensifier gain was kept at maximum with a gate time of $50 \mathrm{~ns}$. One SB-300 and two UG-5 broad-band UV transmitting filters were used to block interference from Mie scattering and flame luminosity. The LII images were obtained with the same set-up except for the optical filtering scheme. A $400 \mathrm{~nm}$ narrow-band interference filter with a bandwidth of $70 \mathrm{~nm}$ and a $532 \mathrm{~nm}$ rejection mirror were sufficient to isolate the LII signal. The Mie scattering and direct photography images were acquired with the CCD camera without the intensifier. A $532 \mathrm{~nm}$ narrow-band interference filter with a band-width of $1 \mathrm{~nm}$ was used for the Mie scattering measurements.

The original first attempts in this laboratory at two-dimensional LIF imaging of NO showed that the biggest problem was attenuation of the $226 \mathrm{~nm}$ beam in the combustion chamber due to scattering and absorption by soot particles and hydrocarbon species. Attenuation was measured by passing the UV beam through the combustion chamber and measuring the beam power with and without combustion at different crank-angles. During this test, the injection started at 10 degrees BTDC, and the ignition occurred at top dead center. The equivalence ratio was set at the minimum level for sustained, repeatable combustion. The attenuation was $100 \%$ until 40 degrees ATDC, then gradually decreased to $15 \%$ at 70 degrees ATDC. The results of the attenuation test were essentially the same when the equivalence ratio was increased or the injection was advanced. Since the soot emission increased considerably under these conditions, this indicates that the dominant factor affecting the change in the transmittance of the combustion medium with crank-angle 
is the change in the density of soot and other absorbing and scattering species due to the changing combustion chamber volume. A similar test for the $532 \mathrm{~nm}$ beam showed that there was no significant attenuation at any crank-angle for this wavelength.

Because of the severe attenuation of the UV beam, the engine operating conditions were chosen to minimize particulate formation rather than maximize the NO concentration. The equivalence ratio was fixed at 0.3. The intake air temperature was set at 38 degrees Celsius despite the fact that higher NO concentrations could be obtained by increasing the air temperature. Previous studies showed that the soot emission increased significantly at higher intake air temperatures. Therefore, the relatively low intake air temperature was selected to reduce the attenuation of the UV beam.

The tailpipe $\mathrm{NO}_{\mathrm{X}}$ concentrations under the chosen operating conditions were $400 \mathrm{ppm}$ and $120 \mathrm{ppm}$ for the swirl and quiescent cases, respectively. Since the NO concentration was higher, initial attempts to acquire NO images were made with swirl generating intake ports. The camera was focussed on only one quadrant of the combustion chamber in order to increase the detection sensitivity. In this configuration, the solid angle of signal collection was larger and the laser sheet energy density was doubled relative to full chamber illumination since the sheet needed to be only half as wide as the combustion chamber. Under these conditions, no NO images could be obtained before 45 degrees ATDC due to complete absorption of the UV beam immediately upon entering the combustion chamber. LIF signal strength increased steadily after 45 degrees ATDC and reasonably strong images were acquired between 55-75 degrees ATDC. However, mixing is vigorous with swirl and any structure in the NO distribution completely deteriorates at late crank-angles. Since one of the main objectives of this project is to observe the interaction between soot and NO, resolving the structure is necessary. Therefore, it was decided to proceed with quiescent combustion for later tests where the effects of flame structure should persist for longer periods.

The initial NO images acquired at late angles with quiescent combustion were very weak and none could be obtained before 40 degrees ATDC. In order to increase the NO concentration and reduce the attenuation of the UV beam, oxygen was added to the intake air. The oxygen concentration which produced satisfactory results was $29 \%$. The oxygen enrichment resulted in a drastic reduction in soot concentration, as indicated by much less soot deposition on windows than that occurred for combustion without oxygen enrichment. With enrichment, the engine could be fired up to fifty times without cleaning the windows. Also, as a result of oxygen enrichment, the tailpipe $\mathrm{NO}_{\mathrm{X}}$ concentration significantly increased from $120 \mathrm{ppm}$ to $1100 \mathrm{ppm}$. Although the NO formation increased by an order of magnitude, an analysis of the extended Zeldovich mechanism showed that the temperature increase needed to achieve such a jump was only $140 \mathrm{~K}$ for flame temperatures near $1800-2200 \mathrm{~K}$.

- Two-dimensional imaging of NO was possible at almost all the crank-angles following ignition with oxygen enriched quiescent combustion. The camera was focussed on only one quadrant of the combustion chamber on the laser sheet entry side. However, significant interference from laser-induced PAH fluorescence was encountered before 5 degrees ATDC so images obtained before 5 degrees ATDC will not be presented.

The NO images taken at early crank-angles still show signs of severe beam attenuation. Figure 3-1 is a series of NO images between 5-15 degrees ATDC. The LIF signal exists only near the wall, which means that the UV sheet is totally absorbed in less than $1 \mathrm{~cm}$ upon entering the combustion chamber. This is still a significant improvement over the NO imaging attempts without oxygen enrichment. Although these are very weak images, they prove that NO formation starts very early after ignition. The strength of the NO images increases steadily due, at least partially, to increasing transmittance of the combustion medium at later crank-angles. Figure 3-2 shows this increase after 15 degrees ATDC. Independently acquired Mie scattering, and LII images are also shown in Figure 32 for corresponding crank-angles. After 40 degrees, the average intensity of the NO 
images does not change much. Considering the fact that the transmittance of the combustion medium increases significantly at later crank-angles, this observation indicates that the NO formation practically stops around 40 degrees. There is a slight reduction in image strength after 70 degrees due most probably to lower NO concentrations as a result of the expanding volume of the combustion chamber. 
Figure 3-1. NO images from 5 to $15^{\circ} \mathrm{CA}$

$=$

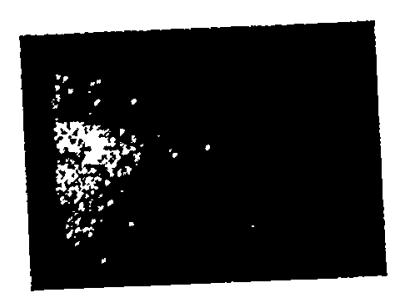

可

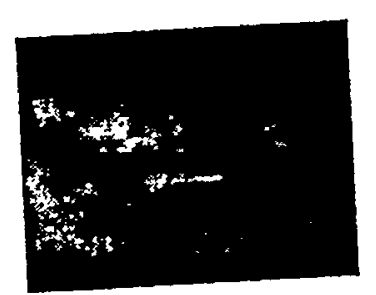

11

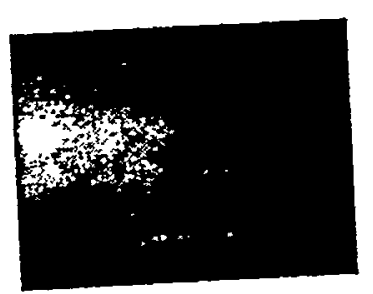

13

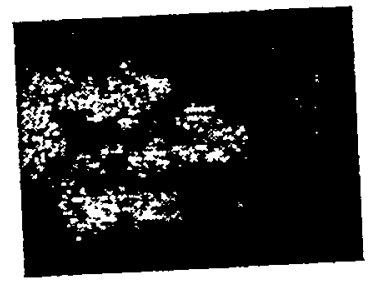

15 
Figure 3-2. NO, light scattering and LII images after $15^{\circ} \mathrm{CA}$
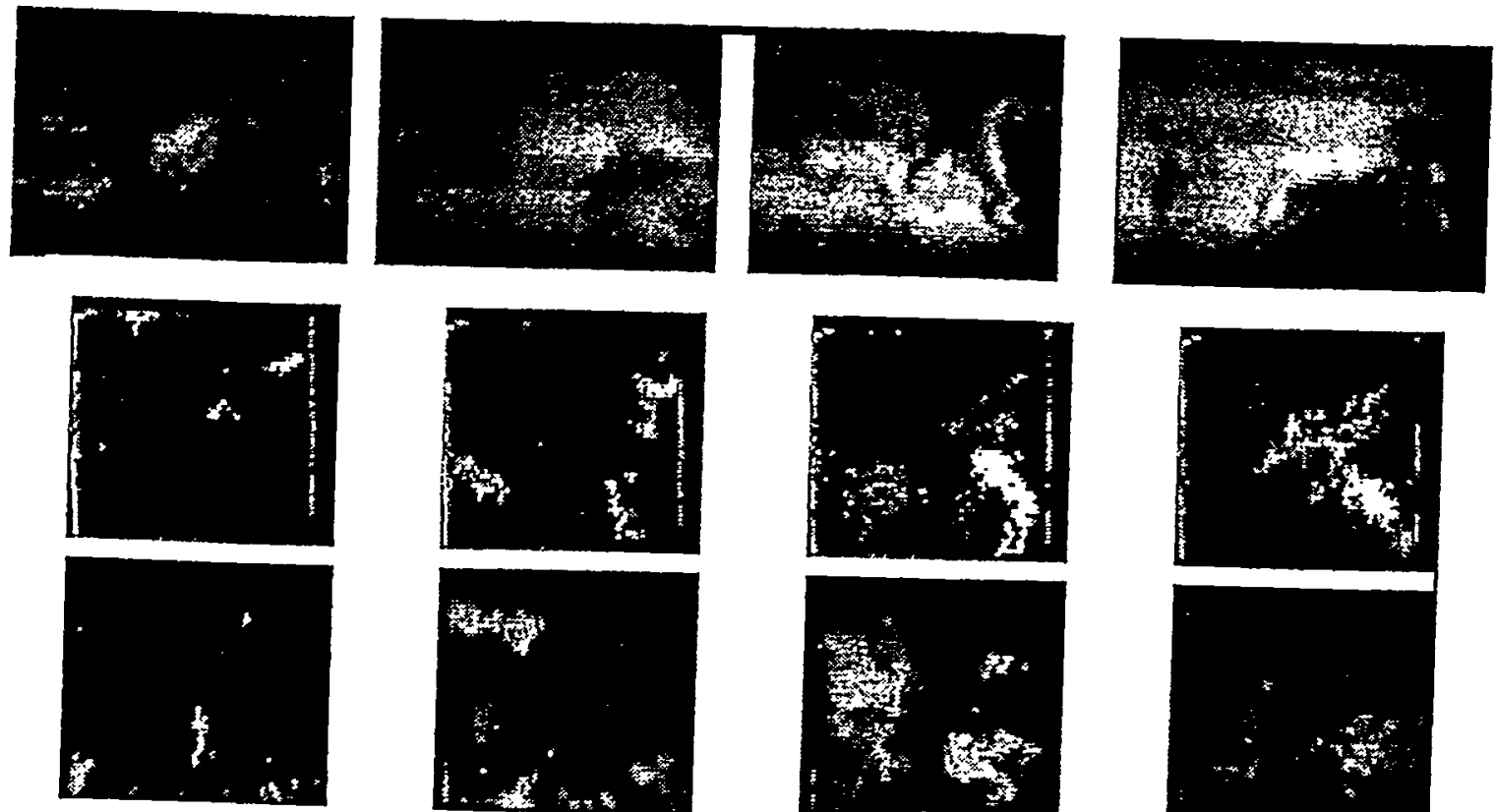

21

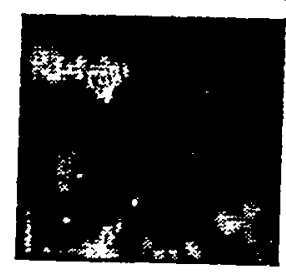

30

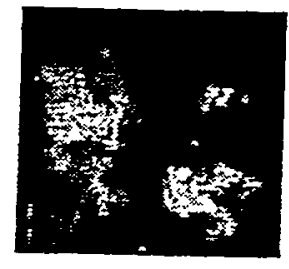

90

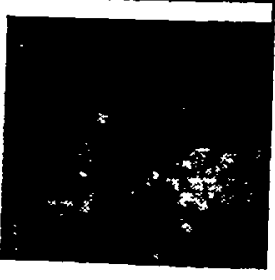

固 


\subsection{NO Imaging without Oxygen Enrichment [2]}

Table 3-1 compares the conditions for initial studies with oxygen enrichment work and a follow study for the NO measurements as well as the baseline conditions used in most of the work. Clearly significant progress was made toward more realistic conditions but as indicated in Figure 3-3 the heat release profile is still highly premixed compared to the baseline heat release. In this study planar LIF was used to image NO and planar light scattering was used to image the soot. Light scattering was used due to its simplicity, relative to $\mathrm{LII}$, and the fact that no intensifier was required.

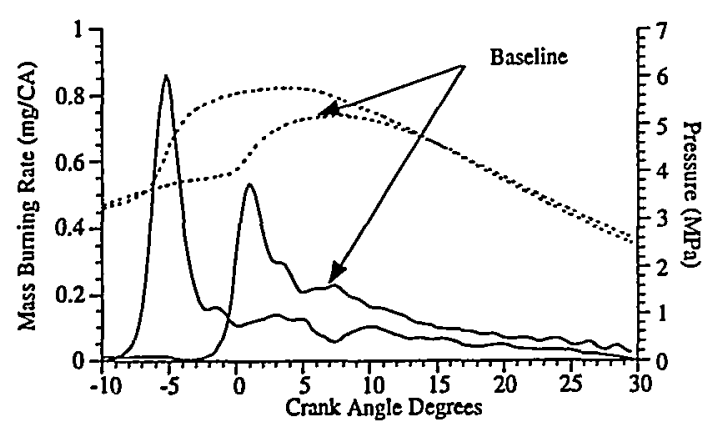

Figure 3-3. Pressure profile and heat release for NO study compared to that for baseline operating condition

The imaging system for NO consisted of a Reticon double intensified CCD camera with 128x128 pixels and a personal computer with an Poynting image acquisition system. The laser system consisted of a Quanta-Ray DCR-3 Nd:YAG laser which provided a $10 \mathrm{ns,} 360$ $\mathrm{mJ}$ pulse at $532 \mathrm{~nm}$ while operating at $10 \mathrm{~Hz}$, as well as a PDL-3 tunable dye laser and a WEX-2 wave extension system, both manufactured by Quanta-Ray, to obtain the UV beam needed for PLIF imaging of NO. The output from this system was $2.7-2.8 \mathrm{~mJ} / \mathrm{pulse}$ at 226 $\mathrm{nm}$. The Mie scattering images were acquired using the $532 \mathrm{~nm}$ output of the Nd:YAG laser at a laser energy of $50 \mathrm{~mJ} / \mathrm{pulse}$. The laser beam was converted into a sheet $1 \mathrm{~cm}$ wide for NO imaging and $2 \mathrm{~cm}$ wide for soot imaging. The sheet thickness was about $0.2 \mathrm{~mm}$ in both cases. The NO images were acquired with a photographic quality, UV transmitting reflective lens. The intensifier gain was gated at approximately $1 \mu$ s. One SB-300 and two UG-5 broad-band UV transmitting filters were used to block interference from Mie scattering and flame luminosity. The Mie scattering images were acquired with the CCD camera without the intensifier. A $532 \mathrm{~nm}$ narrow-band interference filter with a band-width of $1 \mathrm{~nm}$ was used for the Mie scattering measurements.

Figures 3-4 and 3-5 present images of NO and light scattering taken over just one quarter of the square combustion chamber for a range of crank angles from $20^{\circ}$ to $50^{\circ}$ after TDC. For each crank angle, images were taken on three planes within the combustion chamber- bottom, nearest the injector, middle and top, closest to the injector. In these images the injector is located in the lower left corner; it is visible in the light scattering images due to light scattered by the walls of the combustion chamber. The images are presented in a gray scale format indicating the relative strength of the signal. Images could be obtained at earlier crank angles but the signal was not due only to NO; therefore, these images are not presented. It is important to note that the NO and soot images were not taken simultaneously nor are the images at different crank angles taken from the same cycle due to the available firing rate of the laser.

As crank angle increases the strength of the NO signal also increases. This increase is not believed to be due to an increase in the NO concentration because the temperatures that are present at the very late crank angles are expected to be too low for the formation of NO. It is possible that some signal attenuation is occurring and that it becomes less important as 
expansion decreases the density in the chamber. In these images clear structure exists in the $\bar{N} \mathrm{O}$ distribution even as late as 50 degrees ATDC. A comparison of the soot and NO images suggests that where the NO is present there is very little NO and vice versa which could be due to the fact that the NO and soot are forming in different regions under the conditions of this experiment with a very high premix burn fraction. However, truly simultaneous experiments must be performed to verify this observation.

In summary, this data has shown that the NO measurements can be made near TDC without oxygen enrichment. In addition the results show that $\mathrm{NO}$ is present at 20 degrees ATDC and that NO and soot appear to occupy different spatial locations. 
Figure 3-4. NO and light scattering images without oxygen enrichment
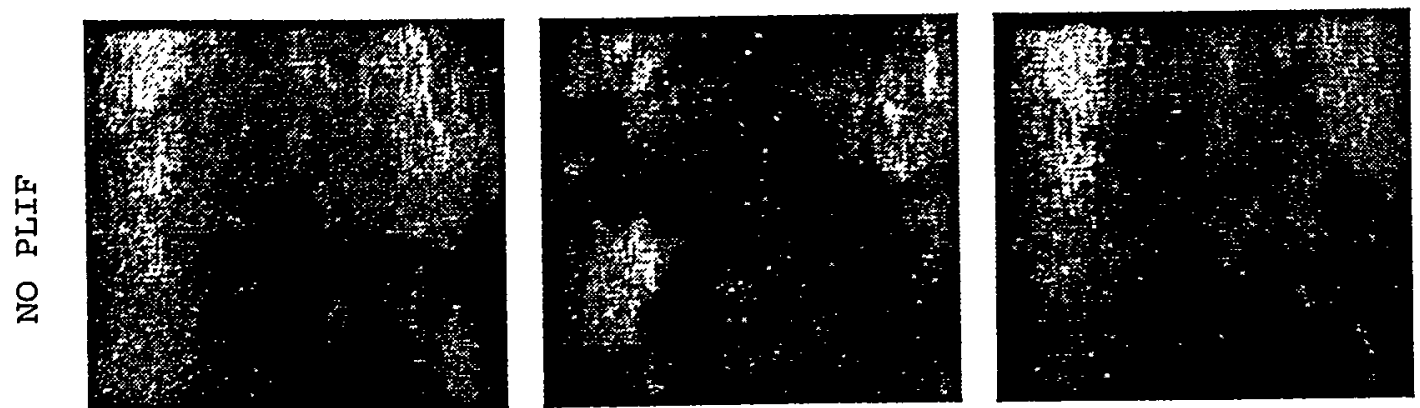

造
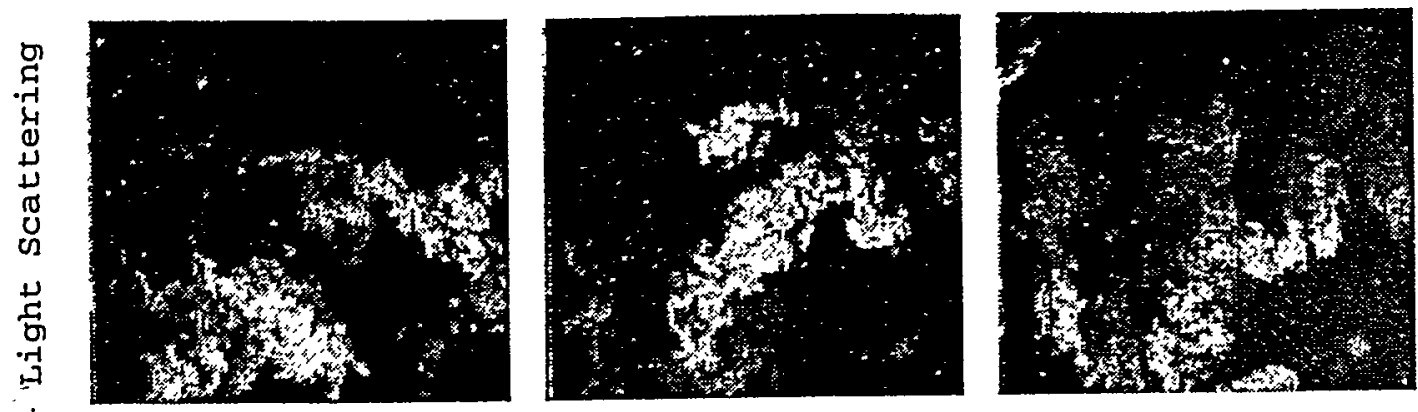

$\stackrel{\circ}{m}$
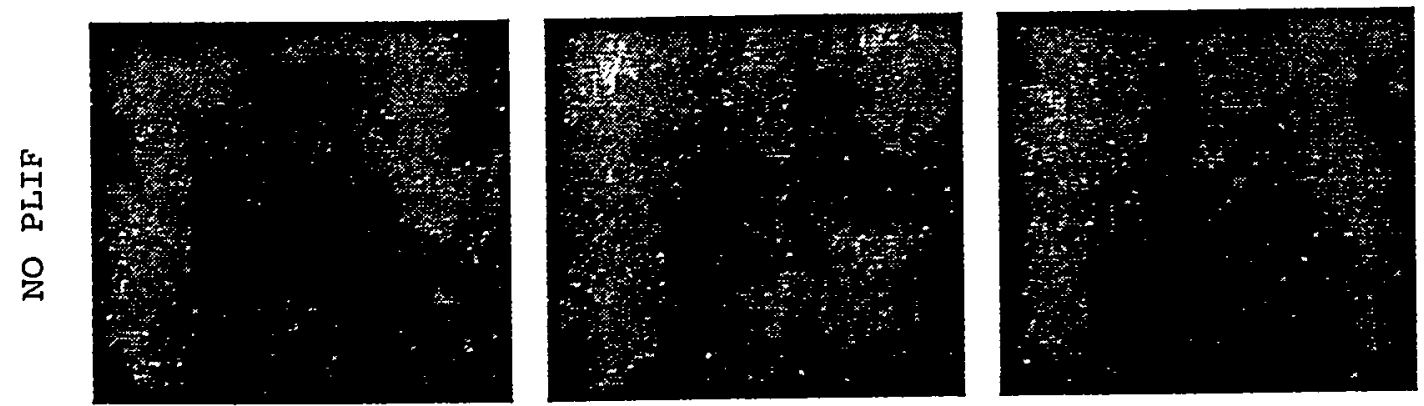

虽
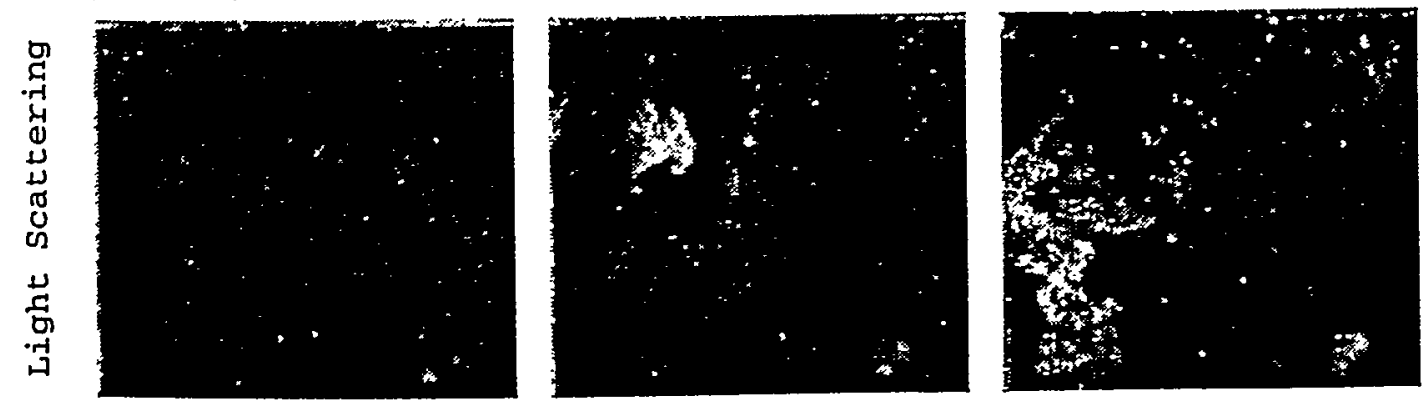
售

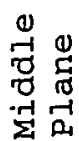

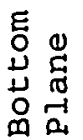


Figure 3-5. NO and light scattering images without oxygen enrichment
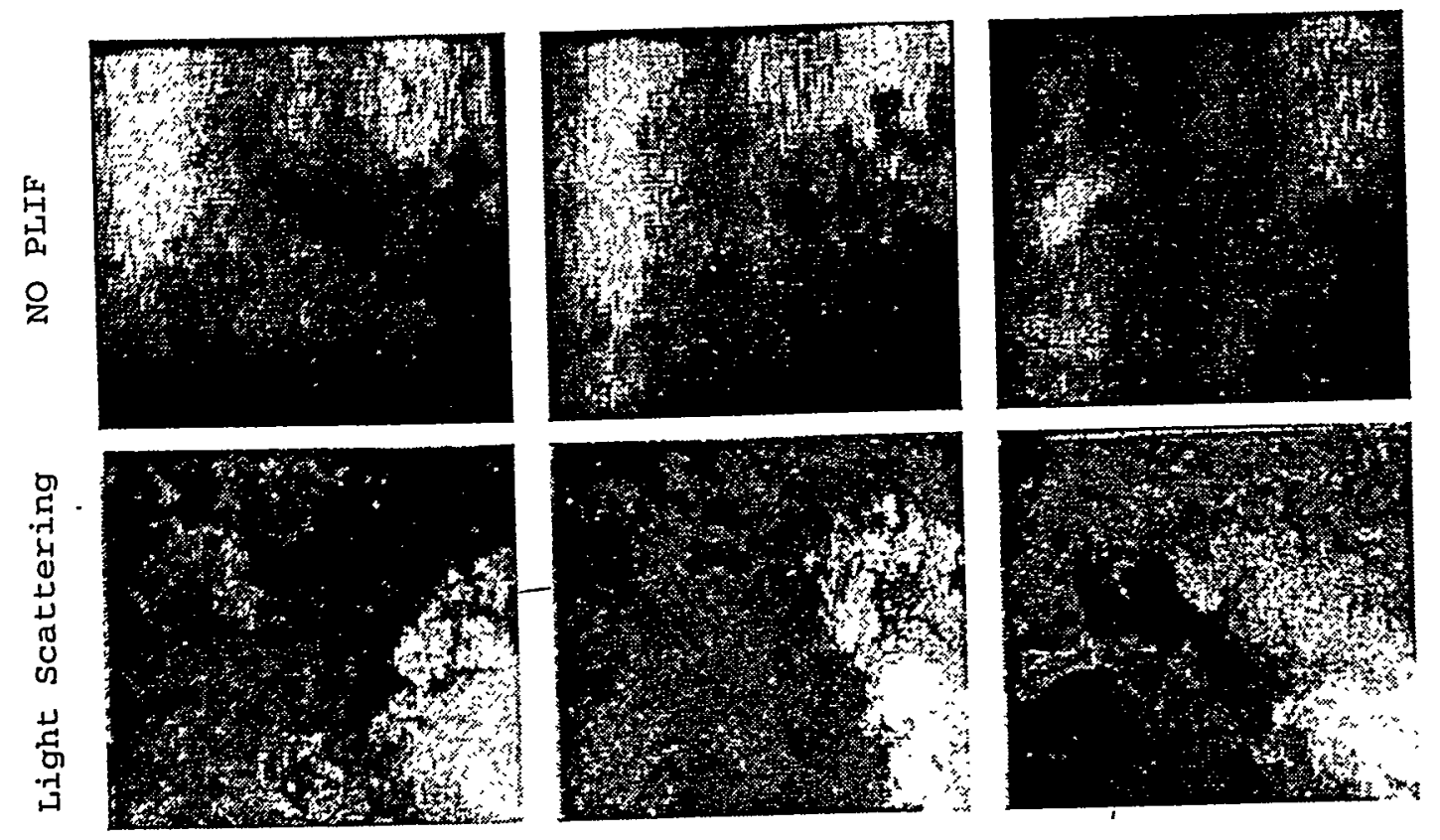

U
秙
in
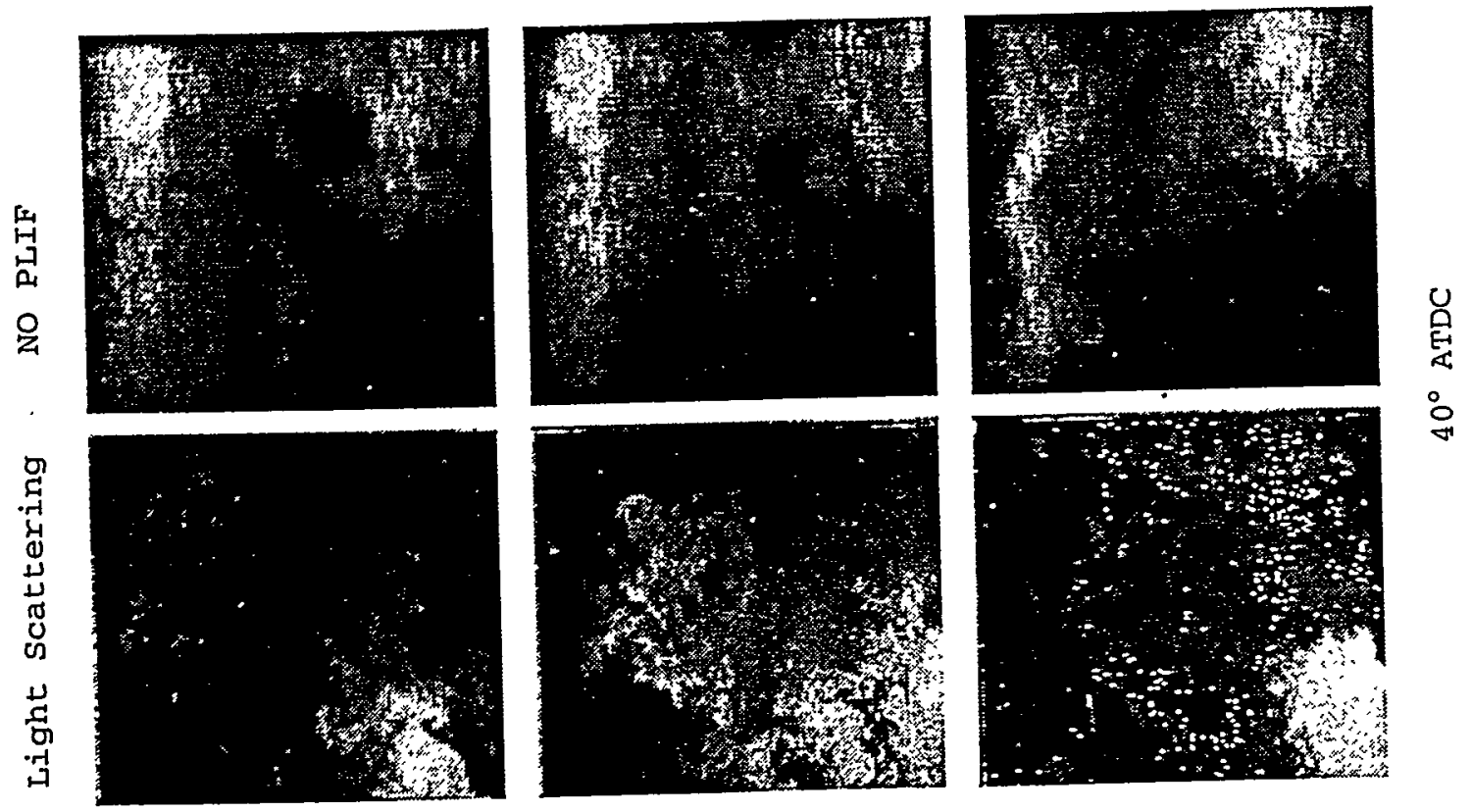
品:

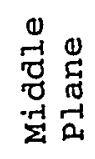

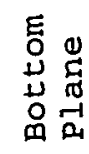




\subsection{Simultaneous LII and Light Scattering for Quantitative Soot Imaging [3] \\ 3.3.1 Previous Work}

When laser light of sufficient intensity is incident upon a gas containing soot particles, absorption of the light can, under certain circumstances, cause significant heating of particles and appreciable incandescence. Often considered a noise effect, laser-induced incandescence (LII) has recently been shown to be useful for diagnostic purposes. Through the work of numerous investigators, the theory of LII and both qualitative and quantitative applications in combustion environments have been established..

LII measurements in a Diesel engine were first performed by researchers at the Combustion Research Facility at Sandia National Labs to make qualitative observations of soot during combustion. A major motivation for the use of LII in this study was the elimination of the effects of fuel droplets which overwhelmed the signal from simple light scattering measurements. These researchers discussed the possibility of quantitative application of the technique but did not demonstrate it. In an extension of their original LII work, the Sandia group performed simultaneous imaging of light scattering and LI signals in a Diesel engine. Through the light scattering equations, they were able to make qualitative inferences regarding both the particle size and volume fractions within the fuel spray plume, but they could not make quantitative measurements due to problems of probe beam attenuation and signal absorption. These experimental difficulties were circumvented in work performed in the Penn State optically accessible engine and quantitative measurements of soot volume fraction and particle size were obtained. The next section discusses the calibration of these methods, the experimental approach, data reduction and illustrative results.

\subsubsection{Apparatus and Experimental Procedure}

The experimental techniques used in this study were first developed in a wellcharacterized ethylene diffusion flame. Regions of known volumetric scattering crosssection in the flame were used to calibrate the light scattering signals. Similarly, the LII signals were calibrated against previously-measured volume fraction profiles in the flame. On the basis of the calibration, soot field measurements were conducted in an opticallyaccessible Diesel engine. Light scattering and LII signals were analyzed using the previously-discussed analyses, resulting in estimations of the soot volume fraction, particle size and number density within the measurement plane.

The choice of laser frequency plays a critical role in the success of the light scattering diagnostics. For this work, the frequency-doubled output of a Spectra-Physics Nd:YAG laser was chosen to generate the light scattering and LII signals. Clearly, the $1064 \mathrm{~nm}$ principal wavelength of the Nd:YAG would significantly improve the accuracy of Rayleigh calculations; however, use of an infra-red probe beam introduces a number of experimental difficulties. After initial images taken from the engine indicated that the bulk of particle sizes did not significantly differ from the Rayleigh regime for $532 \mathrm{~nm}$, the $1064 \mathrm{~nm}$ beam was ruled out for this initial study.

The imaging system centered around two Pulnix TM745 CCD cameras and an EPIX frame grabber. One of the Pulnix cameras was used for light scattering measurements and the second camera was lens-coupled to a Quantum Leap image intensifier supplied by Stanford Computer Optics to provide gating and amplification of the weaker LII signals. Relative calibrations of the cameras were obtained from a crossed-polarizer and neutral density filter setup used to assess the dynamic range, signal-to-noise ratio and gain (where applicable) of each of the camera setups. Absolute calibrations of the cameras were performed by comparison to measurements made in an ethylene diffusion flame.

One of the primary limitations for light scattering diagnostics is the dynamic range of the imaging sensor. Typically, RS170 cameras and frame grabbers are limited to a dynamic range of 8 bits or 256 evenly-spaced levels. However, as has been illustrated, higher dynamic ranges are necessary to sufficiently characterize the expected light scattering signals from small soot particles. Due to the limitations in dynamic range of conventional 
image sensors, the experimental results represent a compromise between the detectability limit and the maximum measurable intensity of the sensor.

A crossed-polarizer and neutral density filter setup was used to calibrate the camera at the laser wavelength of $532 \mathrm{~nm}$. The polarizers used for the calibration were dichroic sheet type provided by Melles Griot. For the calibration, the polarizers were never crossed greater than 80 degrees because the cosine function becomes very steep beyond this point. To extend the dynamic range of the calibration setup, neutral density filters were used to move the usable attenuating range of the polarizers to lesser transmittances. The optical density of the neutral density filters (NDF) and of the crossed-polarizer set were verified using a spectrometer at the laser wavelength.

In order to successfully use 8-bit cameras for light scattering applications, both the camera gain and the camera response function were modified. The response of an imaging sensor is proportional to the incident intensity by the following relationship:

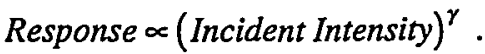

For scientific imaging applications, a linear response of the CCD sensor is usually requested. In uncooled form, the Sony interline chip used in the Pulnix camera is capable of a dynamic range of $56 \mathrm{~dB}$; however, this dynamic range is unattainable by operating the camera in linear mode. To improve the dynamic range of the setup, the $\mathrm{g}$ of the camerawas changed from 1.0 to 0.45 . Although the camera response is rendered nonlinear, considerable improvement to the system dynamic range is achieved. The camera with a $\mathrm{g}$ of 0.45 provides greater access to lower light levels compared to a linear response curve. Additionally, the internal gain of the camera was adjusted to near minimum to improve the signal-to-noise ratio at low light levels. As a result of these two modifications, the full 56 $\mathrm{dB}$ of the camera was rendered usable.

To further extend the dynamic range of the camera used to measure light scattering signals, an image splitter was used to obtain a double image on the CCD sensor. One of the images was filtered through a NDF with an optical density of 1.3 resulting in an attenuation factor of 20. During the experiment, the aperture of the lens was adjusted so that the attenuated image was just below the camera saturation level. In doing so, the unattenuated image had regions of significant saturation. During the analysis, light scattering signals were obtained from the side of the sensor without the NDF. In the event that a pixel was saturated, the corresponding pixel behind the NDF was scaled and used instead.

The combination of the two images theoretically yielded a total system dynamic range of $82 \mathrm{~dB}$. However, in practice, the setup only yielded a usable dynamic range of $73 \mathrm{~dB}$ allowing for visualization of particles with a $D_{10}$ of $28 \mathrm{~nm}$ and larger. Use of neutral density filters of greater optical density was attempted; however, problems associated with overexposure of the other half of the sensor began to manifest themselves.

Typically, light scattering and absorption signals from soot in an engine are small when compared with flame luminosity. To counter this problem, the Pulnix camera used for imaging of the light scattering signal was gated to the lowest possible setting of $36 \mu \mathrm{s}$. Additionally, a narrow band interference filter at $532 \mathrm{~nm}$ with a $1 \mathrm{~nm}$ pass band was used. Therefore the scattering data are nearly free from background influences of flame luminosity.

Although LII signals are quite strong, they require amplification to be usable. Therefore an image intensifier supplied by Stanford Computer Optics was lens-coupled to the second Pulnix camera. In order to attain increases in dynamic range, the camera was operated with a $\mathrm{g}$ of 0.45 as before. Relative calibrations were performed on the cameraintensifier system as a whole using the crossed-polarizer setup at the detection wavelength through the narrow band-pass filter used for the experiment.

The gain settings on the intensifier and on the lens-coupled camera represent a tradeoff between sensitivity and signal-to-noise ratio of the imaging system. Through trial and error experimentation, a gain voltage of 750 volts was chosen as the best setting. At this 
setting, it was also necessary to increase the gain of the Pulnix camera over the levels used for the light scattering camera. The calibration data for the intensified camera follow a trend similar that of the light scattering camera with the exception of a rolloff beginning for intensifier response values above 200. Due to the rolloff phenomena, experimental errors for higher response values rendered the intensifier unusable at response values above 230 . The combined effects of noise inherent in intensified systems, noise induced by increases in the CCD camera gain, and problems with the intensifier at high response values, a usable dynamic range of only 200 ( $46 \mathrm{~dB})$ was attained. Since the LII signal is directly proportional to the soot volume fraction, the dynamic range of the intensifier was sufficient for the purposes of this work.

Reduction of interference from flame luminosity and from light scattering was accomplished through the use of a $400 \pm 12 \mathrm{~nm}$ narrow band-pass filter supplied by Corion and by adjusting the intensifier gate to the lowest possible setting of $50 \mathrm{~ns}$. Blocking of the $532 \mathrm{~nm}$ signal by the narrow band-pass filter was nearly complete for the LII camera, but some light scattering signal was still evident. Undesirable light scattering signals were especially evident from the combustion chamber walls where significant scattering of the incoming beam occurred. To combat this problem, the intensifier gate was moved to a position $5 \mathrm{~ns}$ after the laser pulse. This adjustment served to completely eliminate extraneous light scattering from the LII signal. Due to the finite time required for the laserheated soot particles to cool, the timing shift did not impair the quality of the resulting LII signal.

\subsubsection{Experimental Setup}

The experimental setup shown in Figure 3-4 was developed such that the calibration data could be gathered simultaneously from the diffusion flame, thus simulating the conditions required for imaging in the engine. A laser sheet $6 \mathrm{~cm}$ in width and $300 \mu \mathrm{m}$ in thickness is formed by a $675 \mathrm{~mm}$ spherical lens combined with a cylindrical lens. Measurements were made using the central $38 \mathrm{~mm}$ of the sheet where the average laser fluence was $2.2 \times 10^{8}$ $\mathrm{W} / \mathrm{cm}^{2}$. A dichroic beam splitter manufactured by CVI was used to reflect the $532 \mathrm{~nm}$ light scattering signal through the previously-discussed image splitter and neutral density filter arrangement. The LII signals were transmitted through the dichroic filter into the intensifier.

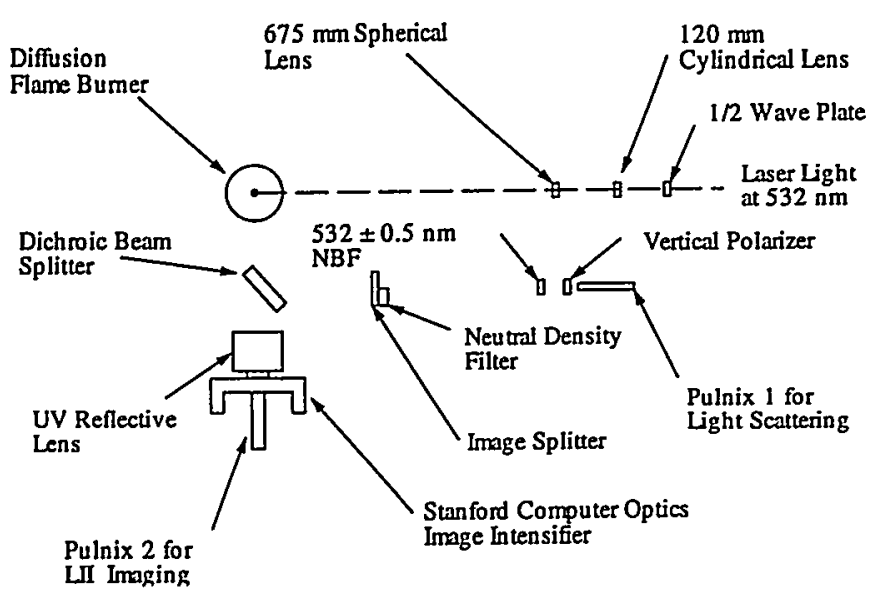

Figure 3-4. Flame calibration setup.

The experimental set-up used for the engine studies is shown in Figure 3-5. A circuit was constructed to coordinate the triggering of the light scattering camera, the image intensifier and the laser. The circuit was driven by a pulse generator for the flame calibration and by an engine-synchronized optical shaft encoder during engine experiments. 
Light scattering signals were acquired directly by an EPIX frame grabber whereas the LII signals were acquired using a Mitsubishi SVHS video recorder. Following the experiment, the LII signals were digitized from the videotape by the frame grabber.

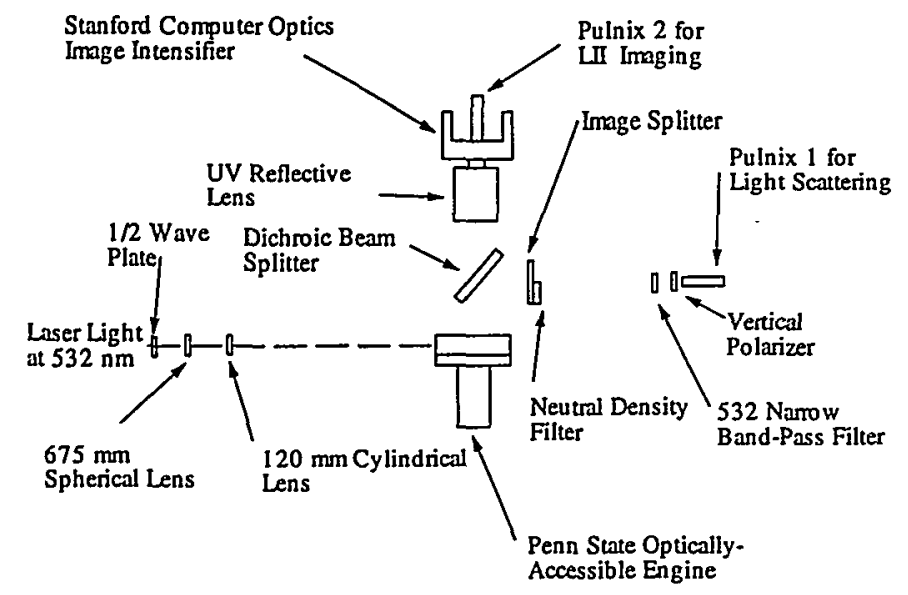

Figure 3.5. Engine experimental setup.

In order for quantitative information to be obtained, an absolute calibration of both the light scattering and LII signals must be performed. Although many possibilities exist for the quantification of light scattering signals, the $L \Pi$ signal must be calibrated against a soot field of known concentration. The well-established soot field of the laminar diffusion flame was chosen as the LII calibration source. Out of convenience, light scattering from the diffusion flame was compared to previously-determined volumetric scattering crosssections to obtain the calibration for $Q_{v}$.

Two principle experimental challenges exist for the calibration of the engine data against the flame data. By far, the greatest difficulties are the sharp gradients in the $Q_{v}$ and LII signals within the diffusion flame. Additionally, the calibration data for the diffusion flame only exist at discrete locations in the flame; therefore, calibrations can be made only over a limited set of areas. To address both of these issues, heights within the flame at which the data are slowly changing and widely varying were chosen as the primary calibration locations. A height of $30 \mathrm{~mm}$ above the burner tube exit proved to be satisfactory for the LII signal while a height of $50 \mathrm{~mm}$ was required for the $Q_{w}$ signal.

The strip of pixels on each sensor corresponding to the test height was separated from the image and calibrated to the data of Santoro et al. As can be seen in Figures 3-6 and 3-7, the calibrated data points are in reasonable agreement with the data of Santoro et al. The calibration equations obtained from the analysis of the flame images were then used to interpret the signals collected from the engine.

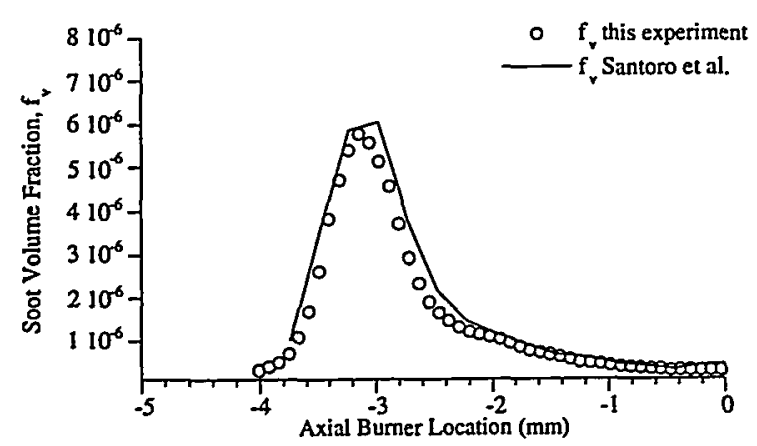

Figure 3-6. Comparison of LII calibration to the soot measurements of Santoro et al. 


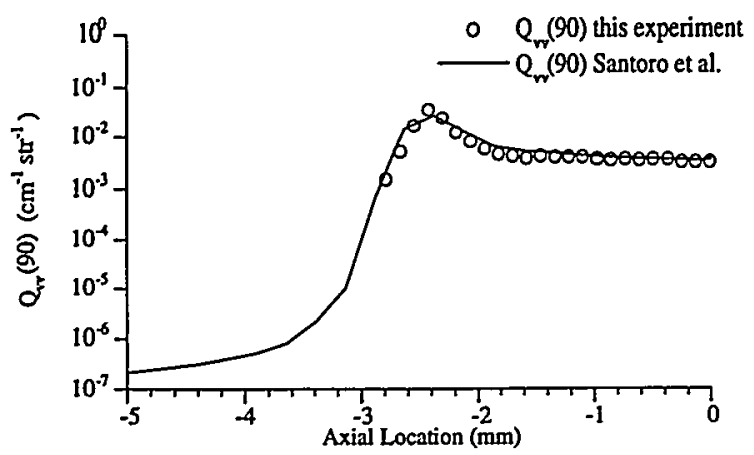

Figure 3-7. Comparison of $Q_{v v}(90)$ calibration to the measurements of Santoro et al.

\subsubsection{Data Reduction}

The data from a given experiment consisted of unattenuated and attenuated light scattering images as well as an LI image. The images were aligned and then analyzed using a computer program based on the Rayleigh relations. Within the program, calibration equations were applied to the raw light scattering and LII signals so that the volume fraction and $Q_{v v}$ were obtained. If the resulting value fell below the noise limits of the system, the value was rejected. In practice, a region could be rejected for insufficient volume fraction, light scattering signal or both. If both of the signals were sufficiently strong, the analysis proceeded and the results were scaled and written to disk.

To maintain an optically-thin soot field, an overall in-cylinder equivalence ratio of 0.35 was used. Preliminary LII images taken at throughout the combustion chamber indicate that the soot volume fractions do not exceed $2.6 \times 10^{-6}$ for any of the measurement planes. As a result, beam attenuation across the combustion chamber was not significant. The overall lean nature of the combustion event also precludes extinction of the LII signal as it travels through the combusting medium to the camera.

The engine was operated in single-shot mode through the use of a high speed valve and engine control system. Prior to taking data, the engine was motored until the cylinder wall temperature reached $250^{\circ} \mathrm{C}$. Once the engine reached the operating temperature, the engine controller was activated, which in turn triggers the laser, cameras and the ondemand-injection system. The images were then acquired and the engine was stopped for cleaning. Under the light loads run for this study, the engine could be fired ten consecutive times before. significant window fouling occurred.

To obtain a general indication regarding the progression of the combustion event, a heat release analysis was performed on the engine pressure data. The heat release and pressure curves represent a 25-cycle average at the same operating conditions used for the soot imaging experiments. As can be seen in Figure 3-8, the diffusion burn rate peaks at approximately $7^{\circ}$ after top-dead-center (ATDC) and continues until approximately $50^{\circ}$ ATDC. When compared to typical heat release diagrams for commercial engines, the combustion event for this study is highly premixed. Three factors which may contribute to the discrepancy are low engine speed, low engine temperature and low injection pressure, each of which serve to increase the ignition delay and thus the premix burn fraction. 


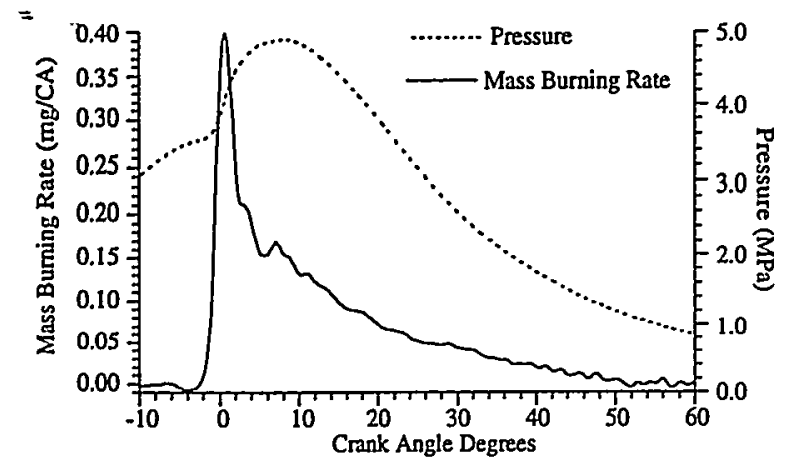

Figure 3-8. Heat release profile for the conditions of this study

\subsubsection{Results}

In order to accurately transfer the flame calibration to the engine, the experimental configuration and laser power used for the calibration was duplicated on the engine setup. To facilitate this endeavor, the entire calibration rig was constructed on optical rails so that it could be easily moved without altering the collection efficiencies of the setup. Five measurement planes were established at different levels in the combustion chamber, as shown in Figure 3-9. The planes begin at $3.0 \mathrm{~mm}$ from the bottom of the combustion chamber and are separated by a distance of $1.5 \mathrm{~mm}$.

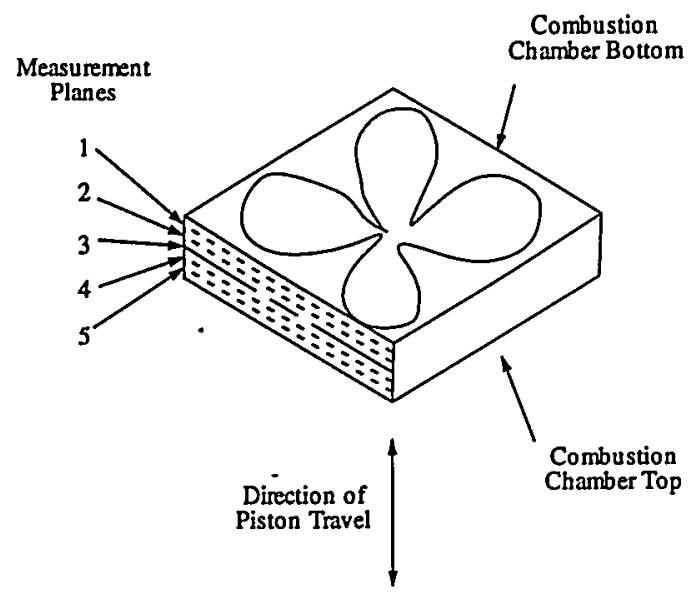

Figure 3-9. Measurement planes within the engine.

The engine results are grouped into two subsets: $\mathrm{LII}$ measurements and simultaneous LII and light scattering measurements. Initially, LII measurements were used to establish the evolution of the average soot volume fraction along three measurement planes in the engine. Then, the LII images were combined with light scattering results to obtain estimates of particle size and number densities. 


\section{VOLUME FRACTION MEASUREMENTS}

LIII images were acquired over the crank angle range from $2^{\circ}$ to $50^{\circ}$ ATDC in $2^{\circ}$ increments at the first, third and fifth measurement planes within the combustion chamber. For each condition, four images were acquired. The calibration was then applied to the results to yield images of the in-cylinder soot volume fraction. To obtain general information regarding the evolution of in-cylinder soot volume fraction, the images were averaged over the entire area of the measurement plane. The time history of soot volume fraction for plane 1 are shown in Figure 3-10.

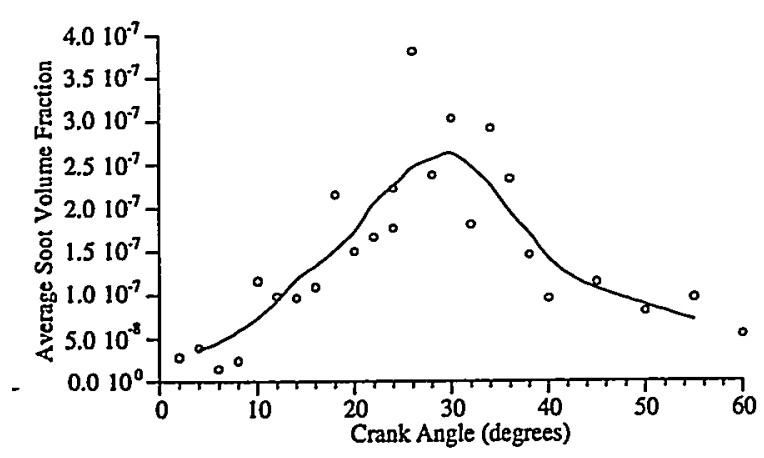

Figure 3-10. Evolution of soot volume fraction at plane 1 in the combustion chamber.

The soot concentration grows to a maximum at approximately $30^{\circ}$ followed by an expansion-induced falloff at late angles. To examine the quantity of in-cylinder soot, the volume fraction results were multiplied by the in-cylinder volume and by the density of soot (taken here to be $1.8 \mathrm{~g} / \mathrm{cm}^{3}$ ). The resulting values are proportional to the soot mass in the measurement plane. To make soot evolution trends clearer, the data were subjected to a 5 point moving window average. The mass of soot along each of the three planes is shown in Figure 3-11. As can be seen in the figure, the soot peaks from 30 to 35 degrees ATDC.

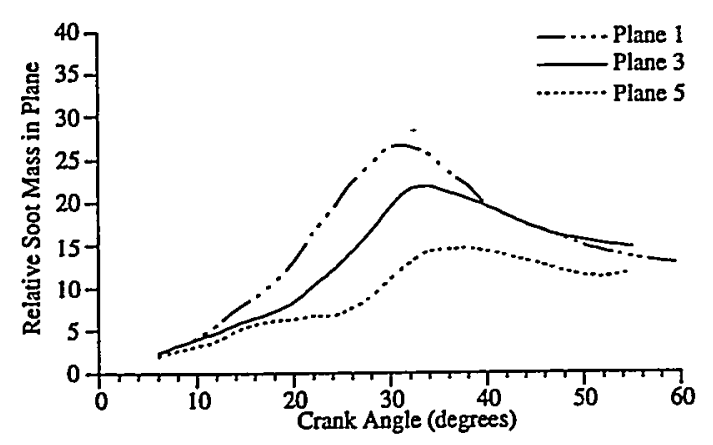

Figure 3-11. Soot mass evolution at planes 1, 3 and 5.

Of the three planes, the mass of soot in the bottom plane is generally highest. It is possible that the mass of soot in the uppermost plane of the combustion chamber is diluted by air motion into the cylinder. The mass of soot in the combustion chamber drops following its peak, indicative of soot destruction and mixing. At later angles, the soot mass 
on each of the planes appears to converge to the same value as mixing of the cylinder contents continues.

\section{SIMULTANEOUS MEASUREEMENTS}

The calibration results were applied to the simultaneous light scattering and LII images obtained in the engine at 10,20,30,40 and 50 crank-angles ATDC at plane 1 located $3 \mathrm{~mm}$ below the upper window. At each angle, ten simultaneous images of light scattering and LII were taken of the combustion chamber. Following the previously-discussed Rayleigh analysis, planar images of soot particle size, number density and volume fraction were calculated assuming a self-preserving size distribution width of 0.285 . A representative series of results for 10,30 and 50 crank-angle ATDC are presented in Figure 3-12. Examination of the resulting images yields information regarding both the temporal and spatial distribution of soot within the combustion chamber.

Further insight may be gained by examining the normalized and smoothed histograms of the particle sizes in the engine, shown in Figure 3-13. Starting at $10^{\circ}$ ATDC, the peak of the particle size histogram is shifted towards small particles as would be expected of the soot formation process. At $20^{\circ} \mathrm{ATDC}$, the histogram has shifted significantly towards larger particles and by $30^{\circ}$ ATDC, a stable histogram shape is evident. It is important to note that the size histograms represent averages over many particles and yield no information regarding the particle size distribution function, $P(D)$. However, it is interesting to note that the histograms of $30^{\circ}, 40^{\circ}$ and $50^{\circ} \mathrm{ATDC}$ follow the functional form of a self-preserving size distribution to within 2.6 percent. 

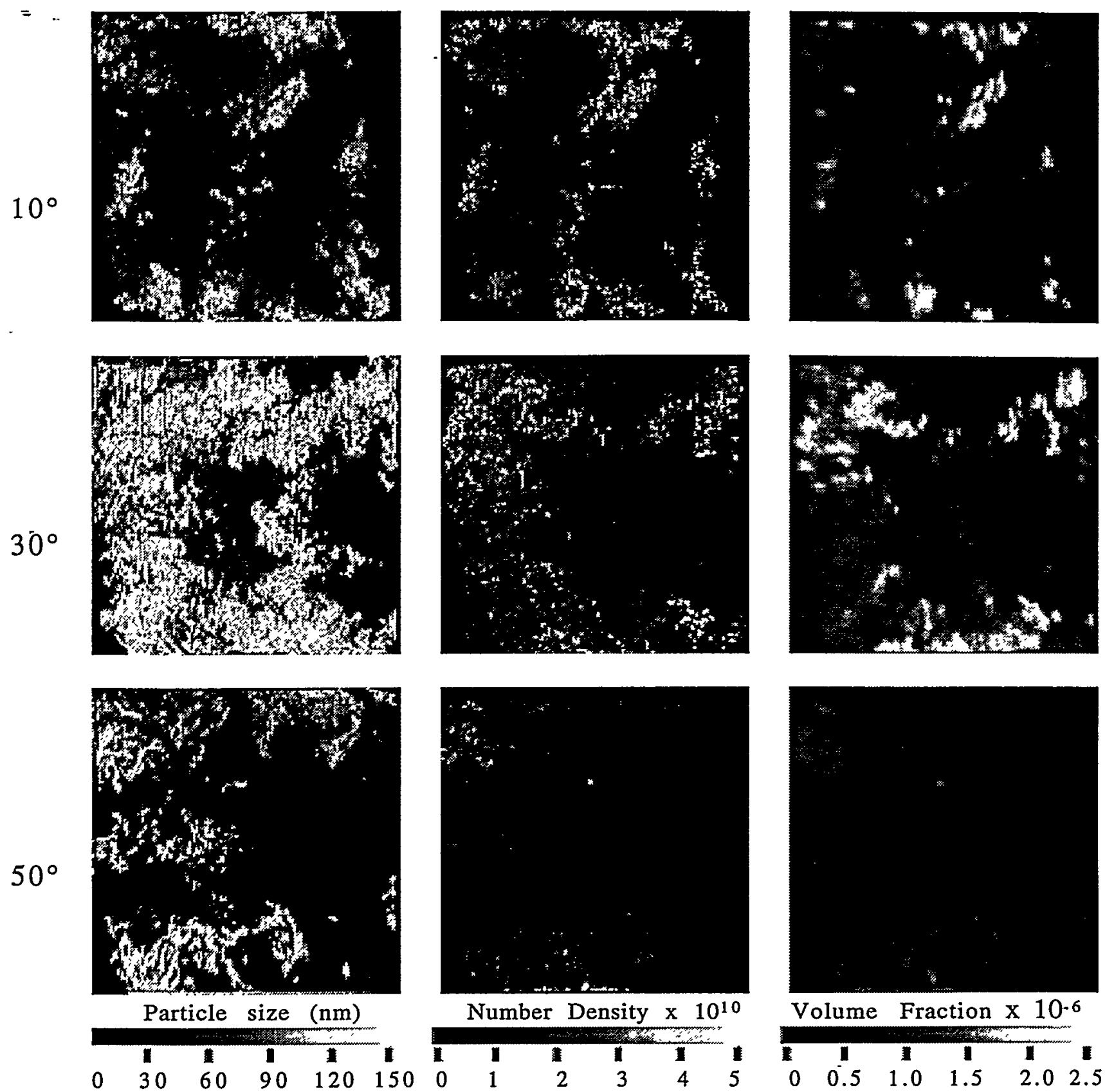

Figure 3-14. Simultaneous imaging results. 
The effects of particle burnout are also evident from Figure 3-14. Although the shifts in the particle distributions appear small, they are indicative of significant changes in the volume fraction of the particle field. Between $30^{\circ}$ and $40^{\circ}$ the mean particle diameter drops by $7 \%$. This slight reduction in mean size generates a $20 \%$ reduction in soot volume. At $50^{\circ}$ the mean particle size drops by $11 \%$ from $30^{\circ}$ corresponding to a soot volume reduction of $30 \%$.

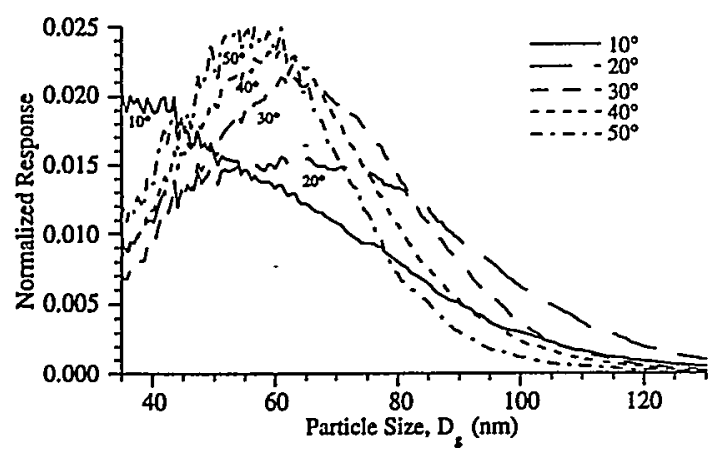

Figure 3-14. Particle size histograms. 


\section{4:0 Parametric Studies}

\subsection{Effects of Intake Charge Dilution with Constant Start of Combustion [4]}

In this study addition of nitrogen and carbon dioxide was used to simulate the effects of EGR on combustion and emissions. The approach was to add either nitrogen or carbon dioxide to the intake air to achieve a specific level of oxygen and then to observe combustion with direct photography, heat release and exhaust emissions. The use of nitrogen allowed the effect of oxygen concentration to be studied while the addition of carbon dioxide determined the effect of a substantial reduction in in-cylinder temperatures. Typical experimental conditions are presented in Table 4-1.

Table 4-1: Experimental Conditions

\begin{tabular}{|l|l|}
\hline Equivalence Ratio & 0.4 \\
\hline Intake Air Temp. & $394 \mathrm{~K}\left(250^{\circ} \mathrm{F}\right)$ \\
\hline Exhaust Pressure & $152 \mathrm{kPa}(22 \mathrm{psi})$ \\
\hline Head Temp. & $394 \mathrm{~K}\left(250^{\circ} \mathrm{F}\right)$ \\
\hline Injector Cracking Pressure & $20.7 \mathrm{mPa}(3000 \mathrm{psi})$ \\
\hline Fuel Components & Cetane / HMN \\
\hline Fuel Cetane Number & 50 \\
\hline Start of Combustion & $3.2^{\circ}$ BTDC $\pm 0.5^{\circ}$ \\
\hline Engine Speed & 900 R.P.M. \\
\hline
\end{tabular}

Data consisting of percent oxygen in the intake gas $\left(\% \mathrm{O}_{2}\right)$, start of injection (SOI), end of injection (EOI), start of combustion (SOC), and ignition delay (ID) is presented in Table 4-2 and Table 4-3. In order to determine the start and end of injection, photographs were taken of injection while the intake stream was pure nitrogen. The use of nitrogen eliminated visible light from combustion and allowed clear vision of the start and end of injection. The start of combustion was determined by analyzing the derivative of the cylinder pressure curve as mentioned previously. The ignition delay was determined by subtracting the timing at start of injection from the timing at start of combustion.

Table 4-2: Conditions with Nitrogen Dilution

\begin{tabular}{|l|l|l|l|l|}
\hline$\%$ O2 & $\begin{array}{l}\text { SOI } \\
{ }^{\circ} \text { ATDC }\end{array}$ & $\begin{array}{l}\text { EOI } \\
{ }^{\circ} \text { ATDC }\end{array}$ & $\begin{array}{l}\text { SOC } \\
{ }^{\circ} \text { ATDC }\end{array}$ & $\begin{array}{l}\text { ID } \\
{ }^{\circ}\end{array}$ \\
\hline 15.0 & -9 & -1 & -3.2 & 5.8 \\
\hline 17.0 & -7 & 0 & -3.3 & 3.7 \\
\hline 19.0 & -6 & 2 & -3.2 & 3.8 \\
\hline 20.9 & -5 & 3 & -3.2 & 2.8 \\
\hline
\end{tabular}

Table 4: Conditions with Carbon Dioxide Dilution

\begin{tabular}{|c|c|c|c|c|}
\hline$\% \mathrm{O}_{2}$ & $\begin{array}{l}\text { SOI } \\
{ }^{\circ} \mathrm{ATDC}\end{array}$ & $\begin{array}{l}\text { EOI } \\
{ }^{\circ} \mathrm{ATDC}\end{array}$ & $\begin{array}{l}\text { SOC } \\
{ }^{\circ} \mathrm{ATDC}\end{array}$ & ID \\
\hline 17.0 & -15 & -7 & -3.0 & 12 \\
\hline 19.0 & -10 & -2 & -3.6 & 6.4 \\
\hline 20.9 & -6 & 2 & -3.4 & 2.6 \\
\hline
\end{tabular}

Diluting the intake air with either nitrogen or carbon dioxide had an effect on the ignition delay. However, the effect of the carbon dioxide dilution was much more pronounced than that of the nitrogen dilution. Dilution of the intake air to $17 \% \mathrm{O}_{2}$ increased the ignition delay from 2.6 to $12^{\circ} \mathrm{CA}$. Similar dilution for the nitrogen case 
yielded a change in ignition delay of $3^{\circ} \mathrm{CA}$. The timing for each case was adjusted to align start of combustion within one half degree of $-3.3^{\circ}$ ATDC.

Figure 4-1 and Figure 4-2 show pressure traces for the nitrogen and carbon dioxide cases respectively. Diluting the intake gas with either nitrogen or carbon dioxide produced several changes which were evident from the fired cylinder pressure traces. As the dilution of the air increases, the rate of pressure rise and the peak cylinder pressure increase for the nitrogen cases. However, the results were slightly different for the carbon dioxide cases. With increasing carbon dioxide dilution, the rate of pressure rise did increase, but the peak pressure decreased when compared to the undiluted case. This decrease is due to the higher heat capacity of the in-cylinder gases, resulting in lower pre-ignition pressures and temperatures as well as reduced pressures and temperatures throughout the combustion event. Table 4-4 and Table 4-5 show the measured peak pressures and time of peak pressure for the nitrogen and carbon dioxide cases respectively. The peak pressure for the nitrogen cases increased by a maximum of 1.8 percent as the intake oxygen concentration was decreased from $20.9 \%$ to $17.0 \%$. The peak pressures for the carbon dioxide cases decreased by $7.2 \%$ as the oxygen concentration was reduced from $20.9 \%$ to $17.0 \%$.

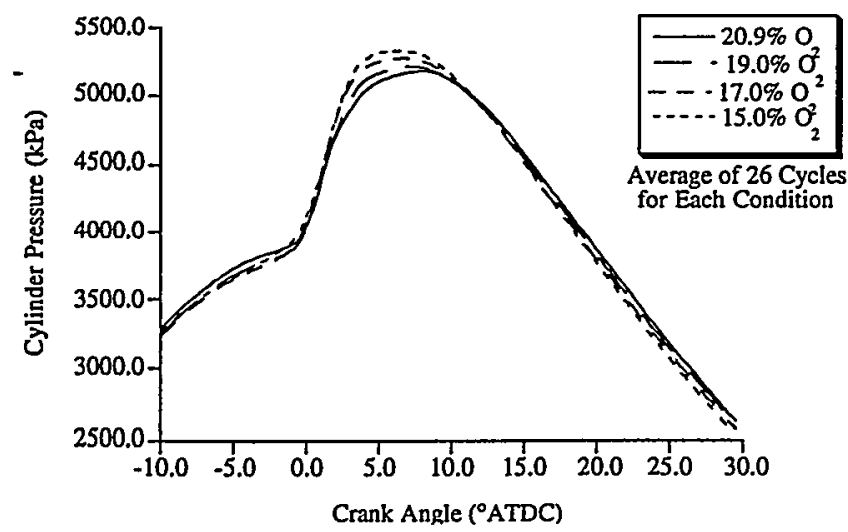

Figure 4-1: Pressure Traces with Nitrogen Dilution

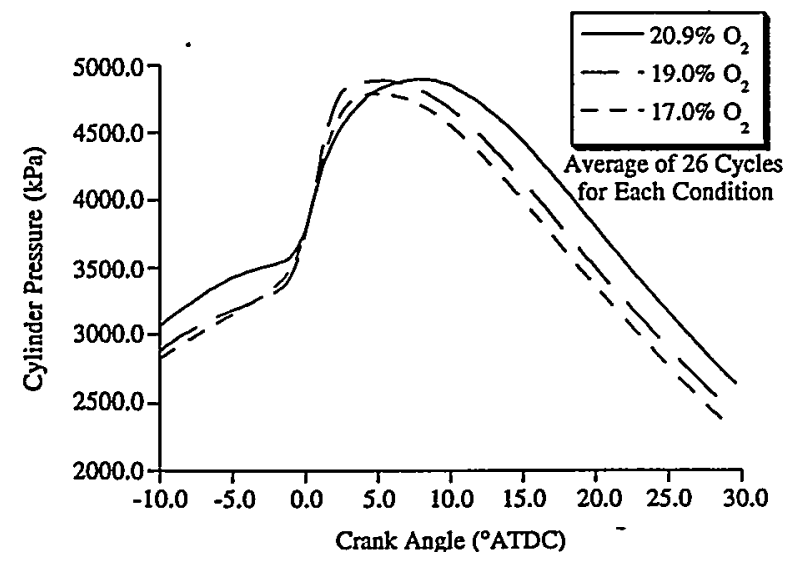

Figure 4-2: Pressure Traces with Carbon Dioxide Dilution 
Table 4-4: Peak Cylinder Pressures and Timing for Nitrogen Dilution Cases

\begin{tabular}{|c|c|c|}
\hline \% 02 & $\begin{array}{c}\text { Peak } \\
\text { Pressure } \\
(\mathbf{k P a})\end{array}$ & @ ${ }^{\circ \mathrm{ATDE}}$ \\
\hline 20.9 & 5182 & 7.8 \\
\hline 19.0 & 5211 & 7.3 \\
\hline 17.0 & 5274 & 6.8 \\
\hline 15.0 & 5327 & 6.3 \\
\hline
\end{tabular}

Table 4-5: Peak Cylinder Pressures and Timing for Carbon Dioxide Dilution Cases

\begin{tabular}{|c|c|c|}
\hline$\%$ O2 & $\begin{array}{c}\text { Peak } \\
\text { Pressure } \\
(\mathbf{k P a})\end{array}$ & @ ${ }^{\circ}$ ATDC \\
\hline 20.9 & 5153 & 8.0 \\
\hline 19.0 & 5194 & 5.6 \\
\hline 17.0 & 4783 & 6.1 \\
\hline
\end{tabular}

Table 4-6: Premixed Burn Fraction with Nitrogen Dilution

\begin{tabular}{|c|c|}
\hline \%O2 & $\begin{array}{c}\text { \% Premixed } \\
\text { Burn }\end{array}$ \\
\hline 20.9 & 26.3 \\
\hline 19.0 & 33.9 \\
\hline 17.0 & 44.5 \\
\hline 15.0 & 51.2 \\
\hline
\end{tabular}

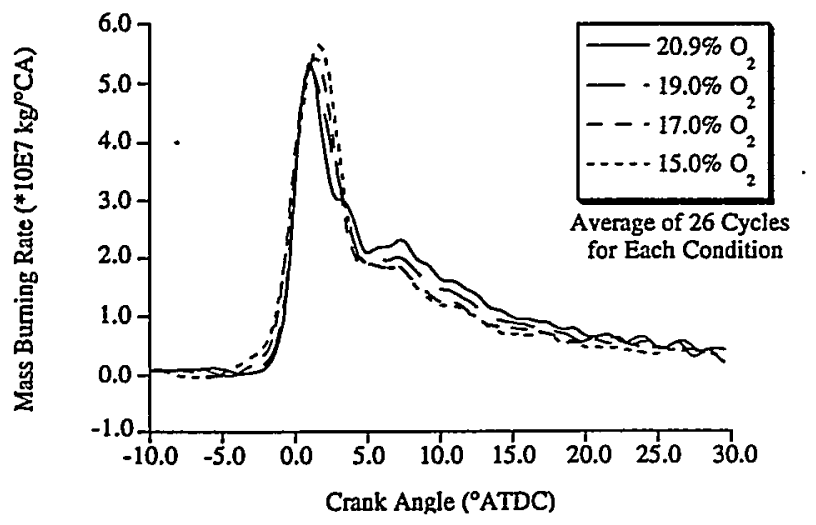

Figure 4-3: Heat Release Curves with Nitrogen Dilution

Heat release curves are presented for the nitrogen cases in Figure 4-3. It was not possible to perform heat release analysis on the carbon dioxide cases due to the lack of a heat release code capable of handling the different specific heat of the intake gas, although 
one is currently being developed. Table 4-6 presents premixed burn fraction data of the nitrogen diluted cases.

The heat release curves for the nitrogen cases show a substantial increase in premixed burn fraction with increasing dilution. The premixed burn fractions shown in Table 4-6 quantify this change; as the oxygen concentration is reduced from $20.9 \%$ to $15.0 \%$, the percentage of premixed burn nearly doubles. This change is a result of the increase in ignition delay with increasing nitrogen dilution, which allows more fuel to vaporize and mix with the cylinder charge before combustion begins. The longer ignition delay is most likely due to the lower oxygen concentration in the combustion chamber.

Pressure - volume diagrams were produced for all of the cases. These plots are not shown here for brevity; however, the area contained in the curve for each case was integrated to find the indicated work done during the cycle. These values were then used to compare loss of efficiency and also to calculate emissions on a power specific basis. The average work for each case is shown in Table 4-7. There was no significant change in the work output when using nitrogen dilution. However, the work decreased by $21 \%$ when the intake oxygen concentration was diluted from $20.9 \%$ to $17.0 \%$ using carbon dioxide. This resulting loss of efficiency was expected due to the increase in specific heat of the in cylinder gas when carbon dioxide is used as a diluent. With the cases of nitrogen dilution, there is no significant specific heat change, and thus no loss of work output. There is a difference between the baseline work outputs for the two cases, due to the fact that the engine was reringed and the injector was rebuilt between the nitrogen and carbon dioxide experiments. Thus, variations in injection characteristics as well as blowby contributed to the work output differences between the two baseline cases.

Table 4-7: Indicated Work as Integrated from P-V Diagrams

\begin{tabular}{|c|c|c|}
\hline$\% \mathbf{~ O}_{2}$ & $\begin{array}{c}\text { Work } \\
\text { (Joules) } \\
\mathbf{N}_{2} \text { Dilution }\end{array}$ & $\begin{array}{c}\text { Work } \\
\text { (Joules) } \\
\text { CO2 } \\
\text { Dilution }\end{array}$ \\
\hline 20.9 & 180.2 & 223 \\
\hline 19.0 & 185.5 & 205 \\
\hline 17.0 & 188.4 & 176 \\
\hline 15.0 & 182.3 & --- \\
\hline
\end{tabular}

Oxides of nitrogen and soot emission data are presented in Figure 4-4 and Figure 4-5, respectively: The emission data is normalized to the work output of the engine to allow fair and consistent comparison between cases where the indicated work has changed. It is clear from Figure 4-4 that dilution of the intake air with both nitrogen and with carbon dioxide was very effective in reducing $\mathrm{NO}_{\mathrm{X}}$ emissions. For the nitrogen dilution case, the soot emission level did not change appreciably with different levels of dilution. Thus, the decrease of luminosity as the dilution rate is increased must be primarily due to temperature changes. However, the addition of carbon dioxide as a diluent substantially reduced the soot emission. This reduction could be due to several factors: the longer ignition delay and associated increase in premixed burn eliminated much of the fuel rich areas required for soot production, carbon dioxide retards the formation of soot precursors, or carbon dioxide accelerates oxidation of the soot. In a combustion bomb experiment used to simulate diesel combustion, lida found similar reductions in soot fraction when air was diluted with $\mathrm{CO}_{2}$.

The overall rate equation for NO formation shows that the initial NO formation rate is extremely dependent on the flame temperature, yet only half-order dependent on the oxygen concentration. The small dependence on oxygen concentration cannot explain the large changes seen in $\mathrm{NO}_{\mathrm{x}}$ production with the changes in oxygen concentration used. Thus, the change in $\mathrm{NO}_{\mathrm{X}}$ emission must be due to changes in flame temperature. To investigate the effect of flame temperature on $\mathrm{NO}_{\mathrm{X}}$ formation, the $\mathrm{NO}_{\mathrm{X}}$ emissions were correlated with a 


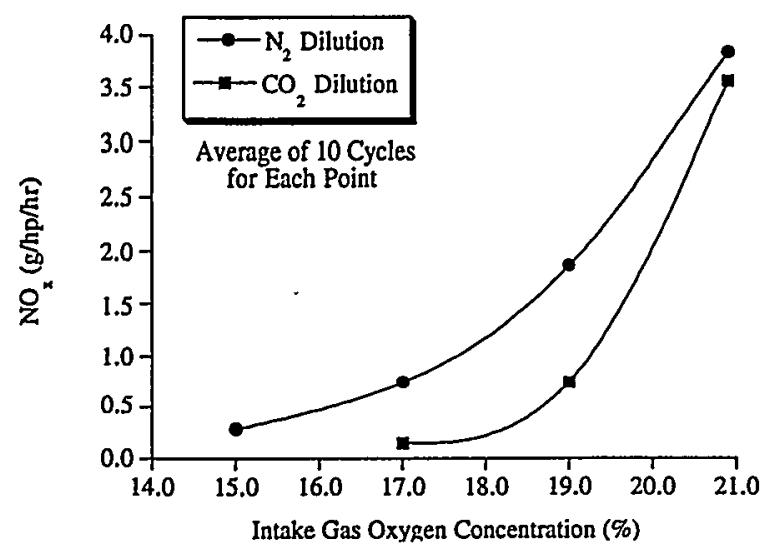

Figure 4-4: Power Specific $\mathrm{NO}_{\mathrm{X}}$ Emission as a Function of Intake Oxygen Concentration

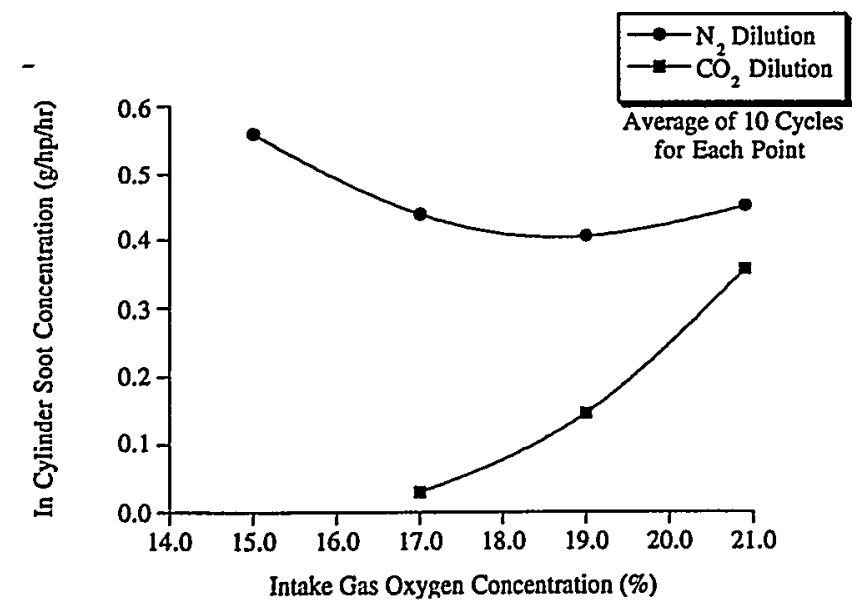

Figure 4-5: Power Specific Soot Emission as a Function of Intake Oxygen Concentration

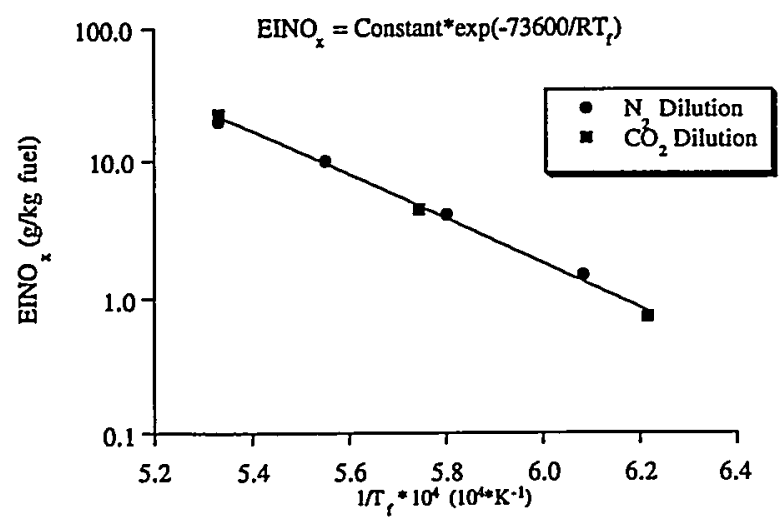

Figure 4-6: $\mathrm{NO}_{\mathrm{X}}$ Emissions Versus Inverse Flame Temperature 
călculated flame temperature for each of the cases. The maximum temperatures of the premixed and mixing controlled phases are close to the stoichiometric adiabatic flame temperature. A chemical equilibrium code (STANJAN) was used to calculate the flame temperatures for the same oxidant compositions used for the engine experiments. A plot of $\mathrm{NO}_{\mathrm{x}}$ emissions ( $\mathrm{g} / \mathrm{kg}$ fuel) versus flame temperature is shown in Figure 4-6.

All data from experiments using either diluent fell on the same line which indicates that temperature dominates the changes in $\mathrm{NO}_{\mathrm{x}}$. Based upon the slope of the line through the data, the overall activation energy for the NO formation process was calculated to be $73,600 \mathrm{cal} / \mathrm{mole}$, quite close to the value reported by Bowman. It is interesting to recall that the overall premixed burn fraction doubled for the $\mathrm{N}_{2}$ case when the oxygen concentration was reduced from $20.9 \%$ to $15.0 \%$. The dominance of flame temperature on $\mathrm{NO}_{\mathrm{X}}$ emissions in EGR studies has been reported by other researchers.

\section{Summary}

Experiments were performed in an optically accessible DI diesel engine in which inert diluents were used to simulate exhaust gas recirculation. Nitrogen was used as a diluent to investigate the effect of reduced oxygen concentration without significantly affecting the specific heat of the cylinder charge, and carbon dioxide was used to investigate the combined effects of reduced oxygen concentration as well as increased cylinder charge specific heat. Injection timing was adjusted to maintain constant start of combustion for all of the cases.

The addition of either nitrogen or carbon dioxide to the intake gas increased the ignition delay. Changes with carbon dioxide were much more severe than changes with nitrogen for the same oxygen concentration. Heat release analysis of the nitrogen cases showed that premix burn fraction doubled as the intake oxygen concentration was diluted from $20.9 \%$ to $15.0 \%$. Peak cylinder pressure and rate of pressure rise increased with increasing nitrogen dilution. Peak cylinder pressure decreased while rate of pressure rise increased with carbon dioxide dilution. The use of nitrogen as a diluent had no effect on the indicated work. Dilution with carbon dioxide caused an $8 \%$ decrease in indicated work for the medium dilution case and a $21 \%$ decrease for the maximum dilution case.

Combustion luminosity photographs taken for all of the cases showed a decrease in luminosity strength and duration as dilution rate was increased using either gas. When oxygen concentration was diluted to $17.0 \%$ with carbon dioxide, very little luminosity was present at any crank angle. The decrease in luminosity with nitrogen was due to a decrease in combustion temperature, while the decrease in luminosity with carbon dioxide dilution was due to decreases in both in-cylinder soot mass and temperature.

Both carbon dioxide and nitrogen addition drastically reduced emissions of $\mathrm{NO}_{\mathrm{x}}$. The emissions of $\mathrm{NO}_{\mathrm{x}}$ were plotted against stoichiometric adiabatic flame temperatures calculated using an equilibrium code. The $\mathrm{NO}_{\mathrm{X}}$ levels correlated extremely well with temperatures. The overall activation energy for NO production was found to be 73,600 $\mathrm{cal} / \mathrm{mole}$. The addition of nitrogen did not substantially affect soot in-cylinder soot levels; however, the addition of carbon dioxide drastically reduced soot levels, presumably due to the increase in premixed burn fraction caused by the longer ignition delay. Additional study using in-cylinder diagnostics on the effects of both of these diluents, particularly carbon dioxide, is necessary to fully understand their effects on soot production and $\mathrm{NO}_{\mathbf{X}}$ emission.

\subsection{Effects of $\mathrm{CO} 2$ Addition with Constant Start of Combustion on Soot Evolution [5]}

4.2.1 Introduction

Following the screening experiments described in the previous section. Experiments were performed to study the effects of $\mathrm{CO} 2$ addition on the evolution of soot duing combustion. 
The diluent feed system was used to meter bottled carbon dioxide into the intake manifold through variable area flow meters where it mixed with a compressed air supply. The compressed air supply provided air with constant humidity and also allowed boosting of the intake air pressure to simulate turbocharging. The carbon dioxide was metered into this stream at $10.5 \%$ on a molar basis to achieve $19 \%$ oxygen mole fraction. The two sets of experiments were run at fixed fuel delivery. With and without dilution, the equivalence ratio based upon the ratio of fuel to molecular oxygen was 0.4 and 0.45 respectively; the lean conditions were used to avoid difficulties with attenuation of the probe beam and absorption of the LII signal. Other conditions were the same as those described above.

The results for heat release, ignition delay and exhaust emissions were consistent with the results described above. Therefore only the soot evolution results from LII and Mie experiments will be discussed.

\subsubsection{Results}

Figure 4-7 shows selected combustion images from TDC to $30^{\circ}$ after TDC to illustrate the differences between the baseline combustion and that with dilution. As noted earlier a combustion chamber with a square cross section was used resulting in the square field of view in these images. At the center of the images the dark circle is the tip of the fuel injector which is located in the piston. For the baseline images the four spray plumes are visible at TDC, while the images for combustion with dilution show no plumes at TDC. This difference is a result of the longer ignition delay caused by the lower temperatures and oxygen concentration with dilution which was compensated for by starting fuel injection earlier compared to the baseline. It should be noted that a complete lack of luminosity in some of the images does not mean there is no luminosity being produced, but rather that the camera setup was not sensitive enough to detect that luminosity. Since the f-stop and shutter speed were held constant for all of the experiments to allow direct comparison, the settings had to be such that the camera was just below the level of saturation for the brightest images. Thus the camera was not operating at maximum sensitivity, and low light levels were not detectable.

The first flame luminosity appears in both sets of images at $1^{\circ}$ after TDC. For the combustion with air the luminosity grows to encompass the four fuel sprays by $3^{\circ}$ after TDC. By $20^{\circ}$ after TDC the spray plume shapes are no longer distinct due to the action of the swirl motion of the in-cylinder gases as well as the radial flow induced by piston motion. At $30^{\circ}$ after TDC the luminosity has decreased substantially. With dilution, flame luminosity is less intense and covers less of the combustion chamber at all crank angles. It is essentially undetectable with the chosen camera parameters by $20^{\circ}$ after TDC. The substantial difference in visible light emissions for the dilution case could be due to the lower temperatures with dilution, lower soot concentrations during combustion or both.

The LII signal was used to determine the volume fraction of soot in the plane of measurement located one millimeter from the cylinder head. Figure 4-8 shows that the results of the volume fraction measurement as a function of crank angle. Each point is the average of five to ten images taken from different combustion events. The data in Fig. 4-8 is somewhat misleading, however, since the volume fraction will be affected by the expansion caused by the motion of the piston. To eliminate this effect, the volume fractions are corrected using the ratio of the cylinder volume at a given crank angle divided by the volume at TDC. Thus the resulting quantity is still dimensionless. This volume fraction corrected for expansion is plotted in Fig. 4-9. The results indicate that the dilution significantly decreased the total amount of soot throughout most of the combustion process. At $50^{\circ}$ after TDC the dilution case has approximately $70 \%$ less soot than the baseline case; a result which is quite consistent with the soot emissions measurements.

When combined with the light scattering, the LII measurements allow the distribution of particle sizes to be calculated over the volume of the laser sheet. This data can then be used to determine distributions of particle size which are presented in Fig. 4-10. In this figure the lower cutoff on particle size is due to dynamic range limitations of the camera 
system used in the experiments. Comparison of the two distributions indicates that they are quite similar in shape, size range and most probable particle size, except at $10^{\circ}$ after TDC where the base case with air has smaller particles.

The variation in average particle size is shown in Fig. 4-11 where the average particle diameter is plotted. At $10^{\circ}$ after TDC, with dilution, the average particle diameter is approximately $30 \%$ larger. The 30\% larger particles with dilution would have an equivalent volume slightly more than twice that of average particle in the base case. When combined with the observation that the corrected volume fractions are nearly equal at this point in combustion, the conclusion is reached that fewer soot particles are present with dilution than without dilution. At crank angles of $30^{\circ}$ or more after TDC the planar imaging results indicate that the particle sizes are nearly the same for the two cases and that significantly less soot exists with dilution. Thus these measurements also indicate that fewer soot particles are present with dilution, because the volume fraction of soot is much less while the particle sizes are similar.

4.2.3 Summary

The exhaust emissions measurements of $\mathrm{NO}_{\mathrm{x}}$ and soot were both reduced by the dilution of the intake charge with carbon dioxide. For NOx, the reduction observed was consistent with expected changes based upon changes in peak flame temperature. For soot, the combustion photography images suggested that with dilution, substantially less soot was present during combustion. However the lower combustion temperatures with dilution also contributed to reduced luminosity so the combustion photography results provided only qualitative insights into the differences. The quantitative results from the planar imaging measurements showed that dilution with carbon dioxide reduced the volume fraction of soot during most of the combustion process. When combined with the particle size measurements, the volume fraction results led to the conclusion that the number density of the soot was reduced by dilution. This reduction of the number density of soot by the dilution appears to be caused by the decrease in the amount of fuel that combusts under mixing controlled conditions which favor soot formation, as hypothesized by earlier researchers. Decreased burning under mixing controlled conditions results in the formation of fewer soot particles which then grow to sizes that are similar to those without dilution.

While the present results are consistent with such an explanation, they do not completely rule out effects of the reduction in temperature on soot formation and oxidation rates. Nor do they rule out the possibility that the carbon dioxide diluent may participate in the oxidation of soot. Additional studies under different experimental conditions are required to confirm that the reduction in the number of soot particles is exclusively due to changes in the heat release characteristics. 
Figure 4-7: Selected Combustion Images with and without dilution

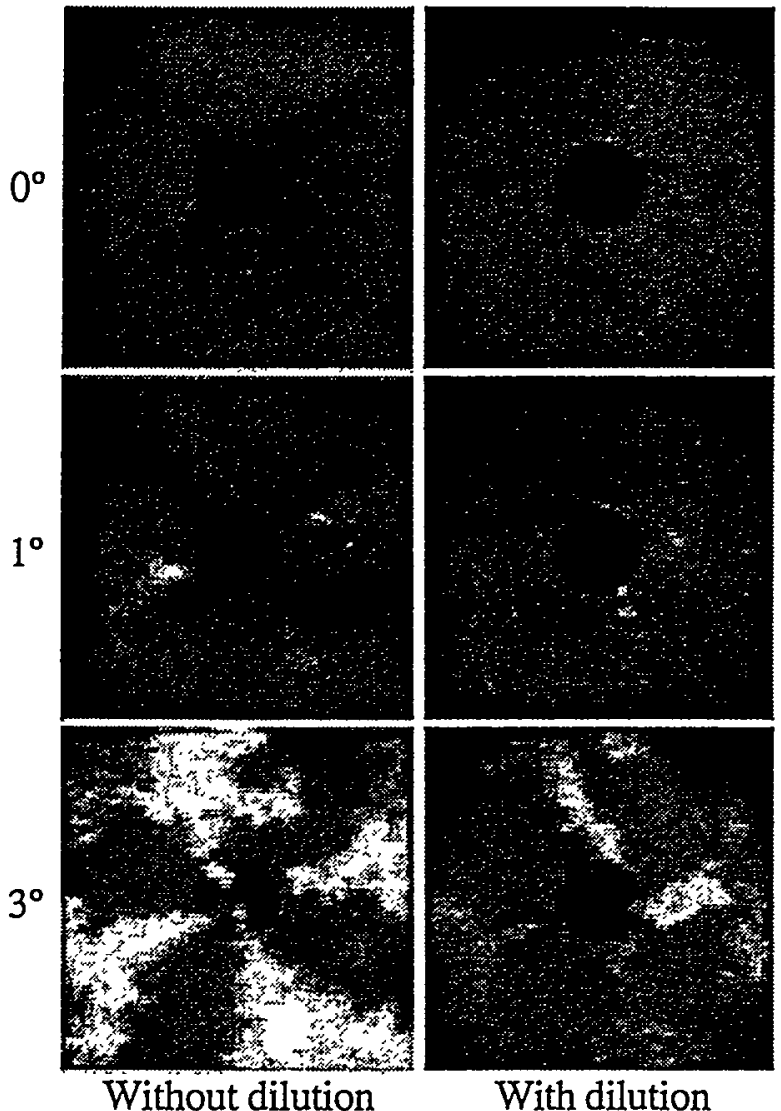

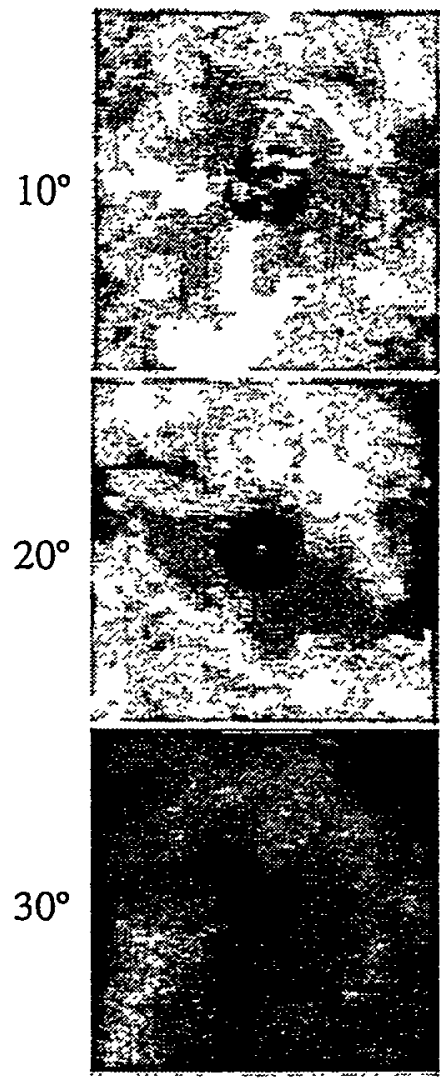

Without dilution

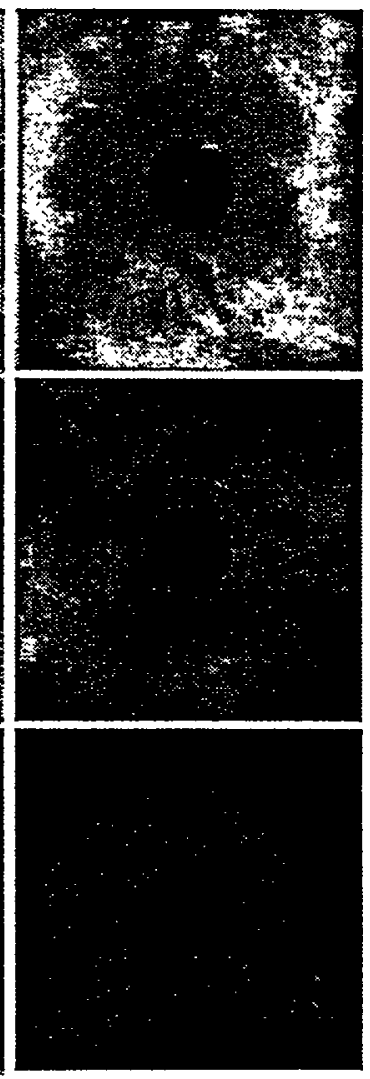

With dilution 


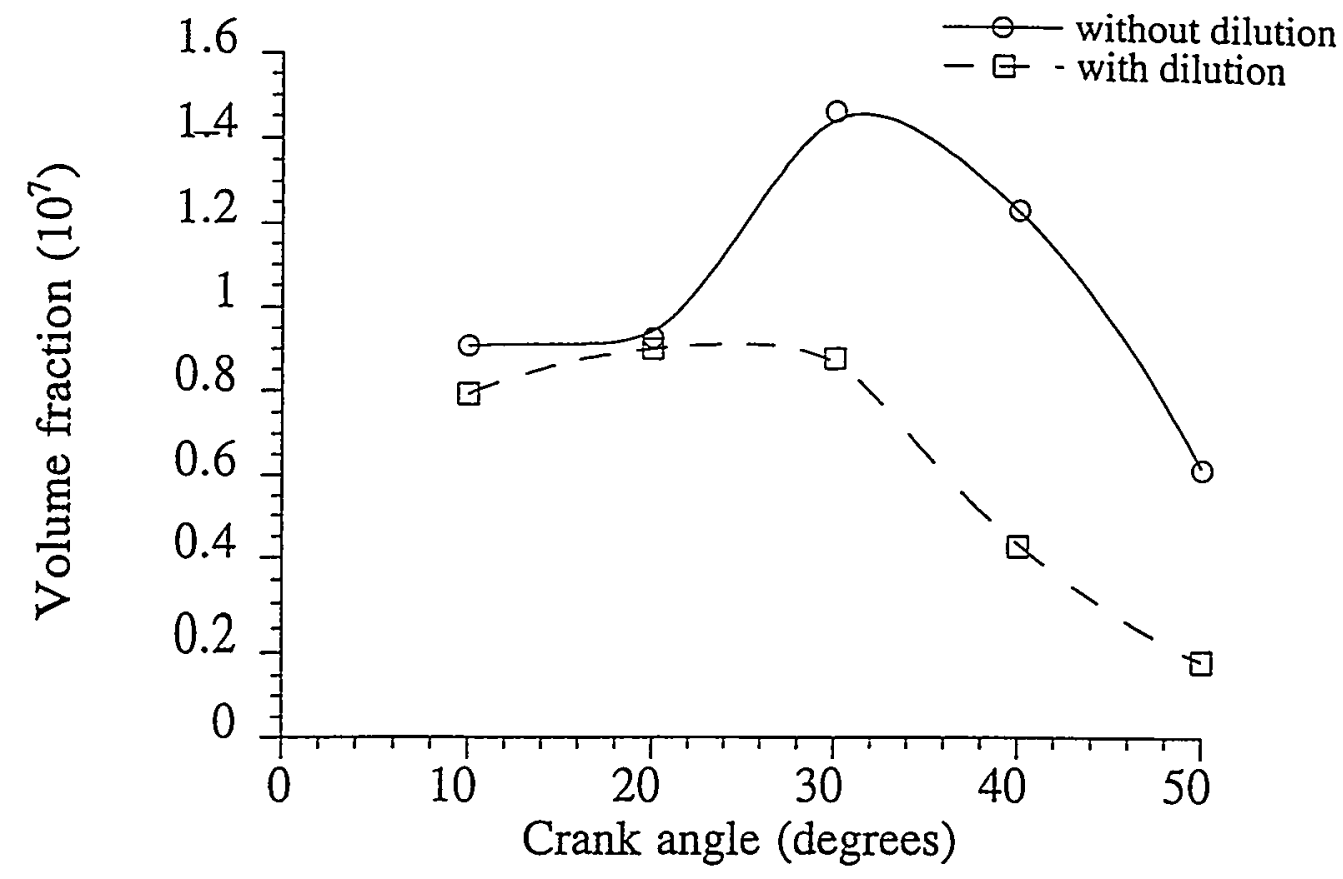

Figure 4-8. Soot volume fraction

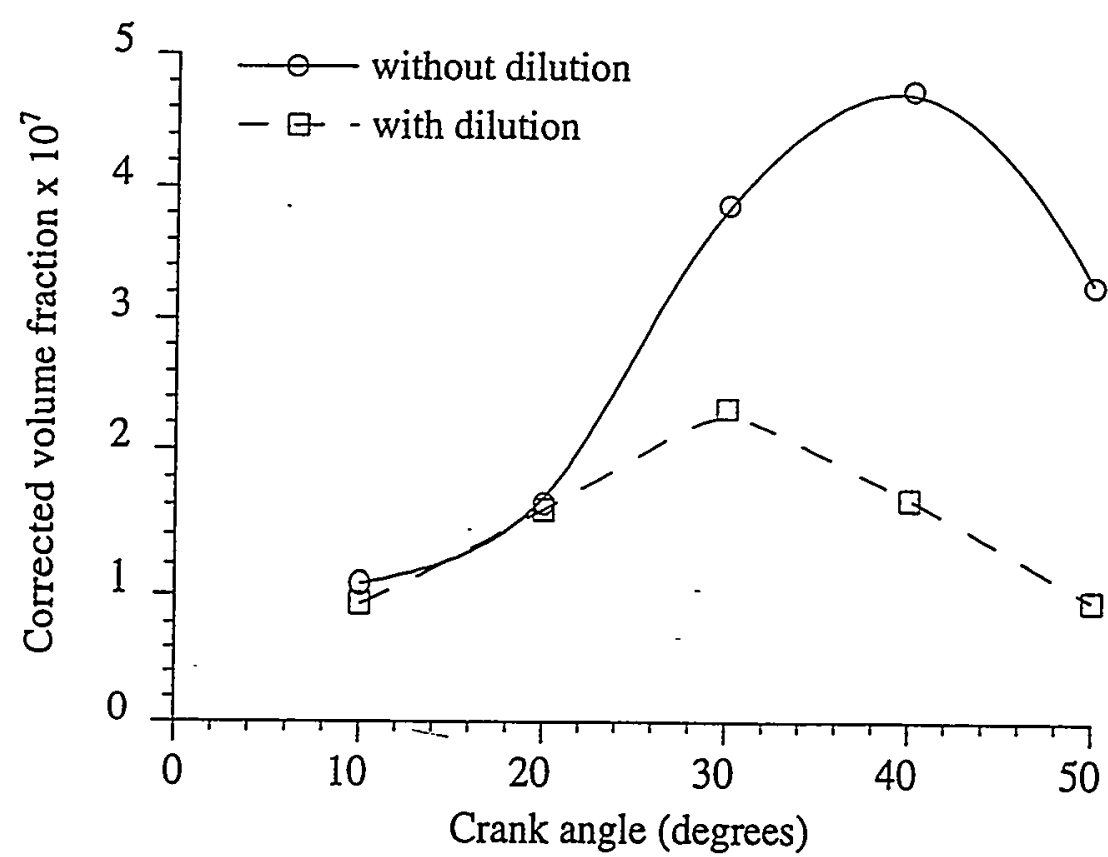

Figure 4-9. Corrected soot volume fraction 

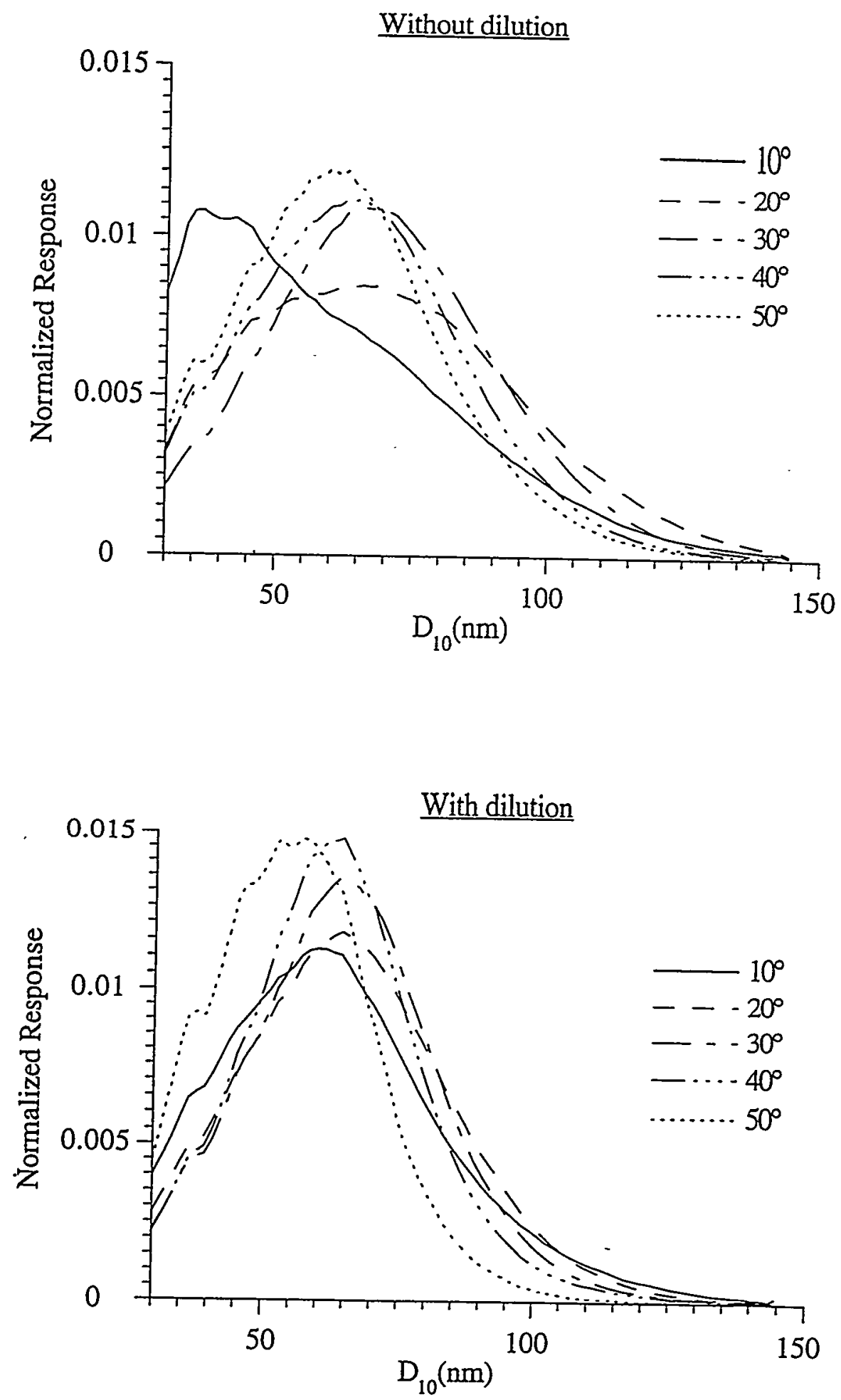

Figure 4-10 Particle size distributions 


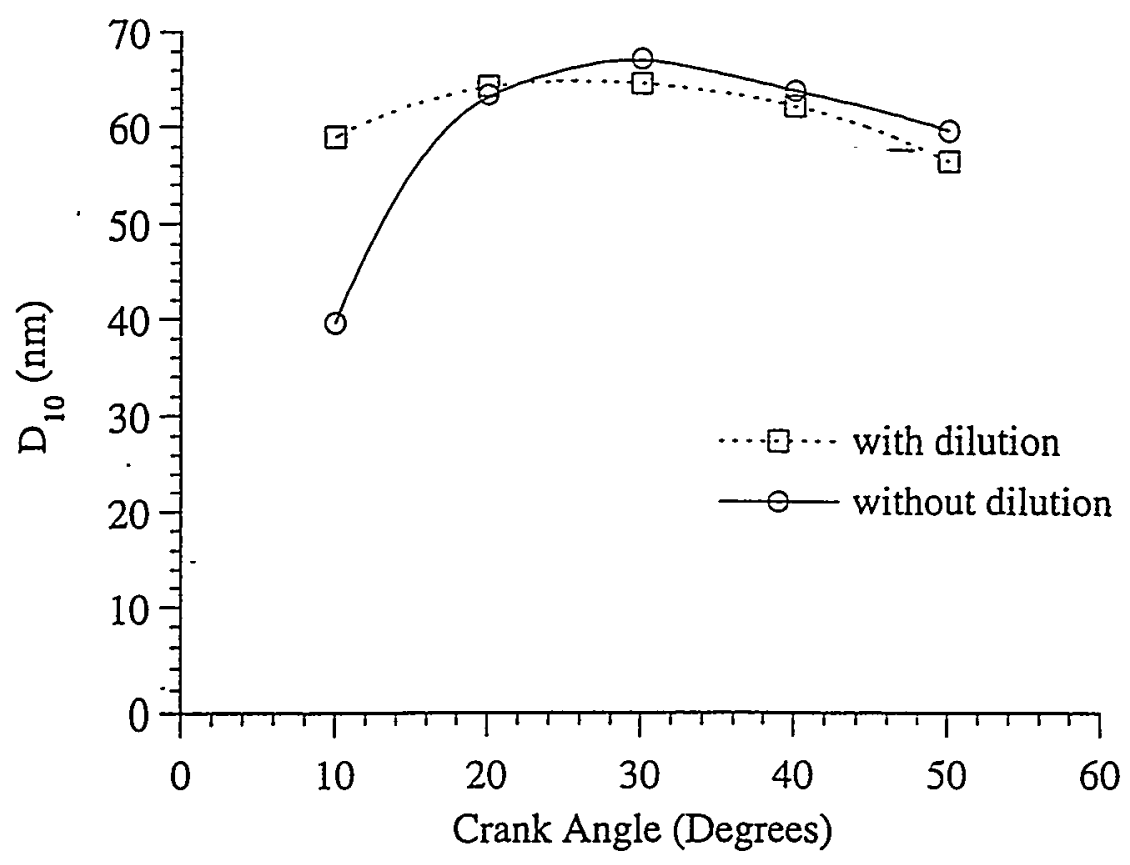

Figure 4-11. Variation in average particle size 


\subsection{Effects of Intake Charge Dilution with Control of Heat Release Rate 4.3.1 Introduction}

Following the study described above a follow-on study was undertaken to determine the effect of intake charge dilution by $\mathrm{CO} 2$ when the heat release conditions were more carefully controlled in an attempt to eliminate the effect of variation in heat release rate on soot production. The experimental conditions used in this study are presented in Table 4-8; in all cases with $\mathrm{CO} 2$ addition the level of oxygen was $19 \%$. The parameters were chosen to maintain a constant start of combustion at 3.2 degrees BTDC for all of the conditions. Furthermore, the temperature- $\mathrm{CO}_{2}$ condition and the back-pressure- $\mathrm{CO}_{2}$ condition were designed to maintain a premixed burn fraction equivalent to that obtained for the baseline condition. The results of the experiments showed that the start of combustion was held to within $3.2 \pm 1.5^{\circ}$ BTDC.

Table 4-8: Experimental Conditions

\begin{tabular}{|l|c|c|c|}
\hline Condition & $\begin{array}{c}\text { Intake Charge } \\
\text { Temperature }\end{array}$ & $\begin{array}{c}\text { Intake Charge } \\
\text { Pressure }\end{array}$ & $\begin{array}{c}\text { Injection Timing } \\
\text { Rack Setting }\end{array}$ \\
\hline Baseline-Air & $250 \mathrm{~F}$ & 22 & 0.15 \\
\hline Baseline- $\mathrm{CO}_{2}$ & $250 \mathrm{~F}$ & 22 & 0.299 \\
\hline Temperature- $\mathrm{CO}_{2}$ & $365 \mathrm{~F}$ & 22 & 0.15 \\
\hline Back-Pressure- $\mathrm{CO}_{2}$ & $300 \mathrm{~F}$ & 26 & 0.15 \\
\hline
\end{tabular}

\subsubsection{Results}

Figure 4-12 illustrates typical pressure versus crank angle relationships for the four test conditions. Figure 4-13 illustrates the indicated work output obtained by converting the crank angle in Figure 4-12 to volume and integrating for the area within the resulting pressure-volume curve. Since the amount of fuel injected is the same for each condition the work output is a direct measure of the process efficiency.

A comparison of Figures 4-12 and Figure 4-13 shows that the amount of indicated work done increases as the peak pressures increase for cases with similar heat release. In all of the conditions except the baseline- $\mathrm{CO}_{2}$ condition, the peak pressures increase as the top dead center pressure increases. As will be discussed later, the baseline- $\mathrm{CO}_{2}$ case produces a higher initial rate of burning resulting in the highest peak pressure of the conditions studied even though the initial pressure is the lowest of all conditions. 


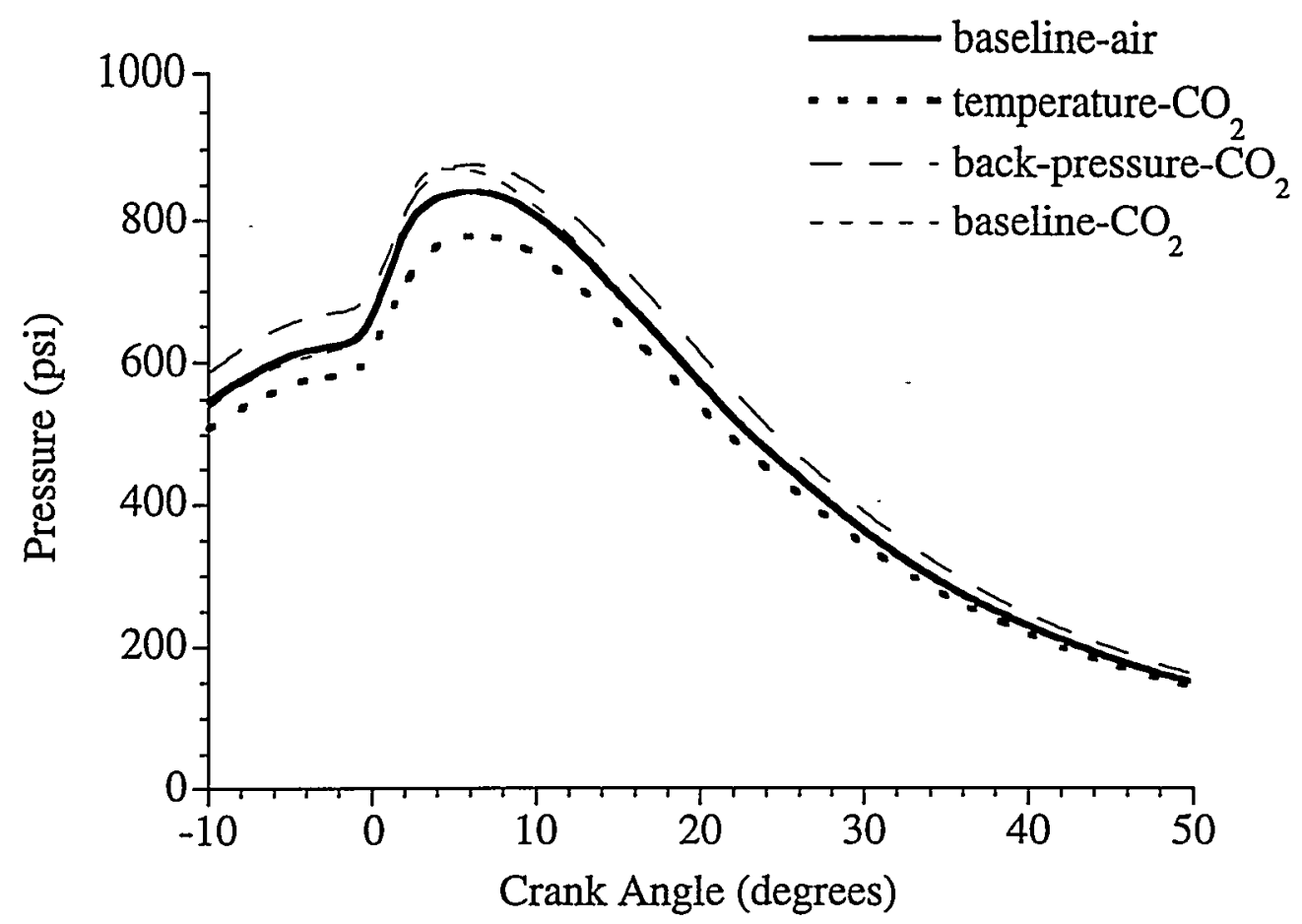

Figure 4-12 Pressure-Angle Relationship. 


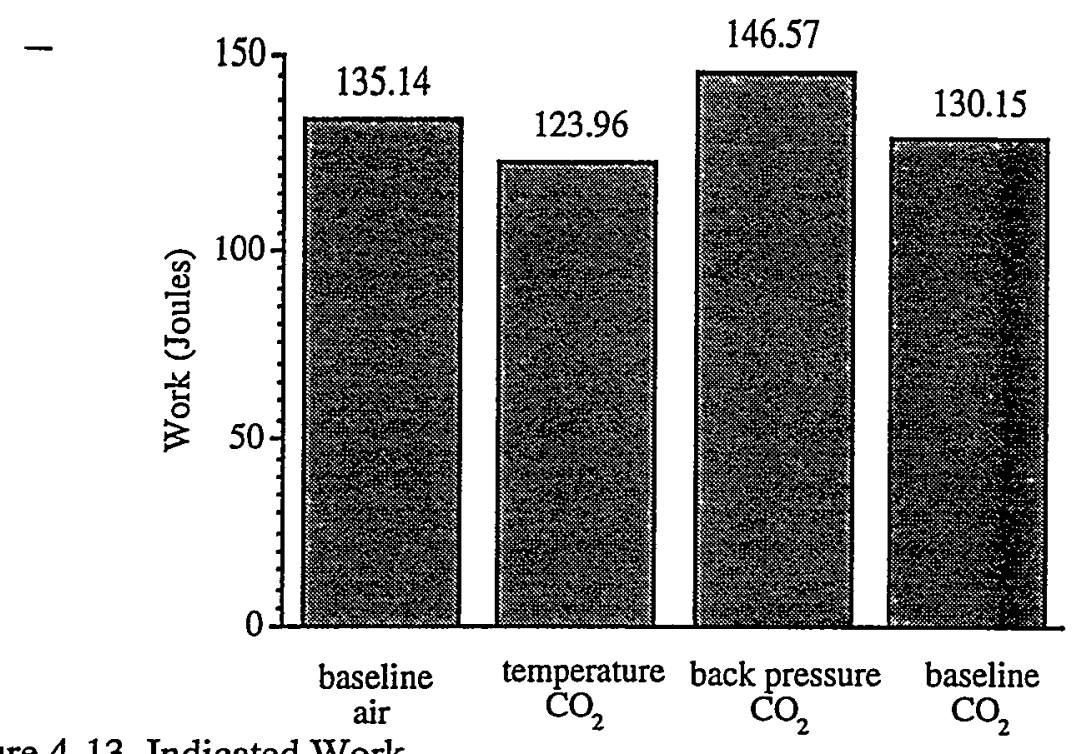

Figure 4-13 Indicated Work.

Mass burning rates were normalized to the total amount of fuel injected and the resulting plots are presented in Figure 4-13. As expected, the premixed burn fraction for the baseline- $\mathrm{CO}_{2}$ condition is significantly higher than that for the other conditions. The longer ignition delay caused by the higher specific heat of $\mathrm{CO}_{2}$ allows more fuel and air mixing prior to ignition such that when combustion commences, a greater amount of charge is burned.

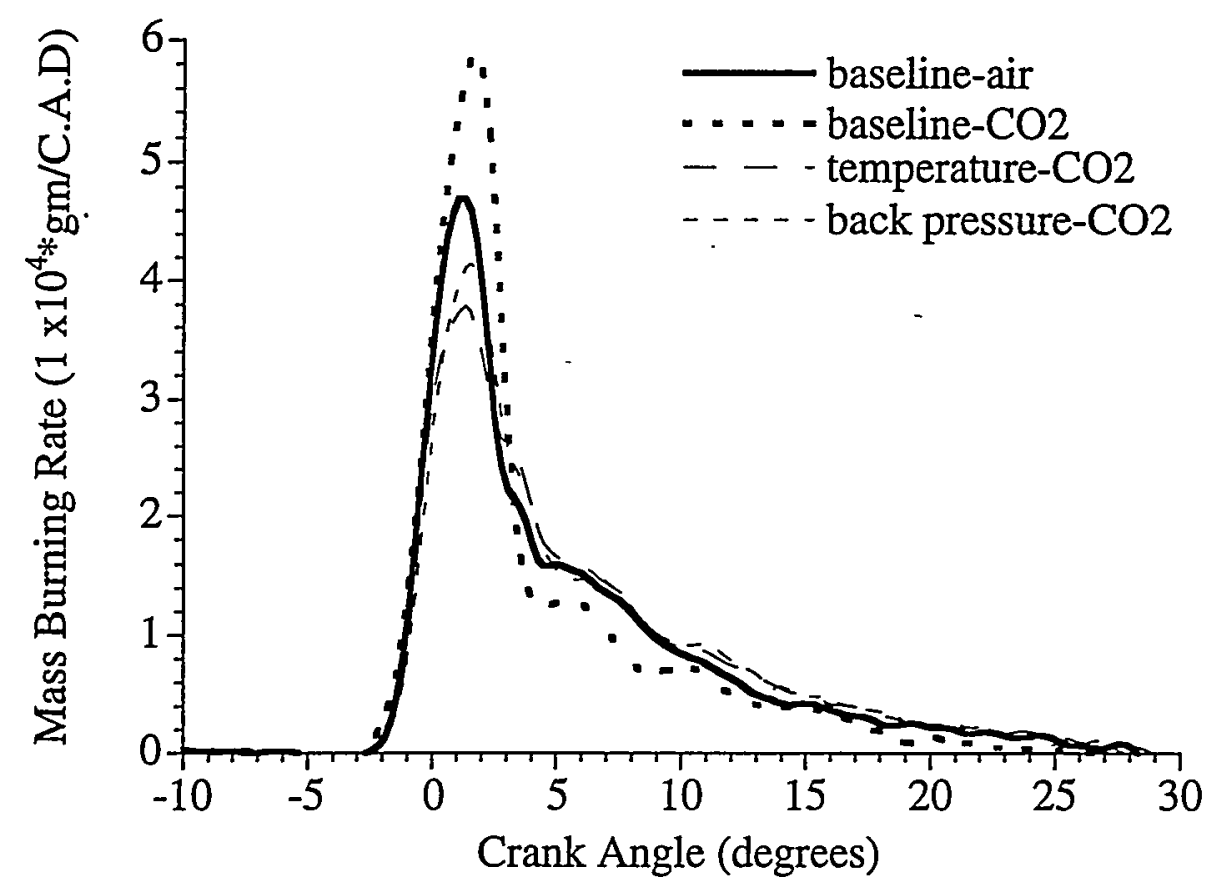

Figure 4-14 Normalized Mass Burning Rate.. 
The emissions data obtained in this study include concentrations of carbon monoxide, oxides of nitrogen and soot. Emissions of NOx and soot were normalized by the indicated power of the engine to allow fair comparison for conditions in which the power output has changed.

Power specific emissions of NOx are shown in Figure 4-15. A substantial but nearly equivalent reduction in NOx emissions between the baseline-air and the dilution conditions is evident. The NOx formation rate shows that the NOx formation rate has an exponential dependence on temperature but only a half-order dependence on the oxygen concentration, thus peak local temperature differences are expected to be the primary reason for the differences in NOx emissions found in this study. In order to study the dependence of the NOx formation rate on local flame temperatures, a correlation between NOx concentrations and calculated stoichiometric adiabatic flame temperatures was made.

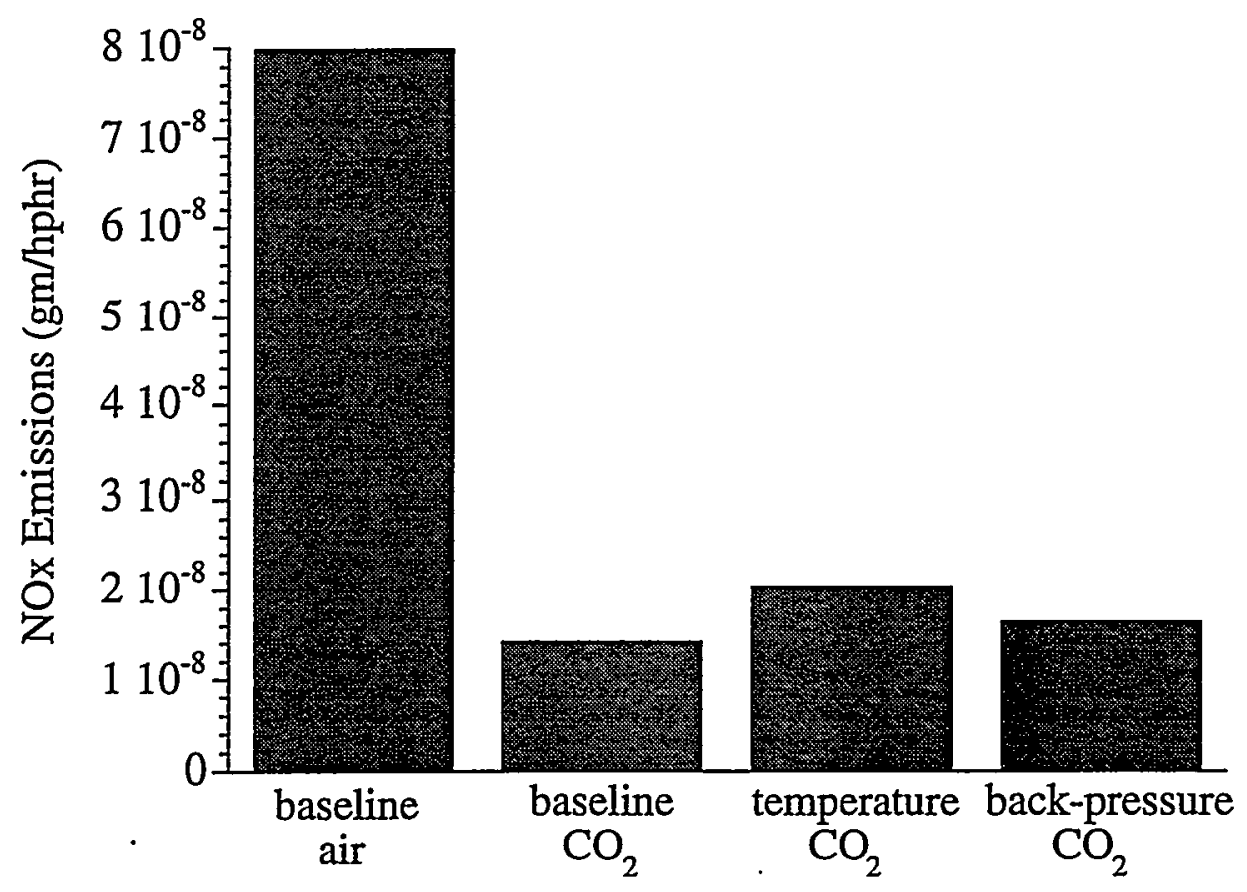

Figure 4-15 NOx Emissions for All Test Conditions. 


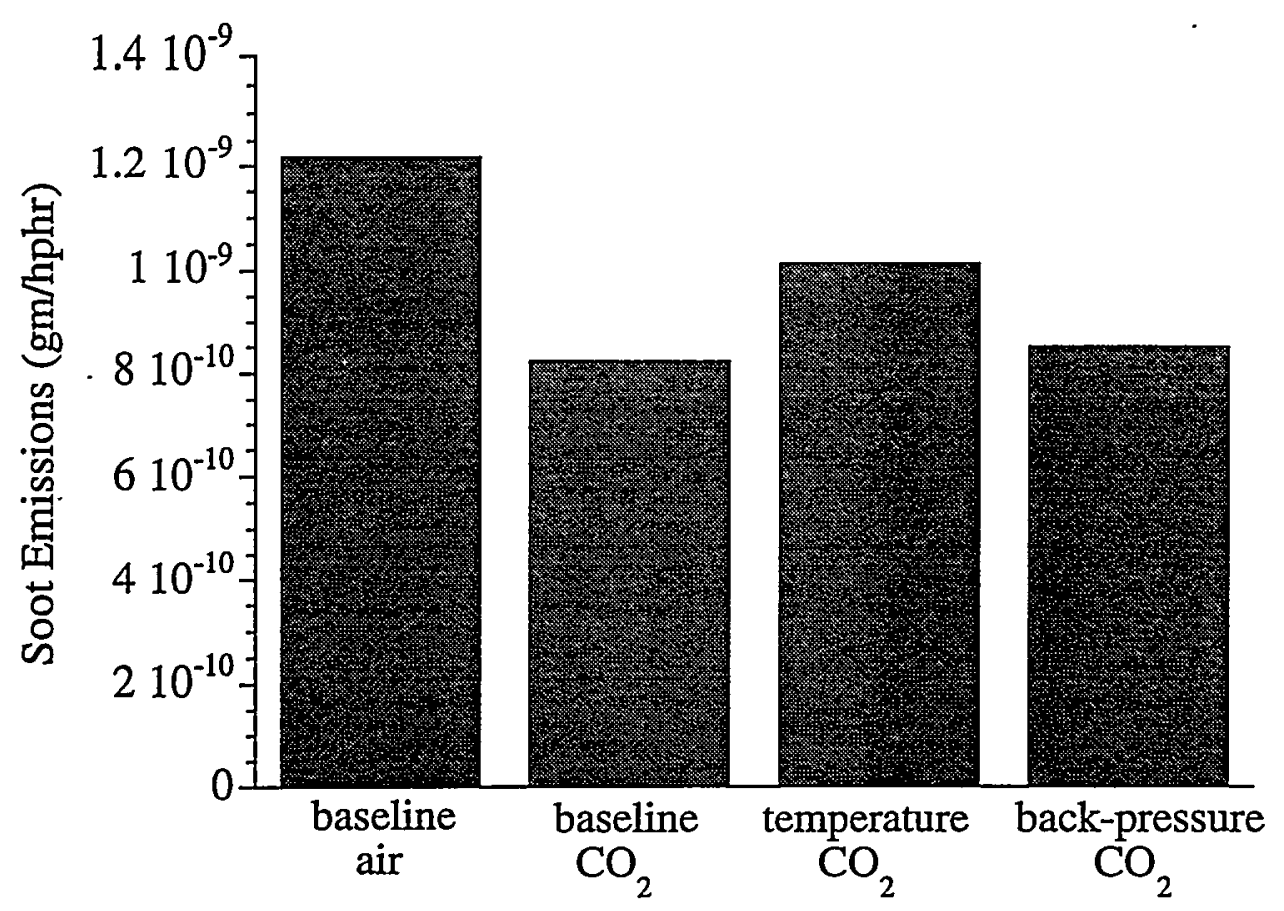

Figure 4-16 Specific Soot Emissions. 


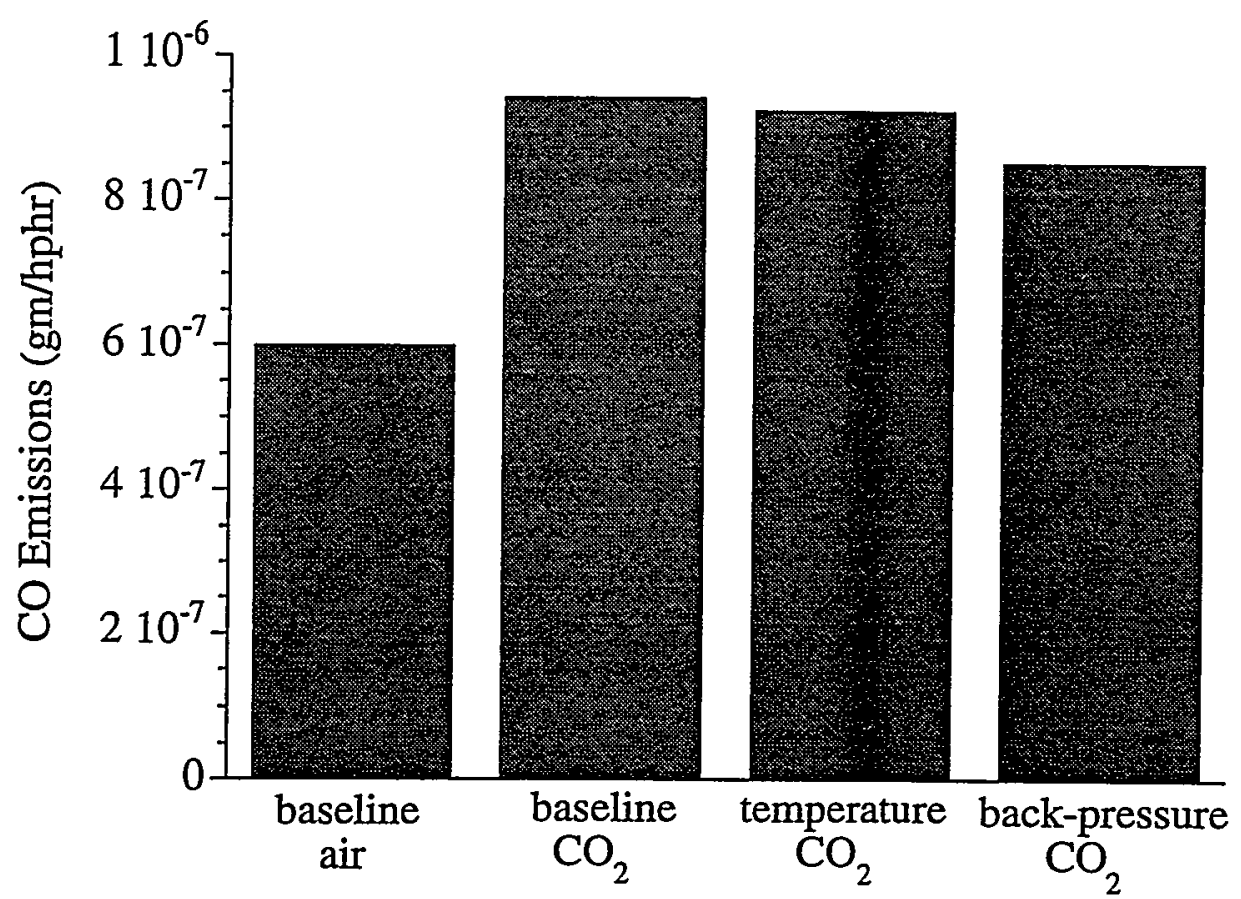

Figure 4-17 CO Emissions for all Test Conditions.

Specific soot emissions data obtained from extinction measurements were averaged over 10 to 15 separate cycles and the results are shown in Figure 4-16. In earlier studies, a greater reduction in soot emissions has been associated with a higher premixed burn fraction. The relative levels of soot emission between the baseline-air condition and the baseline- $\mathrm{CO}_{2}$ condition are in agreement with this idea because the baseline- $\mathrm{CO}_{2}$ condition has both a higher premixed burn fraction and lower soot emissions compared to the baseline-air condition. This same reasoning, however, does not explain the reduction in soot emissions observed for the temperature- $\mathrm{CO}_{2}$ and back-pressure- $\mathrm{CO}_{2}$ conditions relative to the baseline-air conditions. Recall that these two conditions produce approximately the same premixed burn fractions as the baseline-air condition but within the standard deviation of the extinction data, soot emissions for these two conditions are equivalent to that for the baseline- $\mathrm{CO}_{2}$ condition. Consequently, the association of premixed burn fraction on the reduction of soot could not be made in this study.

CO emissions shown in Figure 4-17 were obtained because some authors suggested that the reduction in soot emissions under simulated EGR conditions may be due to $\mathrm{CO}_{2}$ reducing soot by converting it to CO. However, Figure 4-16 and Figure 4-17 shows no direct correlation between the specific emissions of soot and $\mathrm{CO}$. The general trends in the levels of $\mathrm{CO}$ and soot emissions does indicate, however, that the dilution conditions are responsible for producing higher levels of $\mathrm{CO}$ and lower levels of soot than the baseline-air condition. This result may be due to soot conversion to $\mathrm{CO}$ or $\mathrm{CO}$ and $\mathrm{OH}$ quenching.

In the next few paragraphs, results from simultaneous LII and light scattering experiments will be presented. In the process of acquiring the data for this experiment, luminosity was observed at 5 and 10 degrees in the LII images. However, at 20 degrees and beyond the luminosity was no longer measurable. The presence of the luminosity at 5 and 10 degrees prevented spatial resolution of volume fraction, particle size and number 
density. However by subtracting an averaged luminosity signal from the LII images, average soot volume fractions could still be obtained.

Volume fraction data from the LII were taken at angles 5, 10,20, 25, 30, 40 and 50 and are shown in Figure 4-18. These soot volume fractions were corrected for the effects of expansion by multiplying by the volume at the given angle and dividing by the volume at top dead center.

The general trends in volume fraction indicate a rapid initial rate of soot production for all of the conditions. This trend increases in the following order:baseline- $\mathrm{CO}_{2}$, backpressure- $\mathrm{CO}_{2}$, temperature- $\mathrm{CO}_{2}$, and baseline-air. Peak volume fractions occur between 10 and 20 degrees corresponding to the regions of highest flame luminosity..

Several unexpected observations have been made regarding the trends in the soot volume fraction. In the back-pressure- $\mathrm{CO}_{2}$ and the baseline- $\mathrm{CO}_{2}$ conditions, a dip occurs at 25 degrees. Similar activity is observed in the baseline-air condition but to a lesser extent. At 50 degrees all of the conditions show an increase in soot volume fraction. This result does not indicate production because heat release indicates that burning has stopped long before 50 degrees and thus soot can no longer be formed. The most probable reason is turbulent air motion which is believed to randomly blow soot into and out of the plane of view.

The numbers to the right of the curves in Figure 4-18 indicate soot volume fractions obtained from extinction measurements. Comparing these numbers to soot volume fractions obtained by LII shows good agreement for the back-pressure- $\mathrm{CO}_{2}$ and baseline$\mathrm{CO}_{2}$ conditions while significant is indicated for the other two conditions.

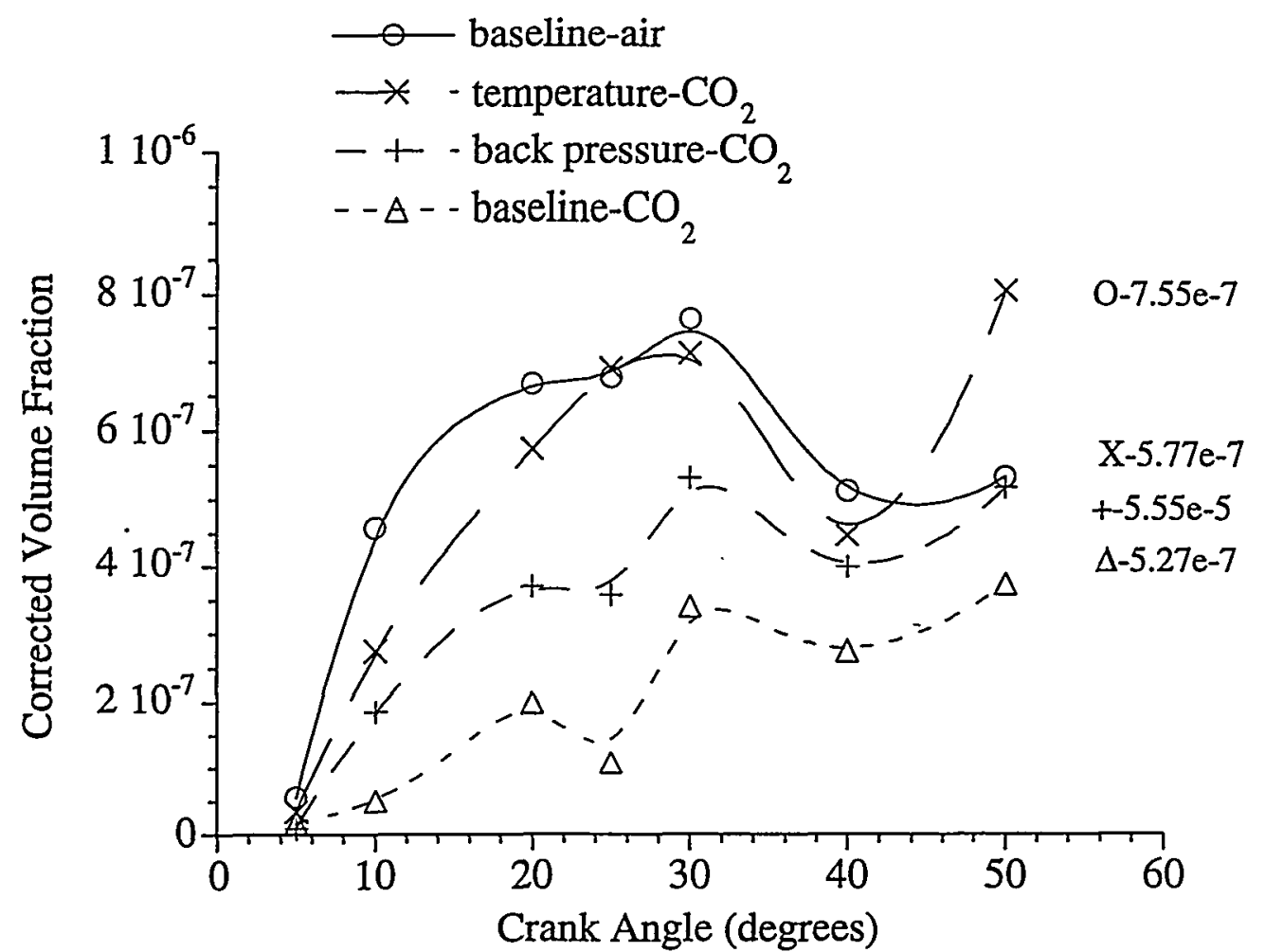

Figure 4-18 Corrected Volume Fraction.

Mean particle sizes were obtained from histograms of the number density weighted diameters fitted to a log normal distribution (39). The data for this study is shown in Figure 4-19. As indicated in the figure, particle size trends are similar for the three dilution conditions but relative sizes vary at different crank angles. At early crank angles, the 
temperature- $\mathrm{CO}_{2}$ condition has larger particle sizes than the baseline- $\mathrm{CO}_{2}$ condition by as much as 8 nanometer and sizes larger than the back-pressure- $\mathrm{CO}_{2}$ condition by as much as 16 nanometers. Beyond 30 degrees, however, the particle sizes for these condition are nearly identical. In the baseline-air condition, particles start off at smaller sizes than in the dilution condition but grow to similar sizes at 30 degrees. From 40 to 50 degrees significant particle size reduction occurs which is indicative of particle oxidation.

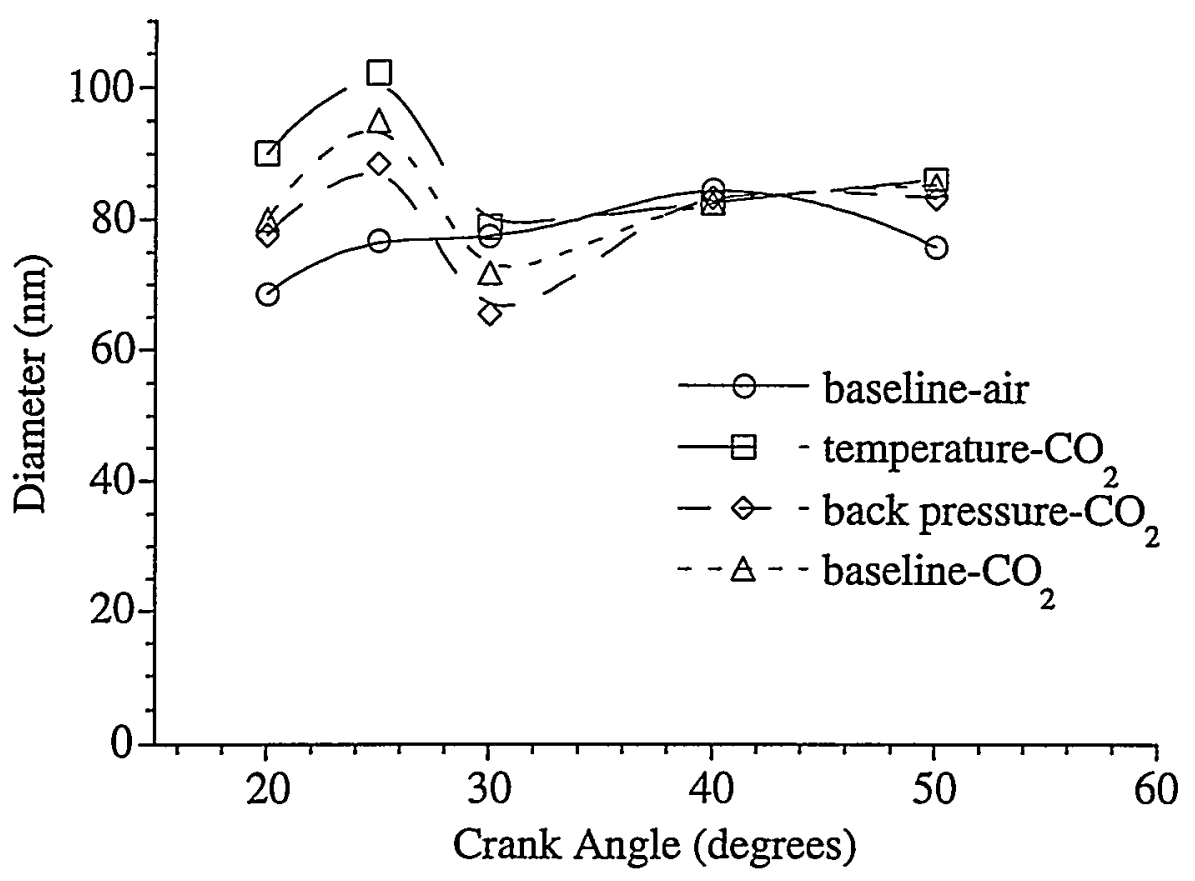

Figure 4-18 Average Particle Size.

Although the number densities can be deduced directly from an observation of the soot volume fraction and particle size, this data is shown in Figure 4-19 for completeness. The general trend in number density for all of the conditions indicates a growing number of particles peaking at 30 degrees followed by a reduction in the number of particles due to coagulation and oxidation. The peak in number density for the baseline-air condition at 20 degrees is not understood.

At 20 and 25 degrees, the baseline- $\mathrm{CO}_{2}$ condition has a significantly lower number of soot particles than the other dilution conditions. At 30 degrees the number of particles for the baseline-air, temperature- $\mathrm{CO}_{2}$ and back-pressure- $\mathrm{CO}_{2}$ conditions is much closer while the baseline- $\mathrm{CO}_{2}$ still has a significantly smaller number of particles. In an earlier study described in the previous section it was found that a fewer number of soot particles are present in the baseline- $\mathrm{CO}_{2}$ condition compared to the baseline-air condition. This result was also observed in this study. 


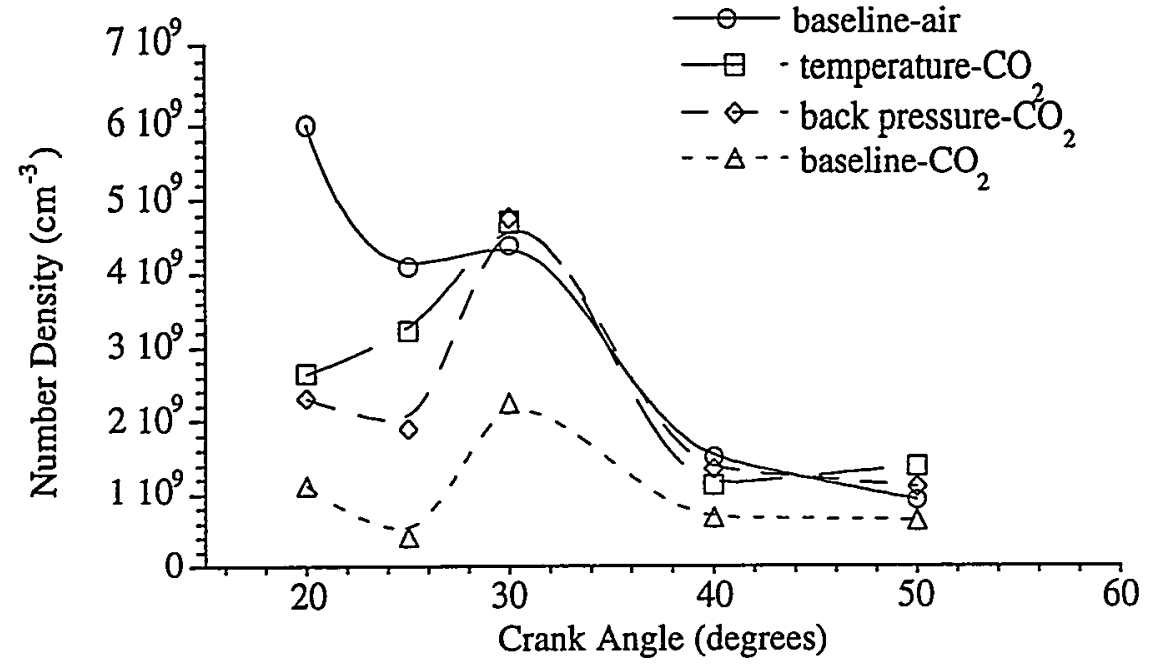

Figure 4-19 Average Number Density. 


\subsection{Effect of Intake Charge Temperature on Soot Evolution}

Another important variable used by engine manufacturers to control NOx is intake charge cooling. In order to observe the effects of temperature on soot formation within the engine, pressure traces, luminosity, light scattering and LI images were acquired from the engine at $120^{\circ} \mathrm{C}, 145^{\circ} \mathrm{C}$ and $200^{\circ} \mathrm{C}$. To maintain the TDC air density and trapped mass, the intake manifold pressure was boosted at the higher temperatures to compensate for differences in the inlet air density. The majority of the quantitative imaging experiments were performed at a plane located $2 \mathrm{~mm}$ from the upper combustion chamber window. Additional information regarding the soot distribution at the baseline operating condition was obtained from planar volume fraction measurements made at distances of 3,6 , and 9 $\mathrm{mm}$ from the upper combustion chamber window. The test matrix for the experiments performed for this study are summarized in Table 4.9

Table 4.9. Test Matrix

\begin{tabular}{|c|c|c|c|c|c|c|c|}
\cline { 5 - 8 } & $\begin{array}{c}\text { Intake Air } \\
\text { Temperature } \\
\left({ }^{\circ} \mathrm{C}\right)\end{array}$ & $\begin{array}{c}\text { Intake } \\
\text { Boost } \\
(\mathrm{kPa})\end{array}$ & $\begin{array}{c}\text { Plane(s) } \\
(\mathrm{mm})\end{array}$ & LI & $\begin{array}{c}\text { Light } \\
\text { Scattering }\end{array}$ & $\begin{array}{c}\text { Flame } \\
\text { Luminosity }\end{array}$ & $\begin{array}{c}\text { Simultaneous } \\
\text { Heat Release }\end{array}$ \\
\hline 1 & 120 & 50 & 2 & $\sqrt{ }$ & $\sqrt{ }$ & $\sqrt{ }$ & $\sqrt{ }$ \\
\hline 2 & 145 & 61 & 2 & $\sqrt{ }$ & $\sqrt{ }$ & $\sqrt{ }$ & $\sqrt{ }$ \\
\hline 3 & 200 & 74 & 2 & $\sqrt{ }$ & $\sqrt{ }$ & $\sqrt{ }$ & $\sqrt{ }$ \\
\hline 4 & 120 & 50 & $3,6 \& 9$ & $\sqrt{ }$ & & & \\
\hline
\end{tabular}

\section{Results}

To monitor consistency of the combustion event, pressure traces were taken simultaneously with the imaging data for experiments 1-3. Subsequent apparent heat release analysis of the pressure data indicated that both the start of combustion and the heat release shape remained relatively constant over each of the eight image sets and throughout each of the temperature cases. The average mass burning rate and pressure curves for the three temperature cases are presented in Figure 4-21.

Following a slight dip due to vaporization of the fuel, the mass burning rate curves rapidly increase to a maximum near TDC. By $3^{\circ}$ the initial period of rapid burning is ended and importance of the diffusion-controlled combustion is rising. Diffusion burning rates peak at approximately $6^{\circ}$ followed by a gradual falloff into later crank angles. For this work, the premix-burn fraction was determined by integrating the mass burning rate curves up to the first peak. The result was then doubled and divided by the total area under the curve. In agreement with the work of others work, increases in the intake air temperature served to decrease the ignition delay and thus reduce the premix-burn fraction as tabulated in Table 410 .

Table 4-10. Engine conditions.

\begin{tabular}{|c|c|c|c|c|c|c|}
\hline $\begin{array}{c}\text { Intake air } \\
\text { Temperature } \\
\left({ }^{\circ} \mathrm{C}\right)\end{array}$ & $\begin{array}{c}\text { SOI } \\
\left({ }^{\circ} \mathrm{CA}\right)\end{array}$ & $\begin{array}{c}\text { SOC } \\
\left({ }^{\circ} \mathrm{CA}\right)\end{array}$ & $\begin{array}{c}\text { Ignition } \\
\text { delay } \\
\left({ }^{\circ} \mathrm{CA}\right)\end{array}$ & $\begin{array}{c}\text { Percent } \\
\text { premix-burn }\end{array}$ & $\begin{array}{c}\text { Mean Bulk } \\
\text { Temperature } \\
(\mathrm{K})\end{array}$ & $\begin{array}{c}\text { Peak Bulk } \\
\text { Temperature } \\
(\mathrm{K})\end{array}$ \\
\hline 120 & -5.0 & -3.1 & 2.9 & $15 \pm 3.3$ & 890 & 1010 \\
\hline 145 & -4.6 & -3.2 & 1.4 & $10 \pm 2.8$ & 910 & 1030 \\
\hline 200 & -3.6 & -2.9 & 0.7 & $9 \pm 1.8$ & 970 & 1100 \\
\hline
\end{tabular}


Exhaust soot measurements obtained from extinction measurements were found to correlate well with premix-burn fraction. As summarized in Figure 4-22, exhaust soot concentration was found to increase significantly with decreasing premix-burn fraction. The modest decreases in mass burned in the lower-sooting premix-burn period do not fully account for the larger differences in soot production at the higher temperature cases. 


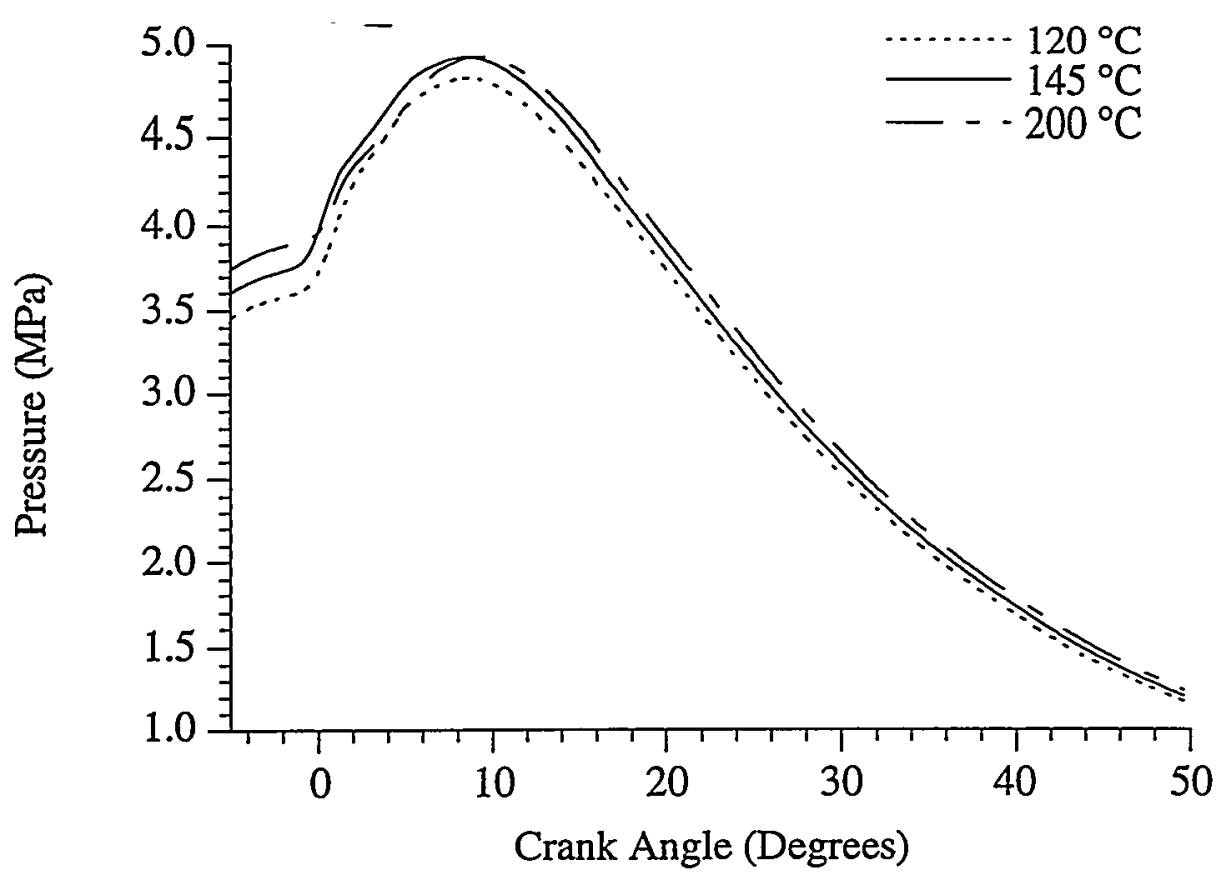

(a)

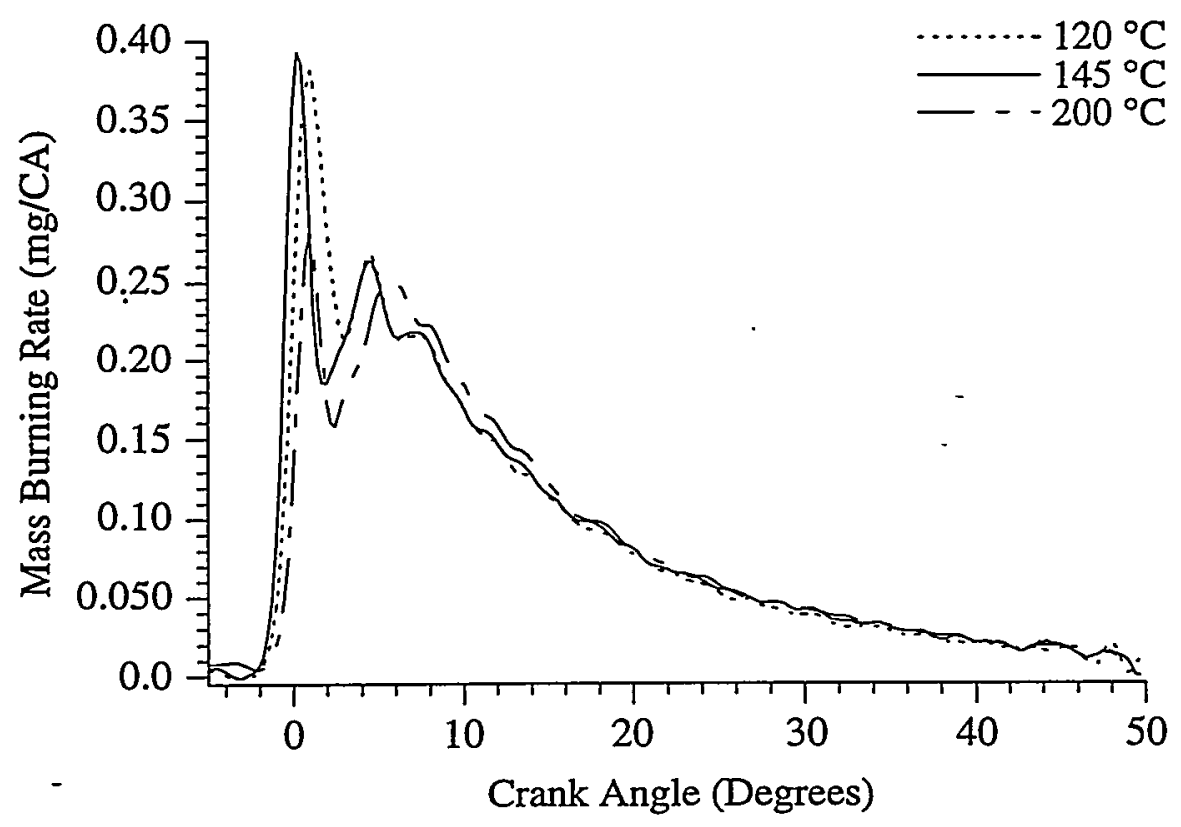

(b)

Figure 4-21. Average mass burning rate and pressure profiles. 


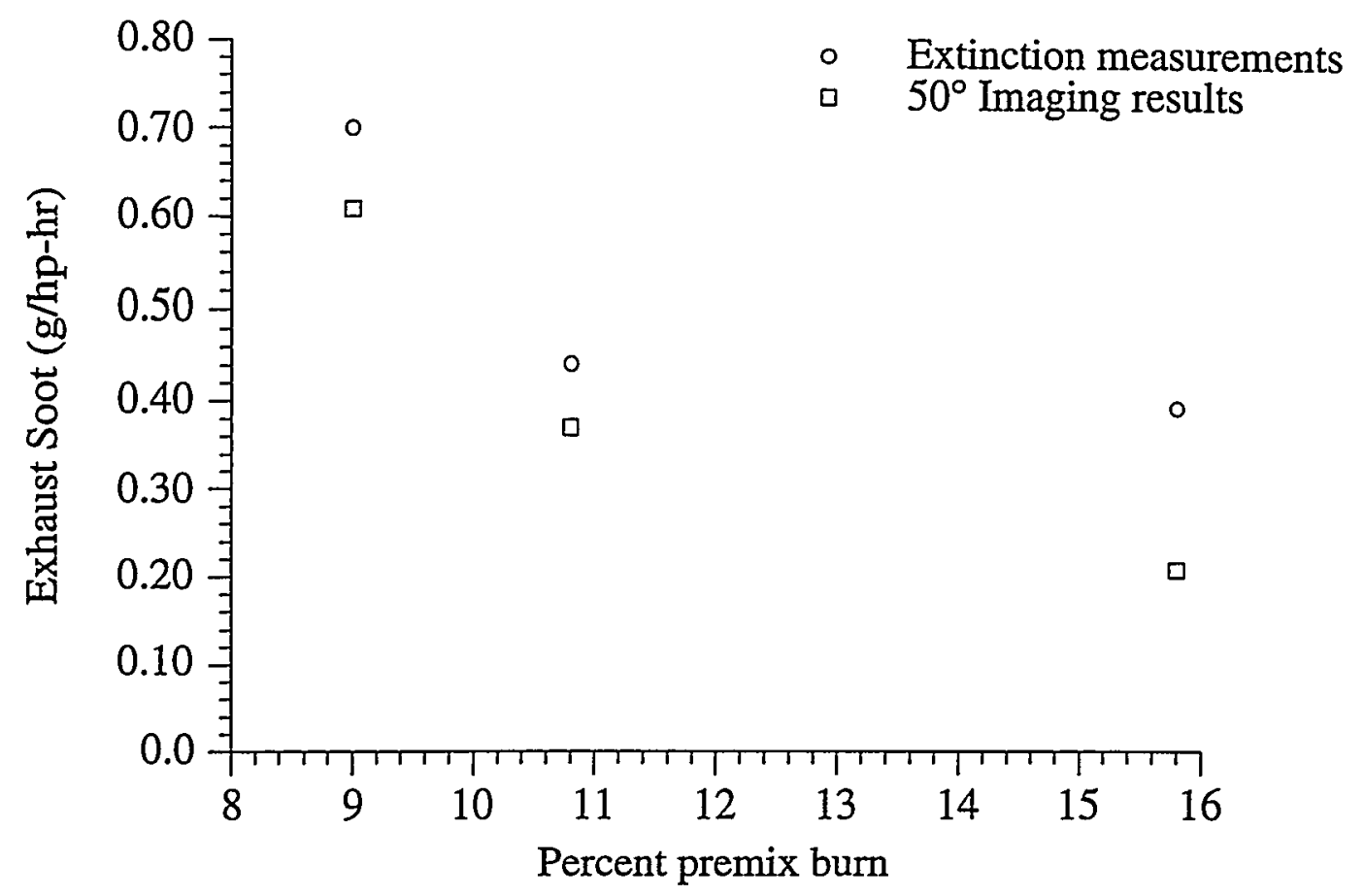

Figure 4-22. Soot production versus premix-burn fraction.

Imaging data were acquired for crank angles ranging from $0^{\circ}$ to $50^{\circ}$ ATDC. For each of the images, the entire combustion chamber was imaged. For experiments 1-3, four luminosity images and eight of the simultaneous light scattering and LII images were acquired at each of the selected crank angles. For the subsequent tables of images, representative images were selected.

To examine the structure and nature of the early soot formation process, direct photography of the combustion luminosity was performed. For the image sets, the entire combustion chamber was imaged and swirl was in the counter-clockwise direction. The four-hole injector and spray plume are evident in the center of the images. For each of the cases, first visible light was evident near TDC although the first luminosity is more pronounced for the $200^{\circ} \mathrm{C}$ case.

Throughout the crank angle range, the luminous intensity is higher for the $200^{\circ} \mathrm{C}$ case. The differences in luminosity are especially evident during early crank angles and decrease at later angles. The luminosity observed at a given crank angle is due to the radiant emissions from soot. The degree of observed radiant emission is related to both the soot temperature and concentration. Therefore, it is not clear whether the increased luminosity evident for the higher temperature cases is caused by increased flame temperature, increased soot concentration, or both. Additionally, the flame luminosity images are integrated in nature and thus yield little information regarding the local structure of the soot field.

For each of the cases, luminosity is first evident in the downstream region of the fuel plume where fuel vapor swept by swirl is present. At later crank angles, the flame 
progresses towards the nozzle tip and engulfs the entire spray region. It is likely that the fuel spray interaction with the flame increases in significance with decreases in ignition delay.

Inspection of the results from the simultaneous imaging study for each of the intake air temperature cases reveals that the structure and evolution of the soot field is similar among the three temperature cases. From the volume fraction images, a higher extent and quantity of soot are evident for the higher temperature cases. However, inspection of the size and number density images reveals that the location, and character of the soot is similar over the three temperature cases.

Several observations can be made from the image sets. Early images yield strong evidence of active soot formation while later images are characterized by more diffuse soot pockets and larger particle diameters. At $3^{\circ}$, soot is distributed throughout the cross section with pockets of high concentration evident along the periphery of the jet downstream from the swirl direction. The measured number densities for the corresponding high volume fraction regions are in excess of $1 \times 10^{11}$ particles $/ \mathrm{cm}^{3}$. Low corresponding particle diameters are also evident, indicative of regions of active soot formation. The center of the plume is filled with larger soot particles of low concentration which have likely been entrained by the combusting plume. At $6^{\circ}$, the structure of the flame is less evident in the planar images. However, regions of high soot concentration and number density with lower particle diameters are still present. At $10^{\circ}$, regions indicative of soot formation similar to those observed at $6^{\circ}$ still persist. Additionally, large areas of low soot concentration were observed. The low concentration regions did not scatter sufficient light to make number density or particle size predictions possible. The corresponding luminosity image indicates that the shape of the low concentration region follows that of the flame. From this observation, it would appear that the low-level signals could be caused by luminosity leaking through the intensifier shutter. However, when the experiment was repeated without the laser, no signals were observed. Another explanation is molecular fluorescence; however, since the LII measurement is made after the laser pulse, it is unlikely that significant fluorescence persists at the time the LII image is acquired. In the absence of identifiable noise sources, the observed increase in LII signals are interpreted as an increase in soot volume fraction.

By $15^{\circ}$, particle sizes are significantly increased over that of the previous angles. Additionally, air motion has carried the bulk of the flame into the corners of the combustion chamber. Images at $20^{\circ}$ indicate further increases in particle size along with a decreased prevalence of soot formation regions that were observed at earlier crank angles.

For angles beyond $20^{\circ}$, the soot volume fraction becomes more uniform and steadily decreases. Likewise, the number density images manifest fewer high intensity regions. Particle diameter images become more uniform and remain relatively constant throughout the rest of the combustion event.

To clarify the qualitative inferences made from the images, the bulk behavior of the images was examined by averaging the images obtained at the crank angle under consideration. All of the images from a given crank angle and temperature were considered for the averaged results. Information regarding the distribution of soot characteristics was provided through histograms of the particle size and number density.

Flame Luminosity

Analysis of the bulk behavior of the flame luminosity indicates that the duration of the luminous emission was slightly increased with elevated intake air temperature. As indicated by Figure $4-23$, the flame extent increases rapidly to a maximum at $6-8^{\circ}$ which is consistent with the peak in the mixing-controlled combustion period indicated by heat release analysis. Additionally, the fractional combustion chamber coverage increases earlier and persists longer for the higher temperature cases. Average bulk temperatures predicted by the heat release analysis for the $200^{\circ} \mathrm{C}$ case are $8 \%$ higher than for the baseline 
case, indicating that some of the differences in flame area could be explained by increased luminosity at higher temperatures.

By normalizing the integrated luminosity by the flame areas in the visible light images, the relative local luminosities of the combustion event can be compared. As illustrated in Figure 4-24, the relative luminosity is similar for each of the cases, with the most significant differences occurring early in the combustion event. The small luminosity peak occurring at $5^{\circ}$ for the 145 and $200^{\circ} \mathrm{C}$ cases corresponds closely to the end of injection and precedes the peak of the mixing-controlled combustion phase indicated by the mass burning rate analysis. It is not clear why the $120^{\circ} \mathrm{C}$ case does not exhibit this peak.

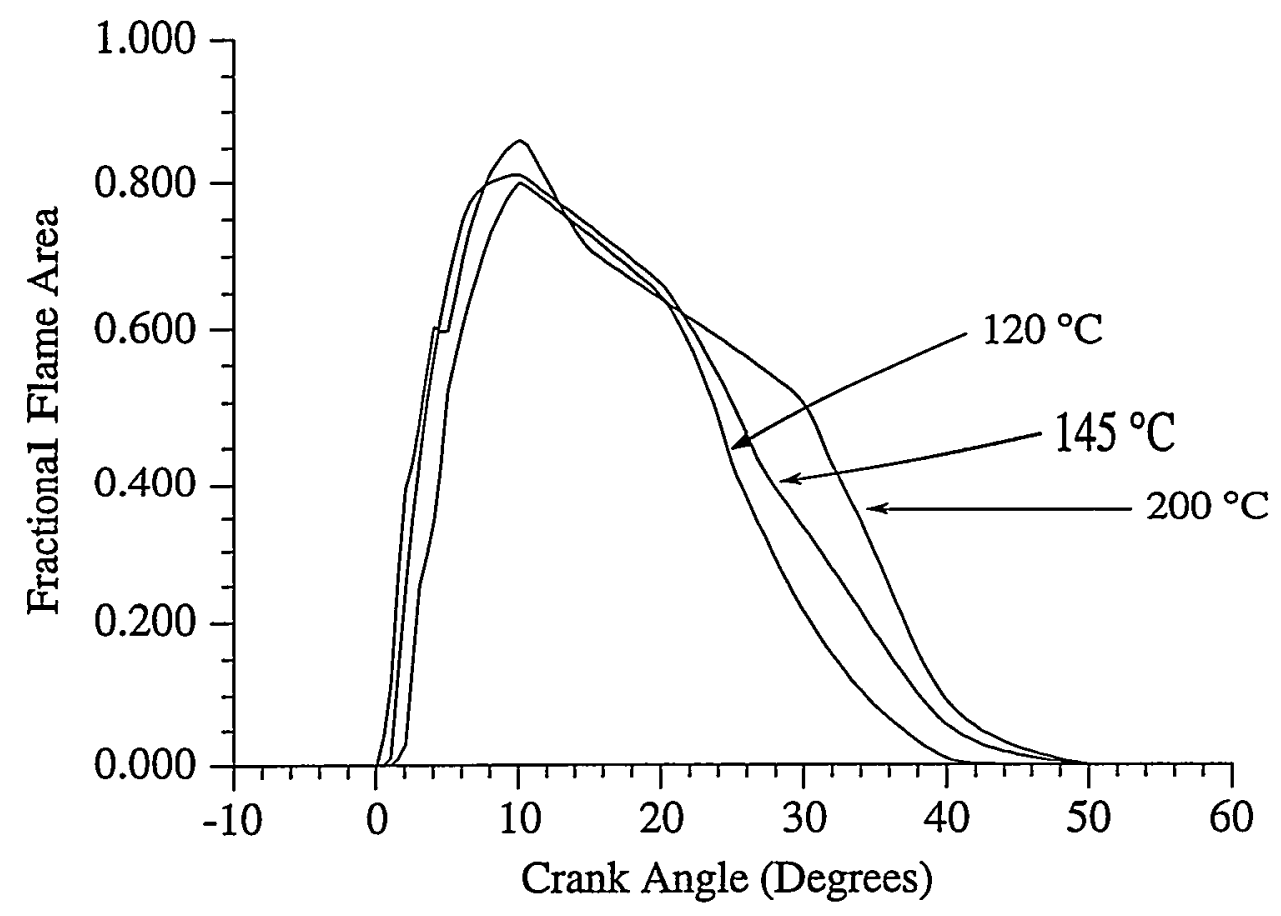

Figure 5-23. Fractional combustion chamber coverage.

Volume Fraction Measurements

To obtain bulk properties of the combustion event, the volume fraction images for experiments 1-4 were averaged over the entire area of the measurement plane. Intake air temperature effects on soot levels at the $2 \mathrm{~mm}$ plane were investigated in experiments 1-3. In experiment 4 , volume fraction measurements were obtained at multiple planes to yield more complete information regarding the soot distribution for the baseline case. 


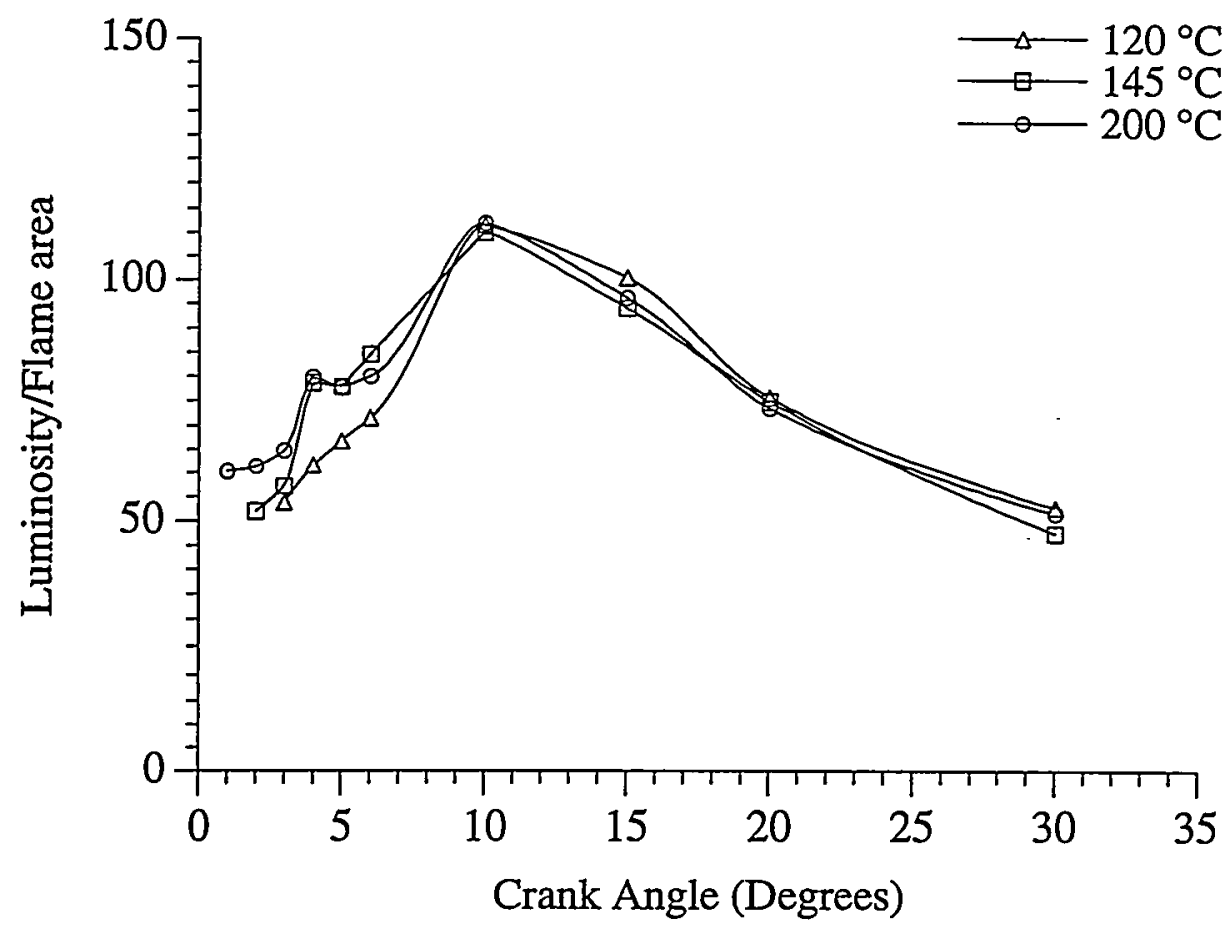

Figure 5-24. Ratio of flame luminosity to flame area.

Volume Fractions for the Intake Air Temperature Cases

Volume fraction measurements for the intake air temperature study are shown in Figure 525 . The dark bars on the plot indicate the exhaust soot volume fraction determined by extinction experiments. For comparison, the value determined for the extinction measurements was expansion-corrected to correspond to the measurements taken at $50^{\circ}$. Agreement between the extinction measurements is excellent for the two higher-temperature cases, but is off by approximately a factor of two for the low-temperature case.

Two of the three cases exhibit a peak in soot concentration at $10^{\circ}$ in Figure 4-25. The peak is also present in the preliminary volume fraction measurements although to a lesser degree. The concentration peak lags behind the peak observed in Figure 4-24 and is likely related to in-cylinder air motion. As indicated by the luminosity images, the flame rapidly engulfs the region of the spray plume following the end of injection. 


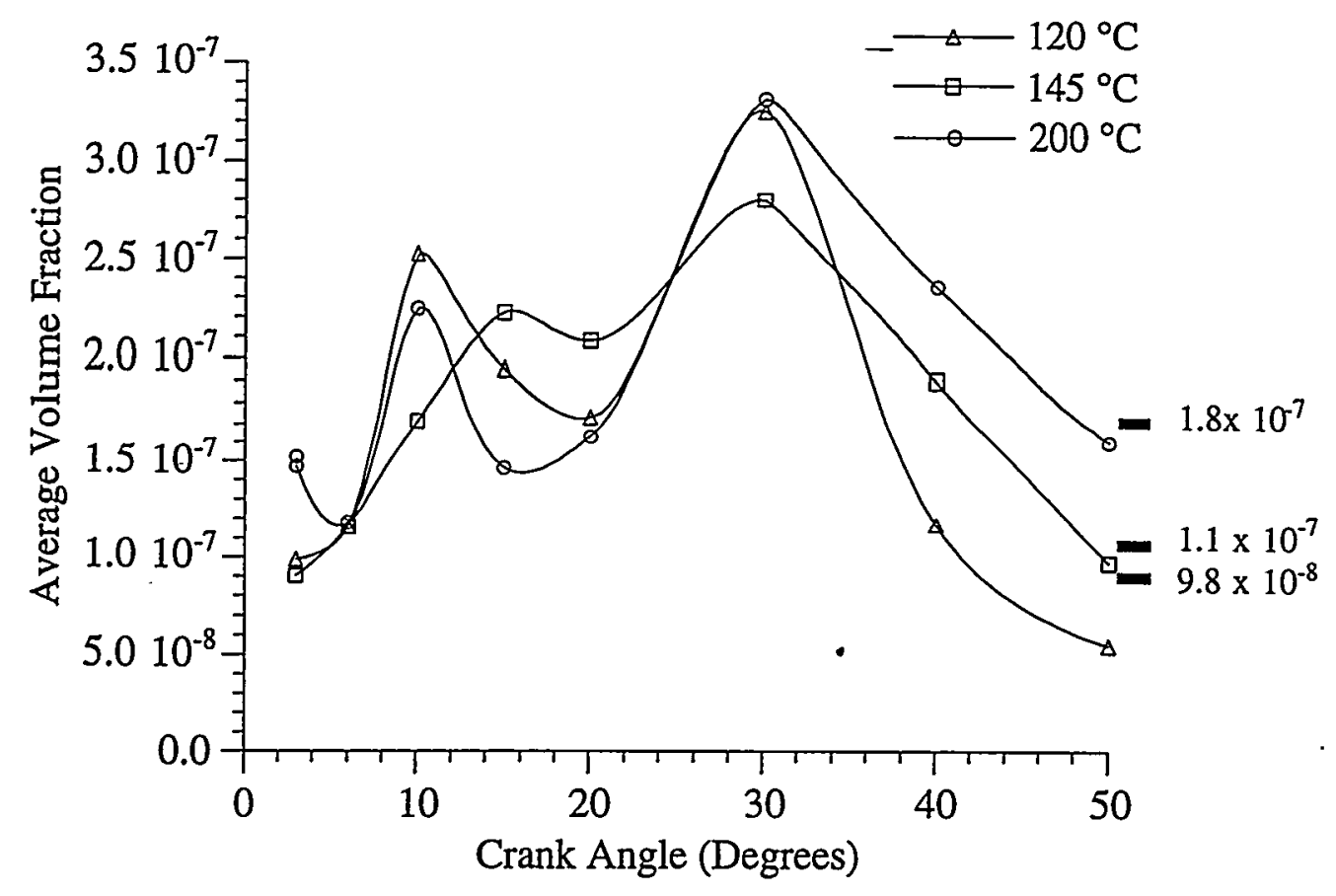

Figure 5-25. Average soot volume fraction for temperature study.

Multi-Plane Volume Fractions for the Baseline Case

Volume fraction measurements obtained at distances of $3 \mathrm{~mm}, 6 \mathrm{~mm}$ and $9 \mathrm{~mm}$ from the upper combustion chamber window are shown in Figure 4-26. The LII images were acquired over the crank angle range from $2^{\circ}$ to $50^{\circ}$ ATDC in $2^{\circ}$ increments. At each crank angle, four images were acquired. The calibration presented in Appendix F was then applied to the results to yield images of the in-cylinder soot volume fraction. Following the calibration, the data from the four images were averaged. Scatter in the figure is due to cycle-to-cycle variations in flame structure. 


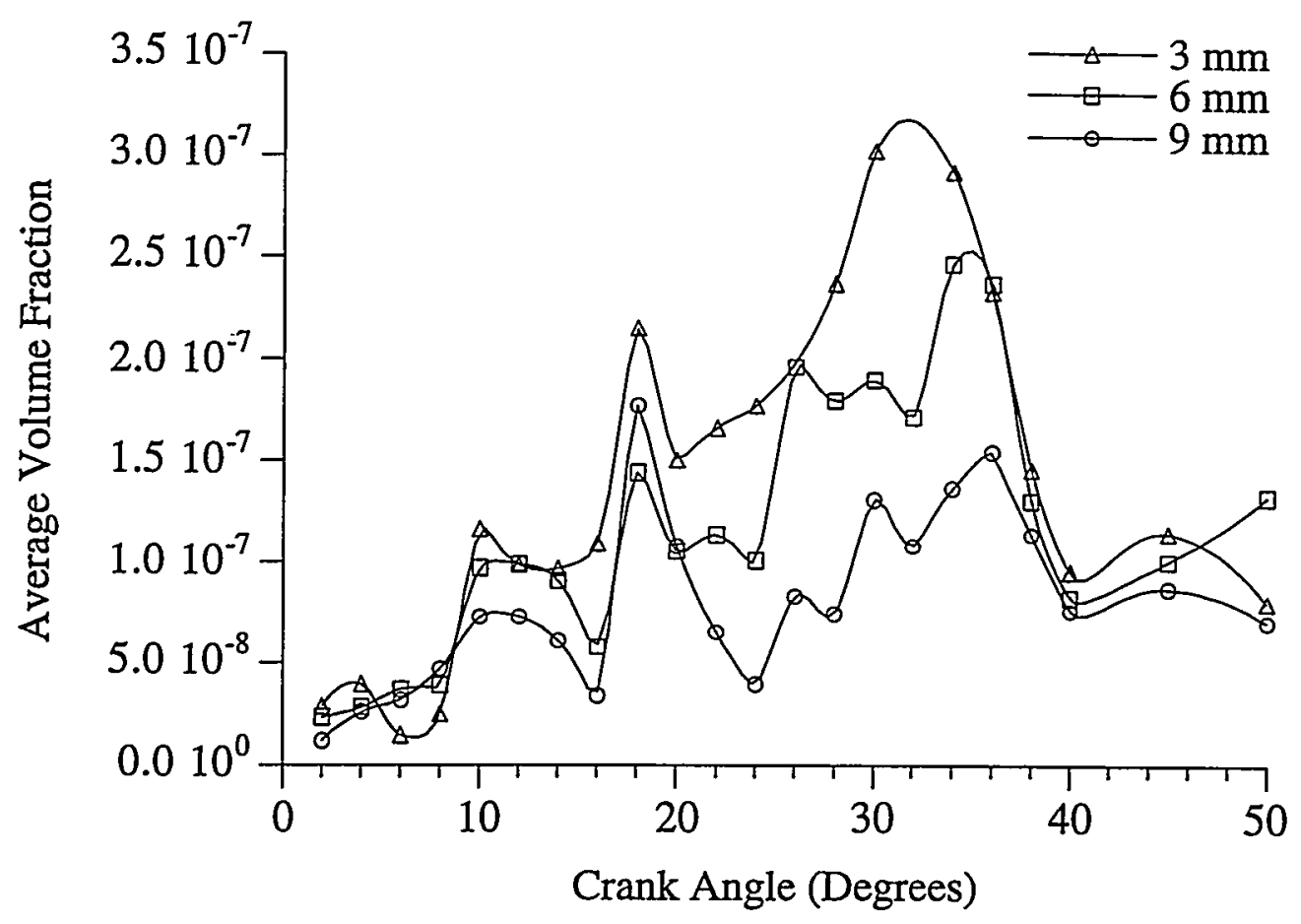

Figure 4-26. Volume fraction histories at various heights in the combustion chamber.

The general shape of the volume fraction curves are similar to those of Figure 4-25; however, improved crank angle resolution reveals more structure. The peak observed at $10^{\circ}$ is more defined and an additional feature is observed at $18^{\circ}$. Again the structure of the volume fraction histories is related to in-cylinder air motion. Among the three measurement planes investigated, soot concentrations are highest for the $3 \mathrm{~mm}$ plane which corresponds to the bottom of the combustion chamber for a production engine. Locally, volume fractions as high as $5 \times 10^{-6}$ were observed. 


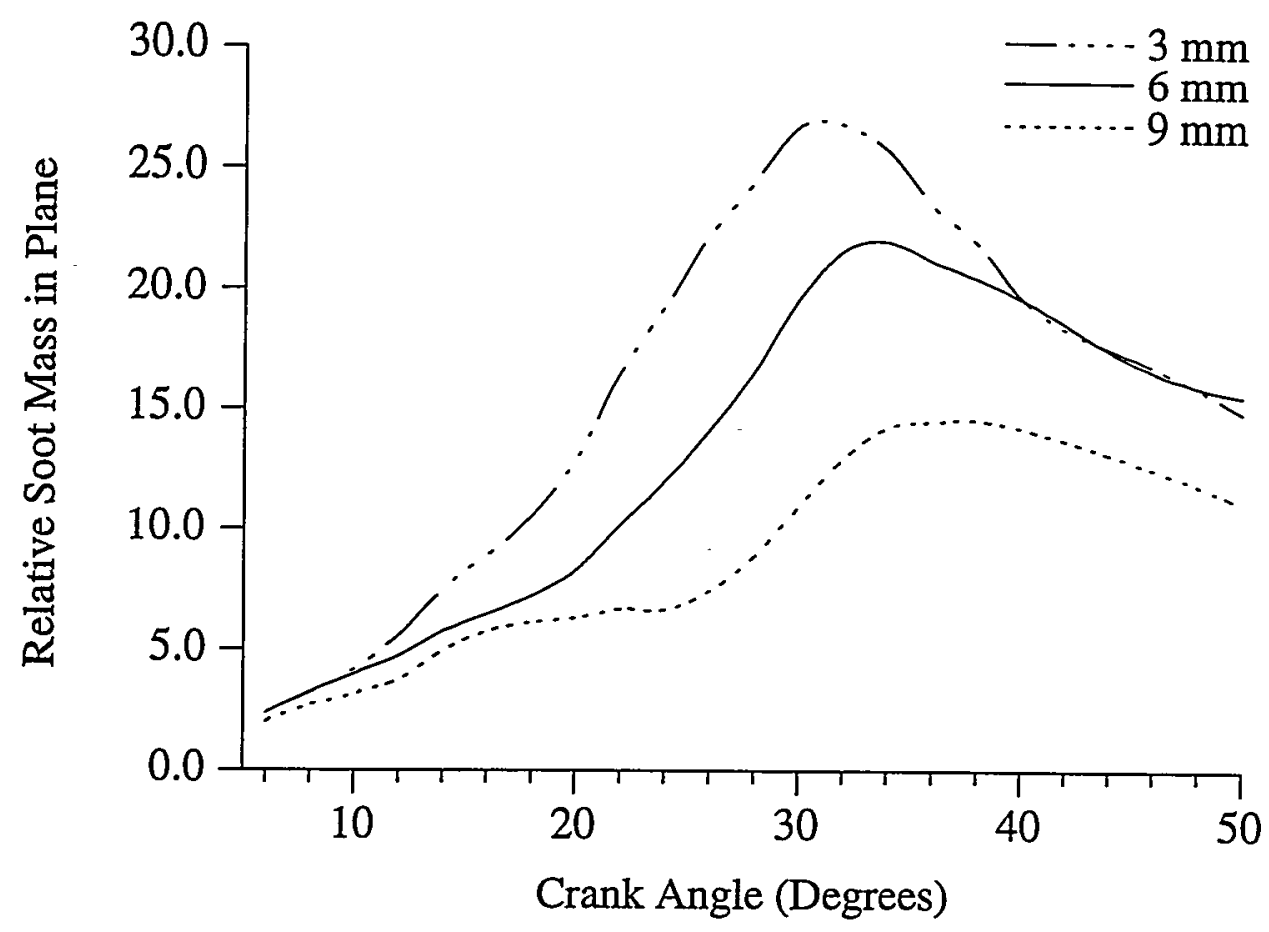

Figure 4-27. Relative soot evolution for the multi-plane data set.

The mass of soot in the combustion chamber drops following its peak, indicative of soot destruction and mixing. At later angles, the soot mass on each of the planes appears to converge to the same value as mixing of the cylinder contents continues. Of the three planes, the mass of soot in the upper plane is generally highest. It is possible that the mass of soot in the $9 \mathrm{~mm}$ plane is diluted by air motion into the cylinder. Comparison of Figure 4-27 to the apparent heat release profiles indicates that the in-cylinder soot mass peaks after $90 \%$ of the heat release process is complete.

To obtain a mean particle size, histograms were constructed of the number density weighted diameters. The resulting histograms were normalized and fit to a log-normal distribution from which the mean diameter could be determined. For the $2 \mathrm{~mm}$ image plane, particle diameters increase sharply up to $30^{\circ}$ and then remain relatively constant as shown in Figure 4-28. The effects of diameter reduction indicative of particle oxidation are not as evident as reported in the literature. 


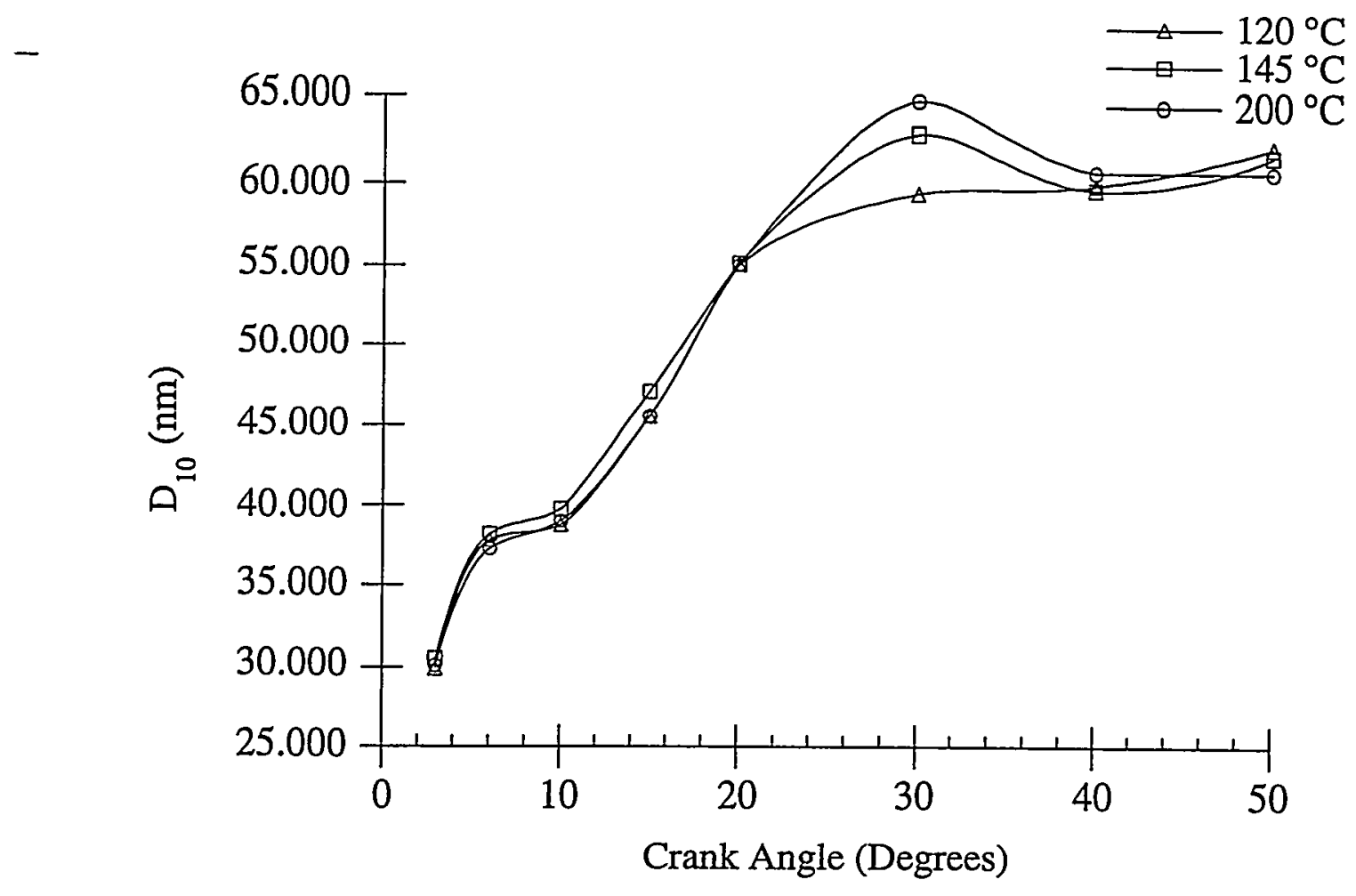

Figure 5.17. Average particle diameter.

Average number density values shown in Figure 5.18 begin high and follow a decreasing trend. At $10^{\circ}$, a peak in number density coincident with the volume fraction peak observed in Figures 5.14 and 5.15 is evident. Although the figure indicates higher number densities at later angles for elevated intake air temperatures, this trend is not consistently followed at earlier crank angles. Again, it is likely that in-cylinder air motion plays a significant role in the shape of the curves at early crank angles.

To obtain a clearer understanding of local number densities, the sum of the number density values across the image was divided by the number of active pixels rather than the total number of pixels as in Figures 4-25 and 4-26. An active pixel is defined as one in which sufficient signal is present to obtain volume fraction, particle diameter and number density. The resulting plot, shown in Figure 4-30 indicates that, over regions where there is measurable soot, the number densities are nearly the same. 


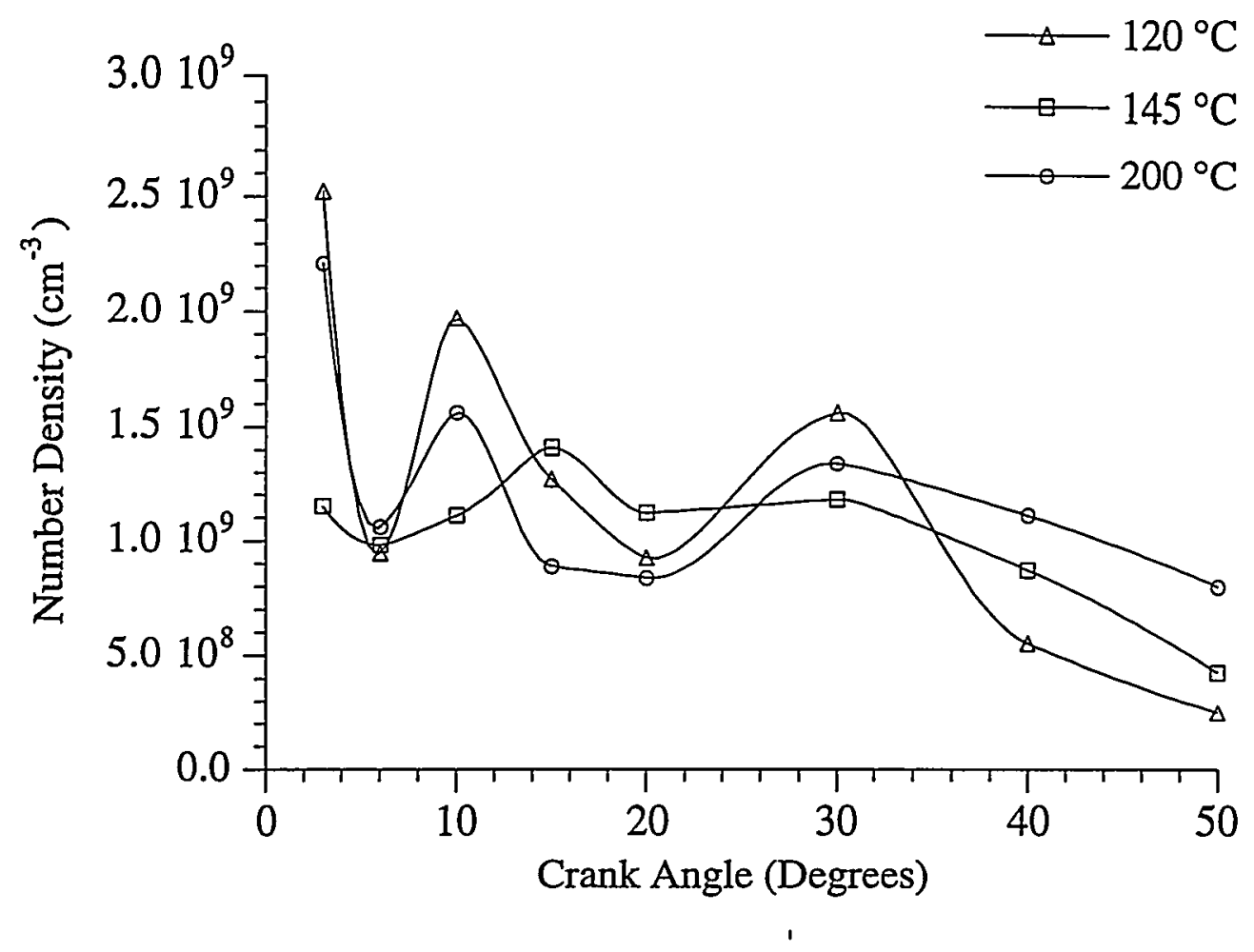

Figure 4-29. Average number density.

From Figures 4-28-30, it is apparent that, although more soot is produced for the high temperature case, the size and local number density of the soot that is produced is similar among the different cases.

\subsection{Effect of Fuel Aromatic Content on Emissions}

The facilities and capabilities developed through the support of the Department of Energy are being applied to research work into the effects of fuel additives on Diesel combustion funded by the Lubrizol Corporation. In preparation for this study two different base fuels were studied, the purely paraffinic fuel used in all of the previous work described above and a fuel with similar Cetane number, but with approximately 30 volume percent aromatic content. The experimental conditions used in this study were essentially identical to those used in the previous studies when combustion in air without dilution was performed.

Although the fuels with and without aromatics were blended to have the same Cetane number the aromatic component evidently had a negative Cetane number effect. This resulted in the aromatic fuel having a slightly longer ignition delay that the non-aromatic fuel. The presence of the aromatic component increased the amount of soot throughout combustion and resulted in approximately $20 \%$ more soot formation. 


\subsection{References}

1) Alatas, B., J. Pinson, T. Litzinger and D. Santavicca, A Study of NO and Soot Evolution in a DI Diesel Engine via Planar Imaging, SAE Journal of Engines 102(3) 1463-1473

2) DoE Workshop

3) Pinson, J., D. Mitchell, R. Santoro and T. Litzinger, Quantitative Planar Soot Measurements in a Diesel Engine using LII and Light Scattering, SAE Paper 932641

4) Mitchell, D., J. Pinson and T. Litzinger, The Effects of Simulated EGR via Intake Air Dilution in an Optically-accessible Diesel Engine, SAE Journal of Engines 102(3):23132331

5) Litzinger, T., J. Pinson, D. Clark and D. Mitchell, The Effects of Intake Charge Dilution on Diesel Soot Evolution, to appear in Combustion Science and Technology Book Series Special Volume in Honor of Irv Glassman.

6) Pinson, J., T. Ni and T. Litzinger, Quantitative Imaging Study of the Effects of Intake Air Temperature on Soot Evolution in an Optically-accessible Diesel Engine, SAE paper 942044 